FERNANDO JUSTULIN

\title{
DESENVOLVIMENTO DE SISTEMA COMPUTACIONAL PARA CÁlCULO DE TRAJETÓRIAS NO PROCESSO DE
}

\section{FILAMENT WINDING}

Dissertação de mestrado apresentada à Escola de Engenharia de São Carlos, da Universidade de São Paulo, como parte dos requisitos para obtenção do título de Mestre em Engenharia Mecânica.

Área de concentração: Projeto Mecânico

Orientador: Prof. Assoc. Jonas de Carvalho

São Carlos 



\section{DEDICATÓRIA}

Aos meus pais, Odair e Helena, a minha irmã Juliana, a minha namorada Raquel. Pelo amor, carinho e compreensão recebidos ao longo do período da elaboração deste trabalho. 


\section{AGRADECIMENTOS}

Ao Prof. Assoc. Jonas de Carvalho, minha gratidão, pela oportunidade, auxilio e dedicação durante o processo de orientação do trabalho.

Ao Dirceu e Sônia Mazotti, pelo incentivo e apoio constante para a realização deste trabalho.

Ao meu grande amigo Edgar, pelos ensinamentos que contribuíram para o desenvolvimento deste estudo.

Aos meus colegas, Jeniel, Mateus, Daniela e Cássio, pela amizade e apoio no decorrer do trabalho.

A todos os professores e funcionários do Departamento de Engenharia Mecânica que sempre tiveram presentes e participativos.

À Escola de Engenharia de São Carlos da Universidade de São Paulo, por disponibilizar sua estrutura.

E principalmente, a Deus, pelas bênçãos concedidas neste trabalho. 


\section{EPÍGRAFE}

"Bendito seja Deus que do alto de céu nos abençoou com toda bênção espiritual em cristo". (Ef 1,3).

Coloquei Nele minha esperança, busquei Sua sabedoria para não desistir dos meus sonhos e poder enfrentar os desafios sem jamais desistir de caminhar.

Por isso rendo a Ele glória e louvor. 


\section{RESUMO}

\section{JUSTULIN, F. Desenvolvimento de sistema computacional para cálculo de} trajetórias no processo de filament winding. 2008. 153 pág. Dissertação (Mestrado) Escola de Engenharia de Escola de São Carlos, Universidade de São Paulo, São Carlos, 2008.

$\mathrm{Na}$ busca pela substituição dos materiais convencionais por materiais com alto desempenho estrutural nos mais variados setores do mercado, os materiais compósitos têm recebido cada vez mais a confiança dos engenheiros projetistas. Isto devido às características, comparadas com materiais convencionais como: baixa densidade associada à excelente rigidez e resistência estrutural, alta resistência à corrosão, resistência à temperaturas elevadas e ótimos resultados estéticos. Um dos processos de fabricação bastante utilizado para a produção de peças nestes materiais é o processo conhecido como Filament Winding ou "Enrolamento Filamentar" Essa técnica consiste em revestir a superfície de um mandril, através do enrolamento de fibras contínuas impregnadas por um banho de resina. As fibras utilizadas nesse processo, geralmente de vidro ou de carbono são posicionadas em uma trajetória calculada por algoritmos matemáticos que determinam o seu posicionamento adequado, o que está diretamente relacionado às propriedades mecânicas desejadas na peça final. Desta forma, este trabalho tem por objetivo desenvolver um sistema computacional para o cálculo da trajetória de deposição da fibra sobre o mandril e seu seqüenciamento durante o processo de Filament Winding. Foram desenvolvidas e implementadas computacionalmente estratégias para os revestimentos circular, helicoidal e polar utilizando trajetórias geodésicas, o que abrange a grande maioria das peças fabricadas por este processo. Os resultados foram validados com exemplo da literatura e, também através de interface com sistema CAD.

Palavras-Chaves: Compósitos, Revestimento, Fibra, Filament Winding, otimização. 


\begin{abstract}
JUSTULIN, F. Development of a computational system for Filament Winding paths and sequences calculation. 2008. 153 pág. Dissertation (Master Degree) - Escola de Engenharia de São Carlos, Universidade de São Paulo, 2008.

In the search for the replacement of conventional materials by those with high structural performance, the reinforced composite materials have increasingly used by engineers during the product development process. The main reasons lies in their excellent characteristics compared to conventional materials such as: low-density associated with high stiffness and strength, good tolerance to corrosion, resistance to high temperatures and good aesthetic results. One of the manufacturing processes most used to produce composite parts is the Filament Winding. This technique consists in winding continuous impregnated fiber by a bath of resin along a mandrel. The fibers used are generally of glass or carbon, guided through a trajectory calculated by mathematical algorithms. Because of the importance of this study, this work proposes and develops a computational system to calculate the trajectories and sequences of the fiber in the Filament Winding process, considering geodesic trajectories during the hoop, helical and polar winding, which cover the majority of parts produced by this process. The routines and system are validated with the literature as well as in the CAD system.
\end{abstract}

Key words: composites, coating, fiber, Filament winding, optimization. 


\section{LISTA DE FIGURAS}

Figura 2.1 - Classificação dos Materiais de Engenharia (Fonte: BEAUMONT, 1989). ......... 26

Figura 2.2 - Organograma de classificação dos materiais compósitos. (Kaw, 1997. Adaptada

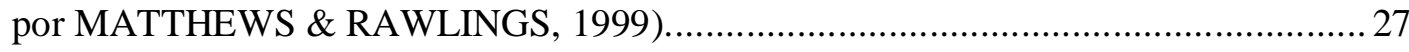

Figura 2.3 - Space Ship One sob a fuselagem de do avião de lançamento White Knight.

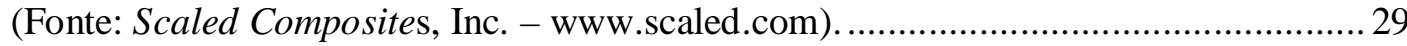

Figura 2.4 - Avião Virgin Atlantic Global Flyer. (Fonte: Scaled Composites, Inc. www.scaled.com)

Figura 2.5 - MV115 Barco construído em compósito responsável por missões em alto mar.

(Fonte: Naval Technology - www.naval-technology.com).

Figura 2.7 - Estrutura de concreto sendo reforçada por fibra de aço. (Fonte:

www.constructalia.com). 33

Figura 2.8 - Turbinas para obtenção de energia eólica. (Fonte: www.greenpeace.org). 34

Figura 2.9 - Quadro de bicicleta fabricado por material compósito revestido por fibra de

carbono. (Fonte: Scott - www.scottusa.com).

Figura 2.10 - Projeto de uma haste femoral produzida por material compósito reforçado.

(Fonte: FILHO, 2006). 36

Figura 2.11 - Efeito da deformação ao redor da fibra na matriz sob tensão: (a) fibra contínua;

(b) fibra descontínua (Fonte: MATHEUWS \& RAWLINGS, 1994). 40

Figura 2.12 - Diagrama tensão-deformação dos principais tipos de fibra (Fonte: MATTHYS, 2000) 42

Figura 2.13 - Ciclo de projeto com materiais compósitos (CARVALHO, 1996)..................46

Figura 2.14 - Autoclave de grandes dimensões. (Fonte: www.bobscherer.com). 50 
Figura 2.15 - Processo de enrolamento de filamento. (Fonte:

http://dev.wilsoncomposites.com)

51

Figura 2.16 - (a) Desenho esquemático do processo de pultrusão; (b) Máquina de pultrusão

(Fonte: Exel Industry - www.exelindustry.com.br)

Figura 2.17 - (a) Desenho esquemático do processo de entrelaçamento; (b) Máquina de entrelaçamento. (Fonte: (a) Intelligent Systems Laboratory/Michigan State Universitywww.islnotes.cps.msu.edu; (b) http://www.omabraid.com)). 53

Figura 2.18- Esquema do processo de moldagem por transferência de resina. (Fonte: FILHO, 2006) 54

Figura 2.19 Representação esquemática de Enrolamento Filamentar(Filament Winding)...... 55

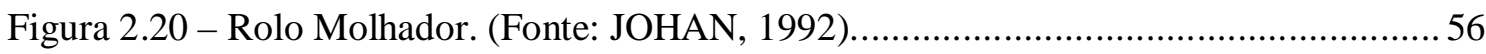

Figura 2.21 - Metodologia utilizada no processo de Filament Winding. (Fonte: CARVALHO, 1996) 58

Figura 2.22 Exemplo de padrões de revestimento (CARVALHO, 1996). 59

Figura 2.23. Ângulo do enrolamento sobre uma superfície de revolução. (Fonte JOHAN, 1992) 60

Figura 2.24 - Estratégia de Revestimento para preenchimento de camadas........................ 61

Figura 2.25 - Máquina de Filament Winding cartesiana. (Fonte: CARVALHO, 1996).........62

Figura 2.26 - Máquina de Filament Winding controlada por comandos numéricos (CNC).

(Fonte: www.globalsecurity.org). 63

Figura 2.27 - Máquina de Filament Winding Robotizada. (Fonte: CARVALHO, 1996)....... 63

Figura 2.28 - Avião Airbus A350. (Fonte: www.thea350.com). 64

Figura 2.29 (a) Dados de entrada do mandril, (b) trajetória da fibra no mandril, (c)

visualização 3D do mandril com cinco olhos, (d) visualização 3D da peça revestida.

(Fonte: Crescent Consultants Limited - www.cadfil.com). 
Figura 2.30 (a) Tela de gerenciamento de projeto, (b) tela de gerenciamento de padrões, (c) tela de do módulo FEA, (d) peça sendo revestida pela máquina. (Fonte: Entec Composites Machines - www.entec.com) 69

Figura 2.31 - Simulação de atrito. (Fonte: Material - www.material.be)............................ 70

Figura 2.32 Simulação da trajetória em peças simétricas e assimétricas. (Fonte: Material www.material.be). 71

Figura 2.33 - Analise de otimização dinâmica da máquina. (Fonte: Material www.material.br). 72

Figura 2.34 - Tela do protótipo. (Fonte: SILVA, 2005)....................................................... 73

Figura 2.35 - Ciclo de vida de um software. (Fonte: PRESSMAN, 2002).......................... 77

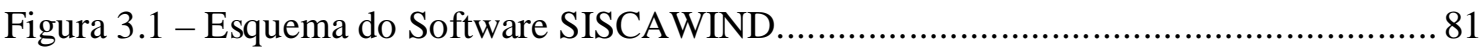

Figura - 3.2 Ambientes de programação Borland C++ 6.0. .......................................... 82

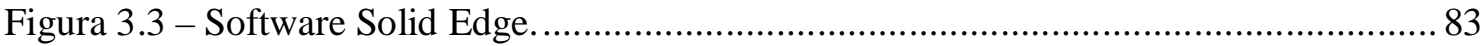

Figura 3.4 - Esquema do Sistema SISCAWIND. ...................................................... 85

Figura 3.5 - Tela principal do software SISCAWIND .................................................. 86

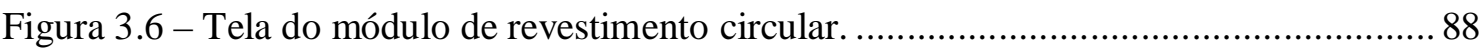

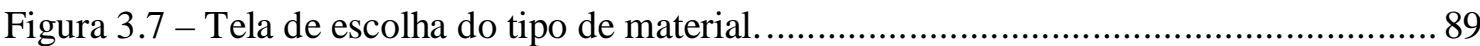

Figura 3.8 - Tela do módulo de revestimento circular após a realização do cálculo............. 91

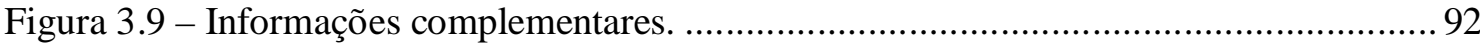

Figura 3.11 - Acompanhamento do cálculo do olho pay-out .......................................... 93

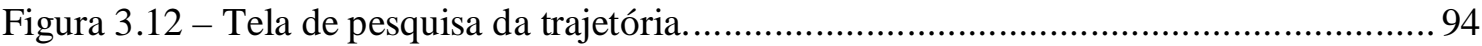

Figura 3.13 - Tela de pesquisa da trajetória com apresentação dos dados. .......................... 95

Figura 3.14 - Tela de apresentação do cálculo pesquisado............................................... 95

Figura 3.15 - Tela do módulo de revestimento circular demonstrando a opção Salvar (X,Y,

Z) 
Figura 3.16 - Valores X, Y e Z no formato xls. 97

Figura 3.17 - Software Solid Edge demonstrando a importação de um arquivo xls.............. 98

Figura 3.18 - Resultado da importação do arquivo xls no software Solid Edge.................... 98

Figura 3.19 - Representação do ângulo Omega (winding) no revestimento helicoidal. ......... 99

Figura 3.20 - Tela do módulo de revestimento helicoidal............................................. 100

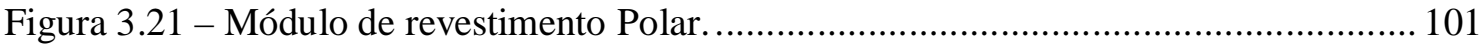

Figura 3.22 - Ângulo Teta (Fonte: GOMES, 2008) .................................................. 103

Figura 3.23 - Ângulo Omega $(W)$ e o Passo $(P)$ na relação do revestimento circular............ 107

Figura 3.24 - Cálculos auxiliares do olho para o ângulo $\theta=90^{\circ}$ (Fonte GOMES, 2009). .... 110

Figura 3.25 - Cálculo da posição do Olho com ângulo $\theta>90^{\circ}$ (Fonte: GOMES, 2009)...... 111

Figura 3.26 - Cálculo da posição do Olho com ângulo $\theta<90^{\circ}$ (Fonte: GOMES, 2009)...... 112

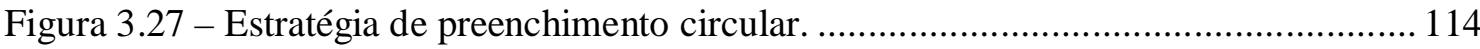

Figura 3.28 - Limite do Ângulo $\omega$ (Fonte: GOMES, 2009).......................................... 116

Figura 3.29 - Limite do Ângulo $\omega$ para o Revestimento Polar (Fonte GOMES, 2009)........ 117

Figura 3.30 - Estratégia de divisão dos Steps. (Fonte: GOMES, 2009)............................ 119

Figura 3.31 - Estratégia de Revestimento Helicoidal e Polar............................................. 119

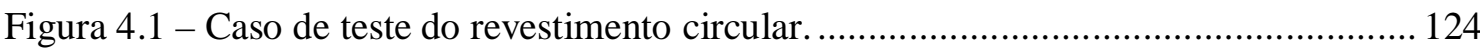

Figura 4.2 - Planilha de cálculo do revestimento circular (Fonte: GOMES, 2009)............. 125

Figura 4.3 - Valores do olho (pay-out) no revestimento circular................................... 125

Figura 4.4 - Valores do olho (pay-out) no revestimento circular (Fonte: GOMES, 2009)... 126

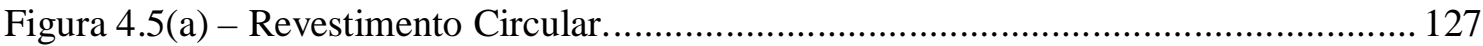

Figura 4.5(b) - Revestimento Circular Ampliada. ........................................................... 127

Figura 4.6- Valores das coordenadas X, Y e Z resultado do revestimento helicoidal. ......... 129

Figura 4.7 - Valores das coordenadas X, Y e Z resultado do revestimento helicoidal. (Fonte

GOMES, 2009). 
Figura 4.8(a) - Revestimento Helicoidal em Andamento............................................... 130

Figura 4.8(b) - Revestimento Helicoidal Finalizado...................................................... 130

Figura 4.8(c) - Revestimento Helicoidal Ampliado. ..................................................... 131

Figura 4.9 - Valores das coordenadas X, Y e Z resultado do revestimento Polar. ............... 132

Figura 4.10 - Valores das coordenadas $\mathrm{X}, \mathrm{Y}$ e Z resultado do revestimento polar. (Fonte

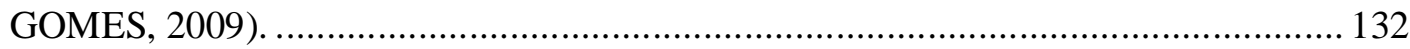

Figura 4.11(a) - Revestimento Polar. ....................................................................... 133

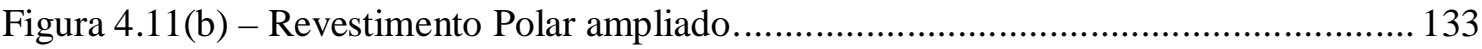

\section{LISTA DE TABELAS}

Tabela 2.1 - Propriedades típicas dos principais tipos de fibra.............................................43 


\section{LISTA DE ABREVIATURAS E SIGLAS}

CAD - Computer Aided Design.

CAE - Computer Aided Engineering.

CAM - Computer Aided Manufacturing

CAWAR - Computer Aided Filament Winding of Asymmetric Parts using Robots.

CNC - Controlado por comando numérico.

$\mathrm{CO}_{2}$ - Gás Carbônico.

FEA - Finite Element Analysis.

GNV - Gás Natural Veicular.

GUI's - Graphics user Interface.

HCI - Human-Computer Interface.

$\mathrm{H}_{2}$ - Hidrogênio.

ISO - International Organization for Standardization.

MCRF - Material compósito reforçado por fibra.

MCR - Material compósito reforçado.

$\mathrm{NO}_{\mathrm{X}}$ - óxidos de Nitrogênio

SISCAWIND - Sistema de cálculo Winding.

SGBD - Sistemas de Gerenciamento de Banco de Dados.

STL - Tipo do Arquivo que tem formado de triângulo.

UNIX - Sistema Operacional.

BCPL - Linguagem de Programação que Originou a Linguagem C

XLS - Tipo de Arquivo do Software Microsoft Excel. 


\section{LISTA DE SÍMBOLOS}

$\left(l_{c}\right)$ - Comprimento crítico da fibra.

$\sigma_{c}$ - Resistência à tração na ruptura da fibra.

$\tau$ I- menor resistência ao cisalhamento da matriz ou da interface.

d - diâmetro da fibra.

$\mathrm{R}$ - o raio do cilindro.

$\alpha$ - ângulo do enrolamento.

Cc - constante para geodésica.

$v$ - Volume da Fibra.

$m$ - Massa da Fibra.

$d$ - Densidade da Fibra.

$h$ - Altura da Fibra.

$D$ - Diâmetro do Cilindro.

$\lambda$ - Ângulo winding limite para a condição de revestimento.

$c$ - Comprimento do Cilindro.

NI - Número de iterações através de um ciclo de $360^{\circ}$.

$d_{t}$ - o decremento de $\theta$.

$I_{r c}$ - Incremento do revestimento circular.

ef - Espessura do filamento.

$N V$ - Número da Volta em que o ponto está.

$\theta$ - Ângulo que inicia o revestimento.

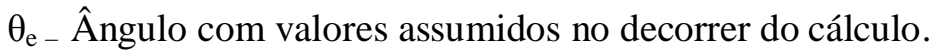

$Q$ - Quadrante do cilindro.

$\mathrm{X}$ - Coordenada de um ponto. 
Y - Coordenada de um ponto.

Z - Coordenada de um ponto.

$\mathrm{I}_{\mathrm{rc}}-$ Incremento da coordenada $(\mathrm{X})$.

$\Delta y$ - Taxa de Variação da coordenada (Y).

$\Delta x$ - Taxa de Variação da coordenada (X).

$P$ - Passo da trajetória.

$\mathrm{X}_{\mathrm{i}}-$ Ponto inicial para coordenada $(\mathrm{X})$.

$\mathrm{X}_{\mathrm{f}}$ - Ponto final para coordenada $(\mathrm{X})$.

$\psi$ - Ângulo Psi.

$\mathrm{R}_{\mathrm{v}}-$ Raio do cilindro virtual.

$O P$ - Distancia OP.

$X^{\prime} P$ - Ponto inicial do Olho.

$\Delta X^{\prime}$ - Ponto da coordenada (X) para o olho guia.

$\Delta \mathrm{Y}^{\prime}$ - Ponto da coordenada (Y) para o olho guia.

$\Delta Z^{\prime}$ - Ponto da coordenada (Z) para o olho guia.

$\mathrm{C}_{\mathrm{r}}$ - Comprimento do revestimento. 


\section{SUMÁRIO}

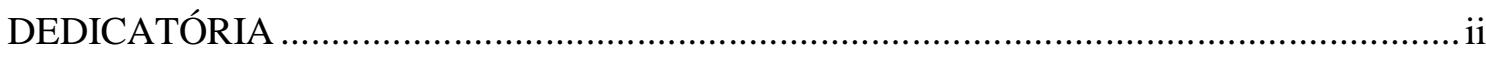

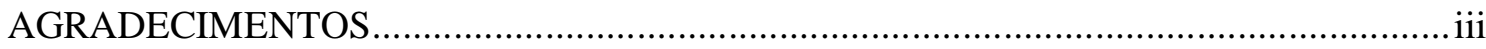

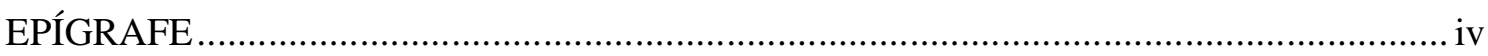

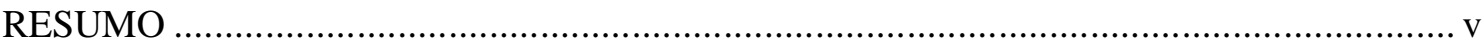

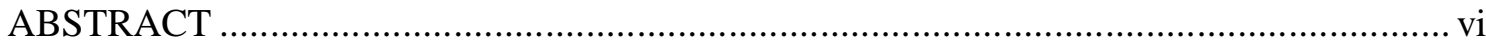

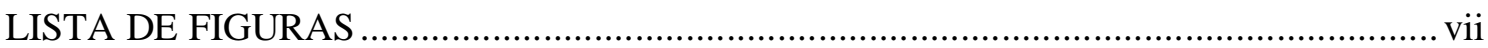

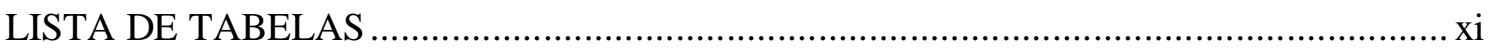

LISTA DE ABREVIATURAS E SIGLAS ....................................................................

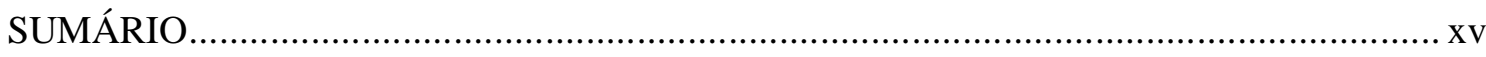

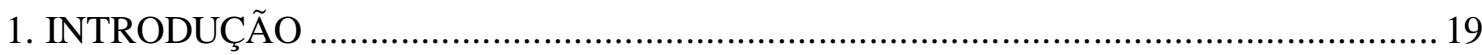

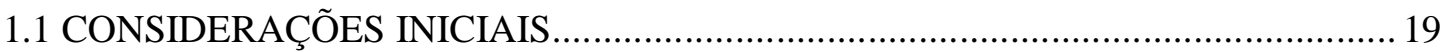

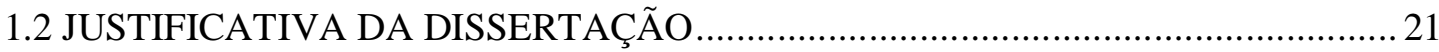

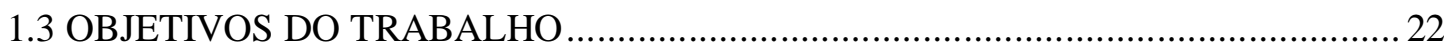

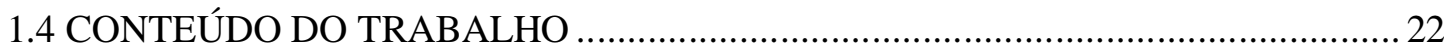

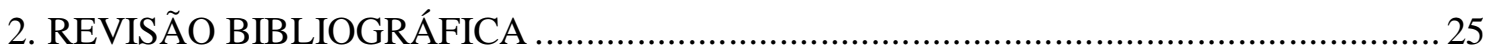

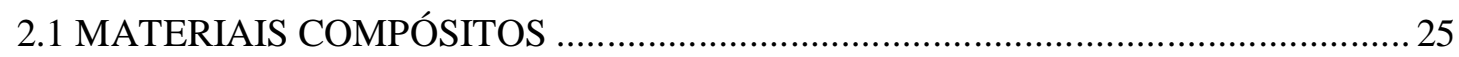

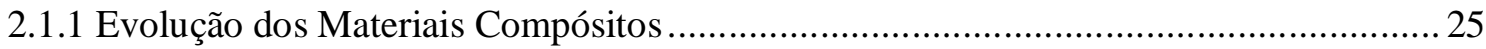

2.1.2 Classificação Geral dos Materiais Compósitos.......................................................... 27

2.1.3 Aplicações dos Compósitos Reforçados ............................................................ 28

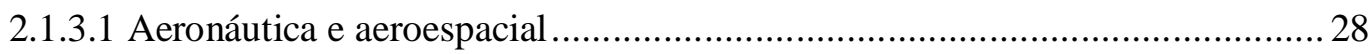

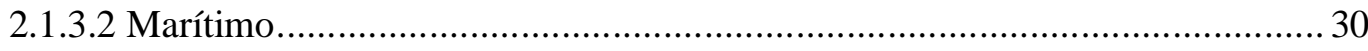

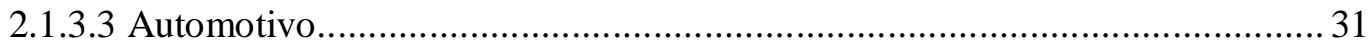

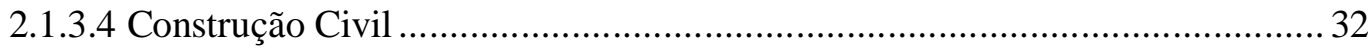




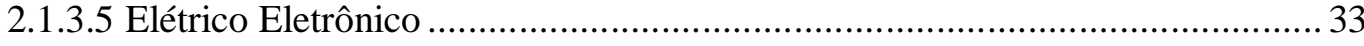

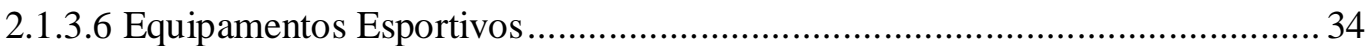

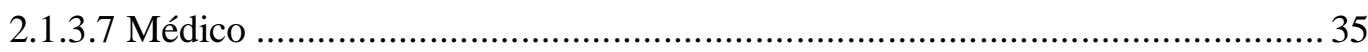

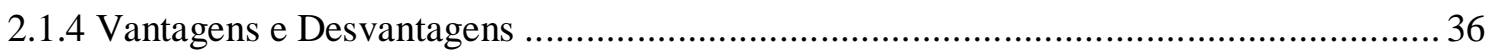

2.2 PROJETO E FABRICAÇÃO EM COMPÓSITOS …………………………………...... 38

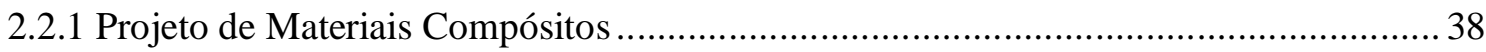

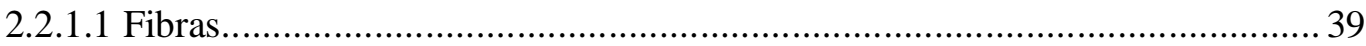

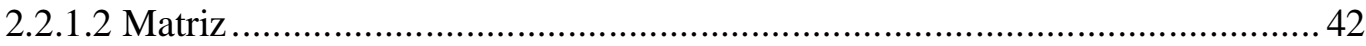

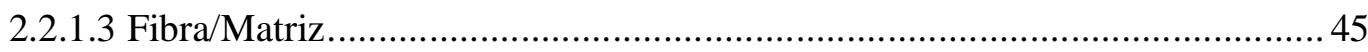

2.2.1.4 Ciclo de Projeto com Materiais Compósitos..................................................... 45

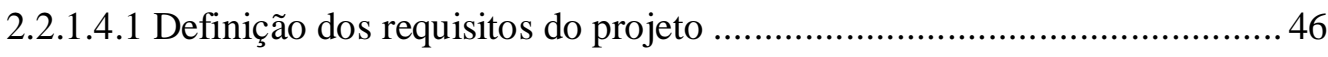

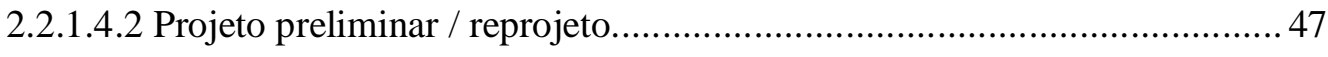

2.2.1.4.3 Previsão de desempenho ......................................................................... 47

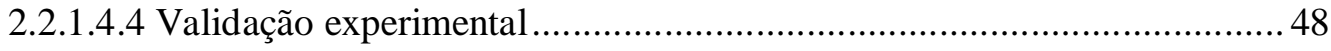

2.2.1.4.5 Especificações de manufatura e produção.................................................. 48

2.2.2 Técnicas de Fabricação dos Materiais Compósitos ........................................................ 48

2.2.2.1 Dificuldades do processo de fabricação........................................................... 49

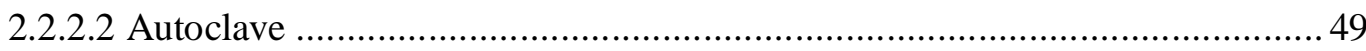

2.2.2.3 Enrolamento de filamento (Filament Winding) ……......................................50

2.2.2.4 Pultrusão (pultrusion)................................................................................. 51

2.2.2.5 Entrelaçamento (braiding) ........................................................................... 52

2.2.2.6 Modelagem por transferência de resina (Resin Trasnfer Molding - RTM) ..... 53

2.2.3 O processo de Enrolamento Filamentar (Filament Winding) ........................................54

2.2.3.1 Ciclo De Projeto Para O Processo de Enrolamento Filamentar ( Filament

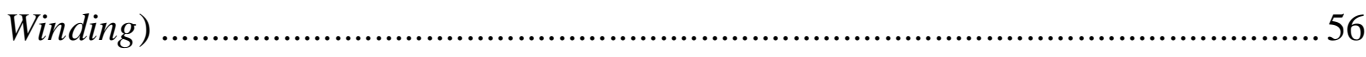




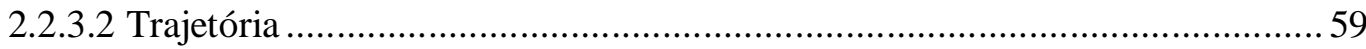

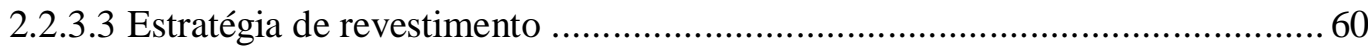

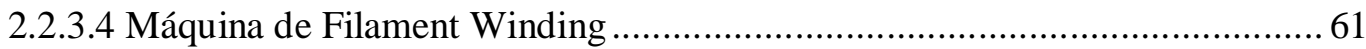

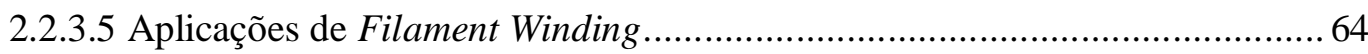

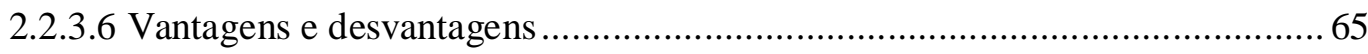

2.3 SOFTWARES EXISTENTES PARA FILAMENT WINDING ................................ 66

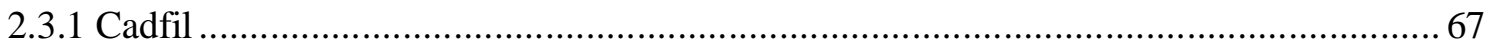

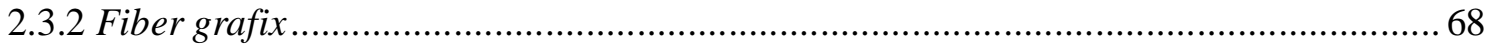

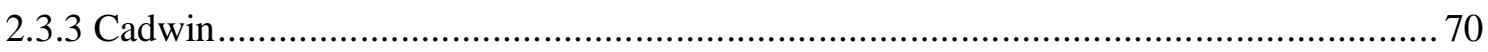

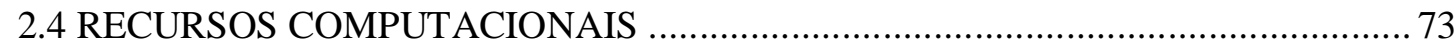

2.4.1 Interfaces Gráficas com o Usuário (GUI’s) ......................................................... 74

2.4.2 Linguagem de Programação C ........................................................................... 74

2.4.3 Sistema Gerenciador de Banco de Dados (SGBD) …............................................ 75

2.5 CONSIDERAÇÕES SOBRE ENGENHARIA DE SOFTWARE.............................. 76

3. METODOLOGIA E IMPLEMENTAÇÃO DO SOFTWARE …................................... 79

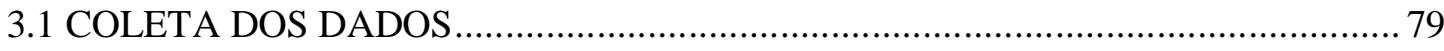

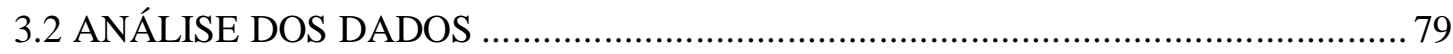

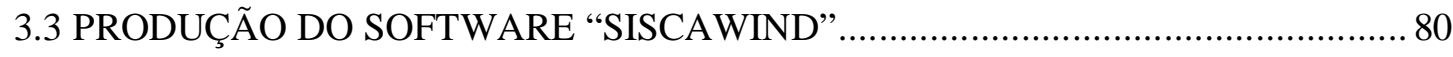

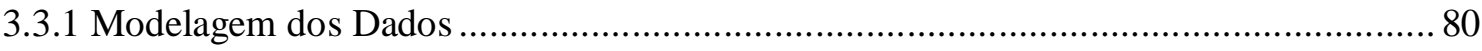

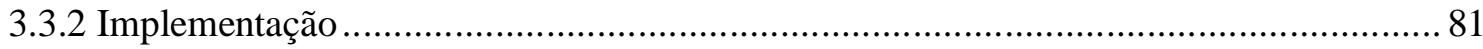

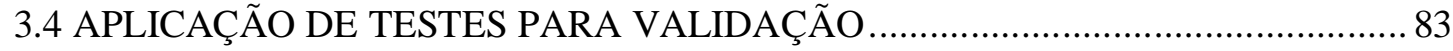

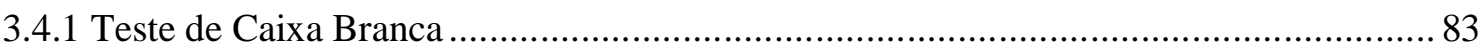

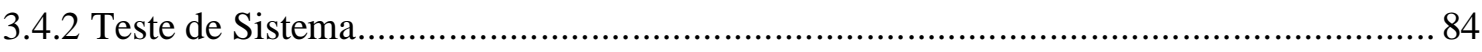

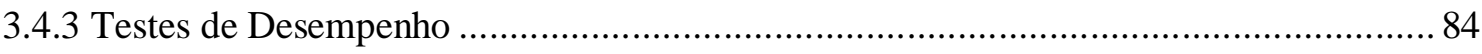

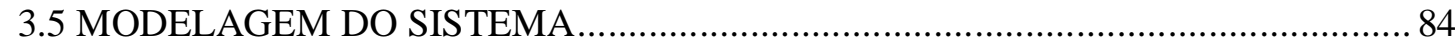


3.5.1 Interface Gráfica Dos Módulos Do Protótipo Siscawind 86

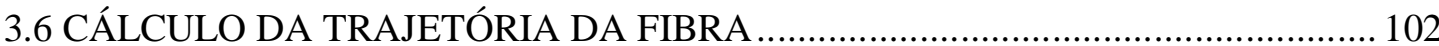

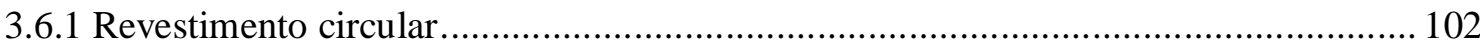

3.6.2 Estratégia de Preenchimento das Camadas no Revestimento Circular....................... 113

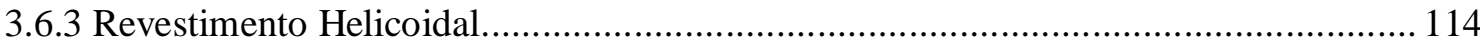

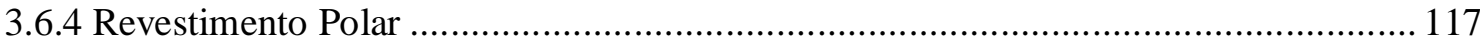

3.6.5 Estratégia de Preenchimento das Camadas no Revestimento Helicoidal e Polar......... 117

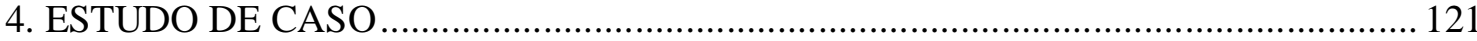

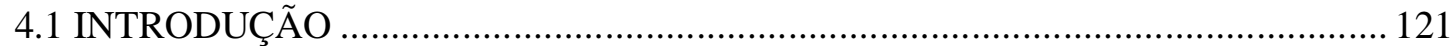

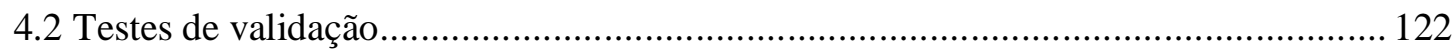

4.2.1 Aplicação do Teste no Revestimento Circular ........................................................ 122

4.2.2 Aplicação do Teste no Revestimento Helicoidal .................................................... 128

4.2.3 Aplicação do Teste no Revestimento Polar............................................................. 131

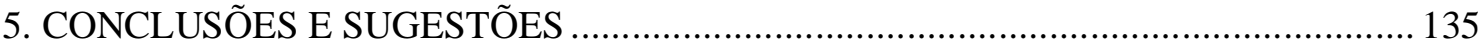

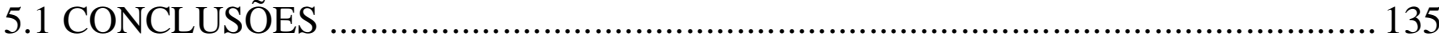

5.2 SUGESTÕES PARA TRABALHOS FUTUROS …............................................... 137

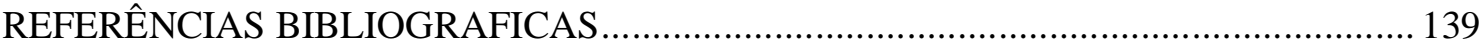




\section{CAPÍTULO 1}

\section{INTRODUÇÃO}

\subsection{CONSIDERAÇÕES INICIAIS}

Os primeiros trabalhos desenvolvidos com materiais compósitos ocorreram aproximadamente na década de 50 com o desenvolvimento de projetos estruturais apresentados pela indústria aeronáutica, que buscava a produção de materiais de alo desempenho estrutural associado à baixa densidade, fator primordial para as aeronaves. Atualmente, os compósitos têm sido aplicados nos mais diversos setores tais como: automotivo, marítimos, ferroviário, construção civil e área médica, dentre outros. Isto devido às inúmeras vantagens oferecidas como: baixo peso associado à alta rigidez e resistência mecânica, alto desempenho devido à versatilidade na customização das propriedades dos materiais de acordo com a necessidade do projeto, baixo custo relativo, quando comparados aos demais materiais.

Com o avanço tecnológico, muitas pesquisas foram desenvolvidas com o objetivo de se obter novas tecnologias de fabricação em compósitos, visando aumentar a qualidade e a redução de custos do processo de produção. Neste contexto, surge o processo de Filament Winding como uma alternativa bastante interessante para obter estruturas em compósitos, normalmente de modo altamente automatizado e com grandes índices de previsibilidade. Existem diferente definições para o termo compósito, dependendo da área de pesquisa. Carvalho (1996), define materiais compósitos com a união química ou mecânica de dois ou 
mais materiais com diferentes propriedades de maneira a gerar um produto final com características físico-químicas superiores àquelas dos materiais individuais.

O processo de Filament Winding consiste em revestir a superfície dos compósitos, através do enrolamento de fibras contínuas impregnadas por um banho de resina na superfície de um mandril, gerando um produto na forma tubular. É de grande aplicação na fabricação de tubos e vasos de pressão. As fibras utilizadas nesse processo, geralmente de vidro ou carbono devem ser posicionadas sobre o mandril em trajetórias matematicamente calculadas de maneira a obter as propriedades desejadas nas direções mais solicitadas da peça final.

Para Carvalho (1996), o processo tradicional de manufatura de materiais compósitos tem se aperfeiçoado ao longo dos anos, devido a necessidade de componentes com novas geometrias, peças com alto desempenho estrutural associados ao crescente uso de materiais compósitos. Portanto o desenvolvimento de algoritmos e rotinas de otimização dos dados de processo em geral; no caso de Filament Winding nos cálculos das trajetórias e seqüenciamento do posicionamento das fibras.

Dentre essas tecnologias, pode-se citar o desenvolvimento de novas máquinas e tecnologias de fabricação em compósitos, tais como ATL (Automatic Tape Lying) e FP (Fiber Placement), extensivamente utilizados na industria aeronáutica. Tais tecnologias, da mesma forma que o Filament Winding, devem ser capazes de revestir a superfície do mandril de maneira a otimizar os dados de processo havendo o mínimo desvio entre a trajetória calculada e a trajetória real executada pela máquina.

Atualmente, existem alguns softwares comerciais voltados para o processo de Filament Winding tais como CadFil da empresa Crescent Consultants Limited, o FiberGrafix da Entc Composites Machines, o CadWind da Pattern Máster. Na área acadêmica, temos o software Cawar, desenvolvido inicialmente por Scholliers (1992) e posteriormente 
aprimorado por Carvalho (1996), bem como um protótipo de software desenvolvido por Silva (2005) na plataforma Windows.

Este trabalho propõe o desenvolvimento de um sistema computacional para o cálculo otimizado da trajetória da fibra no revestimento de materiais compósitos em superfícies cilíndricas.

\subsection{JUSTIFICATIVA DA DISSERTAÇÃO}

Com o avanço tecnológico atual associado ao aumento da concorrência devido à globalização, novas técnicas de projetos de componentes vem sendo desenvolvidas, crescendo a aplicação de compósitos nos mais diversos setores.

Visto que, os compósitos são obtidos da combinação de dois ou mais materiais com características físico-químicas e mecânicas distintas, os trabalhos e pesquisas nesta área são muito promissores, visando a obtenção de peças com alto desempenho estrutural.

A possibilidade de se ter um sistema computacional desenvolvido "in-house" abre novas possibilidades para desenvolvimentos e implementações inovadoras em termos de processo. De posse de tal sistema, o usuário terá a possibilidade de desenvolver e implementar seus próprios algoritmos de cálculo e otimização das trajetórias, o que normalmente não é possível quando se utiliza um sistema comercial.

Como resultado espera-se disponibilizar aos usuários do processo, um ambiente aberto noqual facilmente pode-se implementar novas rotinas e procedimento de otimização das trajetórias de posicionamento e seqüenciamento das fibras. 


\subsection{OBJETIVOS DO TRABALHO}

De acordo com o enfoque apresentado anteriormente, este trabalho desenvolveu um sistema computacional, para o cálculo e otimização da trajetória no processo de Filament Winding em superfícies de revolução. Para isso, o usuário fornecerá os dados de entrada referentes às características geométricas do cilindro e o software calculará as trajetórias nos tipos circular, helicoidal e polar.

Portanto os objetivos deste trabalho são:

1. Fazer um levantamento dos sistemas computacionais disponíveis comercialmente, visando estudar suas características e modo de uso;

2. Desenvolver um algoritmo para o calculo da trajetória nos processos de Filament Winding em superfícies de revolução do tipo circular, helicoidal e polar;

3. Definir uma linguagem de programação adequada para escrever o código fonte do software;

4. Projetar e implementar plataforma computacional para cálculo da trajetória de posicionamento da fibra, com interface amigável, flexível e funcional que proporcione atualizações dos módulos em implementações futuras;

5. Validar os cálculos realizados em aplicações típicas, com visualização no sistema CAD das trajetórias calculadas.

\subsection{CONTEÚDO DO TRABALHO}


O trabalho foi organizado de forma a apresentar a seqüência dos temas necessários para o seu desenvolvimento, abordando as técnicas de manufatura dos materiais compósitos, as novas tecnologias utilizadas, os recursos computacionais utilizados, as rotinas desenvolvidas e a discussão dos resultados obtidos. Deste modo foram propostos cinco capítulos e as referências bibliográficas citadas, segundo o seguinte conteúdo:

1. Introdução - é apresentada a proposta de trabalho, seus objetivos, a justificativa e o conteúdo do trabalho.

2. Revisão Bibliográfica - a revisão bibliográfica apresenta o contexto no qual o trabalho está inserido. A revisão apresenta os materiais compósitos, aplicações, classificações e o projeto de fabricação auxiliado pelos recursos computacionais atuais.

3. Materiais e Métodos - são descritos os materiais (ferramentas) e os métodos utilizados para desenvolver o software SISCAWIND, proposto e desenvolvido neste trabalho, visando o cálculo da trajetória da fibra no processo de Filament Winding.

4. Implementação do Software SISCAWIND - são apresentadas as implementações do software SISCAWIND, detalhando o funcionamento individual de cada módulo do sistema tais como: características do revestimento circular, helicoidal e polar, cálculo da trajetória do cilindro e do olho pay-out e a estratégia de seqüenciamento das camadas. 
5. Resultados e Discussões - são apresentados os resultados obtidos em testes de validação realizados em cada módulo do sistema;

6. Conclusões e Sugestões - é verificado, validade a proposta inicial do trabalho. 


\section{CAPÍTULO 2}

\section{REVISÃO BIBLIOGRÁFICA}

Este capítulo apresenta uma revisão bibliográfica referente ao projeto e fabricação em materiais compósitos bem como algumas ferramentas que auxiliam nesse processo.

\subsection{MATERIAIS COMPÓSITOS}

\subsubsection{Evolução dos Materiais Compósitos}

Segundo Filho (2006), as pesquisas realizadas em materiais compósitos têm aproximadamente 6000 anos se analisarmos o aspecto que os materiais biológicos que constituem parte do corpo humano, de animais e plantas, podem ser considerados compósitos. No Egito por volta de 4000 a.C., utilizavam-se as hastes da planta conhecida como papiro para confeccionar folhas para escrita. O papiro foi o principal suporte da escrita na antiguidade, principalmente no Mediterrâneo, dai o termo papel hoje utilizado. Os egípcios em 1500 a.C. reforçavam as paredes de barro de suas casas com brotos de bambu fixados por cola, buscando produzir construções mais seguras contra as ações da natureza. Outras experiências se deram de 1300 a 1200 a.C. com os egípcios e hebreus no reforço de tijolos com palha picada, técnica utilizada até hoje em algumas regiões.

De acordo com Carvalho (1996), no século XX, mais precisamente na década de 40, começaram a surgir às primeiras aplicações realizadas com materiais compósitos na indústria aeronáutica e militar. Devido ao avanço tecnológico dos últimos anos, acentuadamente 
ocorrida nos processos de fabricação, aliado à busca pela substituição de peças e estruturas metálicas, os materiais compósitos vem sendo muito utilizados nos mais variados setores, tais como engenharia civil, transporte marítimo, medicina, industria automotiva dentre outros. Isso vem ocorrendo devido a diversas vantagens que os materiais compósitos podem oferecer: baixa densidade, resistência e rigidez elevada, resistência à oxidação e corrosão, fatores que refletem uma grande eficiência estrutural no uso destes componentes.

Beaumont (1989) relata que existem mais de 50.000 tipos de materiais patenteados sendo utilizados na engenharia. Estes materiais podem ser classificados como: metais, polímeros, cerâmicos e compósitos.

Carvalho (1996) define os materiais compósitos pela união química ou mecânica de dois ou mais materiais com propriedades diferentes, que quando se unem, formam um novo material com características físico-química superiores às propriedades iniciais individuais. Reinhart \& Clements (1987) definem um compósito como uma combinação macroscópica entre dois ou mais materiais distintos, havendo uma interface reconhecível entre eles. A figura 2.1 nos mostra esquematicamente a definição dos materiais.

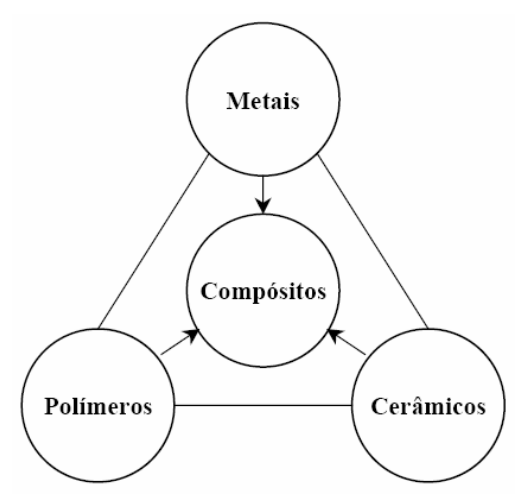

Figura 2.1 - Classificação dos Materiais de Engenharia (Fonte: BEAUMONT, 1989).

Na década de 60 começaram a aparecer às primeiras aplicações de materiais compósitos reforçados por fibra - MCRF ou MCR, ou do inglês: Fiber Reinforced Plastics - 
FRP. Segundo Filho (2001), uma série de pesquisas realizadas pela Royal Aircraft Establishment em Farnborough, na Inglaterra, levaram ao descobrimento da fibra de carbono, material altamente resistente e rígido, que se tornou sem dúvida uma revolução nos materiais de engenharia. $\mathrm{O}$ grande estímulo no uso dos MCRF está relacionado à combinação de alta resistência e rigidez com baixa densidade, o que proporciona uma grande eficiência estrutural destes materiais, combinação que impulsiona os estudos destes materiais até os dias atuais.

\subsubsection{Classificação Geral dos Materiais Compósitos}

Segundo Kaw (1997), utiliza como critério a geometria do reforço. Segundo esta classificação, os diferentes tipos de reforços podem ser classificados como: partículas, flocos ou fibras A figura 2.2 mostra essa classificação com base na geometria de reforço, separandoos em materiais reforçados por fibra, partícula e flocos.

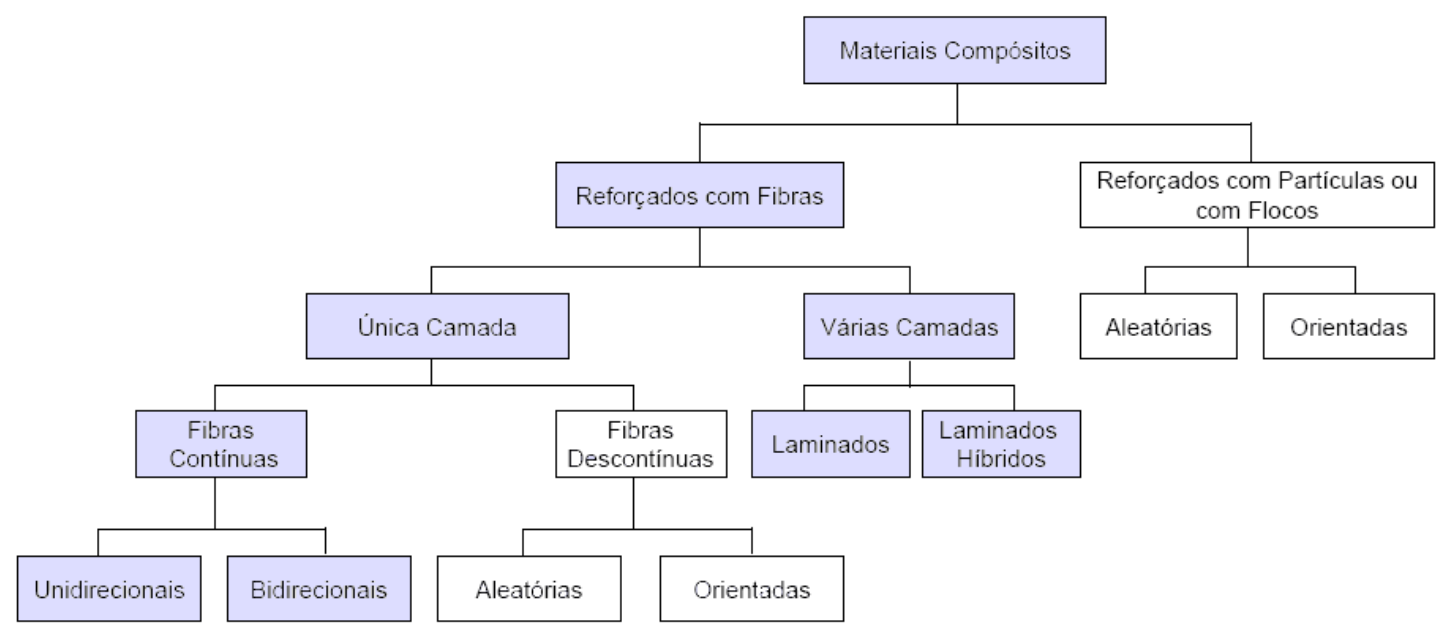

Figura 2.2 - Organograma de classificação dos materiais compósitos. (Kaw, 1997. Adaptada por MATTHEWS \& RAWLINGS, 1999). 
Para Carvalho (1996), o processo de revestimento de superfícies, em especial o de Filament Winding, tem se aperfeiçoado ao longo dos anos. A necessidade de componentes com novas geometrias, projetos com requisitos de desempenho mais exigentes e o crescente uso de materiais compósitos nas mais variadas áreas de aplicação, tem tornado obrigatório estudos, para otimizar as trajetórias de deposição das fibras, levando a componentes com menor massa associada à alta resistência mecânica e menor custo de manufatura.

\subsubsection{Aplicações dos Compósitos Reforçados}

Devido a grande gama de aplicações em materiais compósitos, o objetivo deste tópico é apresentar algumas das aplicações quem vem sendo mais utilizadas pela industria atual. Esses exemplos apresentam uma variedade de campos de aplicações, bem como diversos fatores a serem discutidos como requisitos de engenharia, técnicas de fabricação, mercado consumidor, posição competitiva em relação aos materiais convencionais. Tais aspectos não serão detalhadamente discutidos aqui, somente serão apresentados para suscitar o leitor da importância da analise integrada destes aspectos na seleção destes materiais.

\subsubsection{Aeronáutica e aeroespacial}

De acordo com Filho (2006) o industria aeronáutica e aeroespaciais são as áreas que mais têm se beneficiado pela utilização de materiais compósitos tanto em aplicações civis quanto militares. Pode-se destacar o uso desses materiais em aviões, helicópteros, foguetes, planadores, telescópios espaciais, mísseis, dentre outros. As principais razões pelas quais tais materiais são utilizados nesse setor se devem aos excelentes resultados com relação à rigidez específica, customização de projetos, resistência à fadiga, baixo custo de fabricação e redução 
de manutenção e excelente estabilidade dimensional quando sujeitos a grandes mudanças de temperatura.

Filho (2006) ressalta que seria impossível a construção de algumas aeronaves, sem a tecnologia de compósitos avançados. Um exemplo recente foi o protótipo do projeto das aeronaves White Knight e Space Ship One, construídos inteiramente em materiais compósitos reforçados por fibras de carbono, mostrados na figura 2.3 e figura 2.4. Outro exemplo recente foi o projeto do avião Virgin Atlantic Global Flyer que completou a primeira volta ao mundo da história. Essa volta foi realizada por um único piloto e sem paradas para abastecimentos. Isso foi possível devido à baixa densidade apresentada pelos materiais compósitos revestidos que resultam na economia de energia.

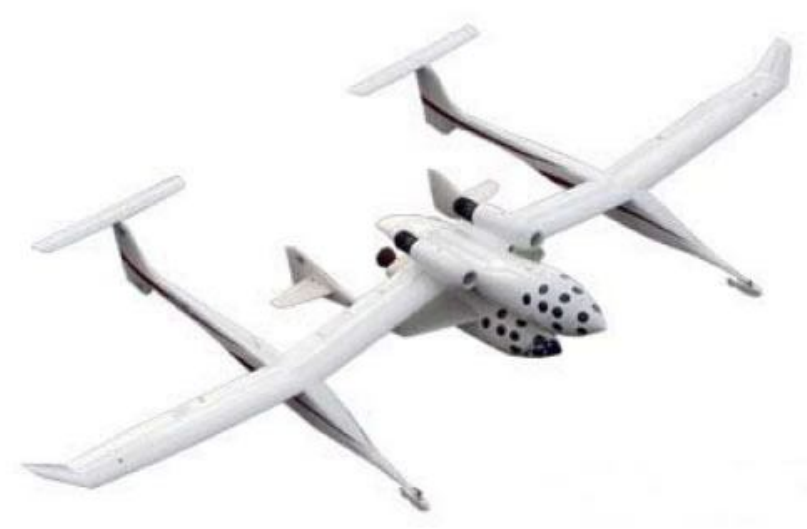

Figura 2.3 - Space Ship One sob a fuselagem de do avião de lançamento White Knight. (Fonte: Scaled Composites, Inc. - www.scaled.com).

Segundo Chawla (1998), o departamento de informações da Boeing (maior fabricante de aeronaves do mundo) fez uma estimativa em relação à economia de combustível em aviões com vida útil de aproximadamente 20 anos e chegou a valores consideráveis. Para realizar uma rota comum, um Boeing 757 ou 767 consome cerca de 120 a 150 litros de combustível por quilograma de peso do avião por ano. Sendo assim, se uma aeronave for inteiramente 
construída em compósitos, a mesma apresentaria uma economia de peso de $1500 \mathrm{Kg}$ em relação às aeronaves construídas com estruturas convencionais, o que representaria, segundo a pesquisa, uma economia de aproximadamente 4 milhões de litros de combustível por avião por ano.

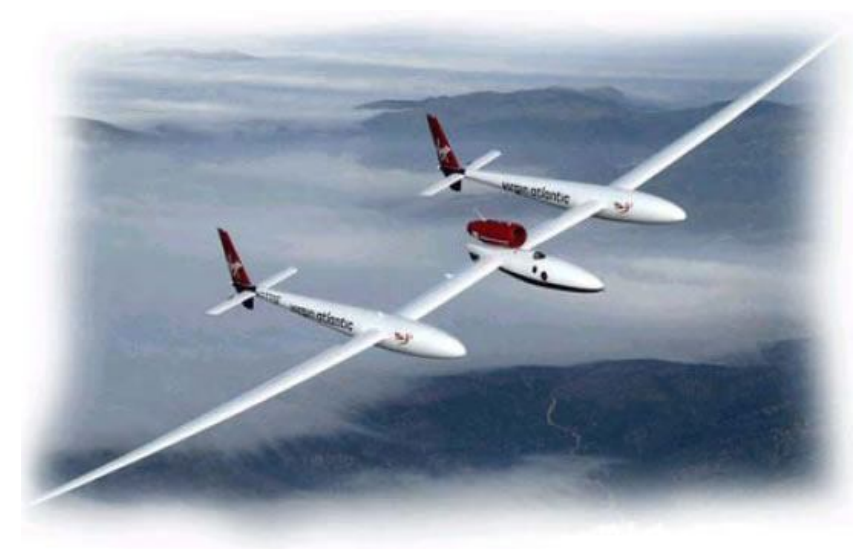

Figura 2.4 - Avião Virgin Atlantic Global Flyer. (Fonte: Scaled Composites, Inc. www.scaled.com).

\subsubsection{Marítimo}

As aplicações de compósitos na indústria marítima tem se dado, devido ao baixo peso apresentado pelo material, excelente resistência, facilidade nas modelagens em superfícies complexas, baixo custo de manutenção, propriedades não magnéticas e ótima resistência à oxidação e à fadiga.

Filho (2006) afirma que enquanto as grandes embarcações são construídas de ferro e aço, as embarcações menores com tamanhos de até 40 metros como lanchas, iates, catamarãs, jet skis, jet boats são construídas em compósitos o que as torna mais acessível ao consumidor. A figura 2.5 mostra um barco construído de material compósito utilizado para patrulha em 
águas marítimas. Outra área que se beneficia da resistência destes materiais são as extratoras de petróleo marítimo. Os equipamentos responsáveis pela extração do petróleo em alto mar como vasos e tubulações de pressão, tanques de armazenamento, oleodutos, dentre outros são produzidos atualmente por compósitos poliméricos reforçados por fibras.

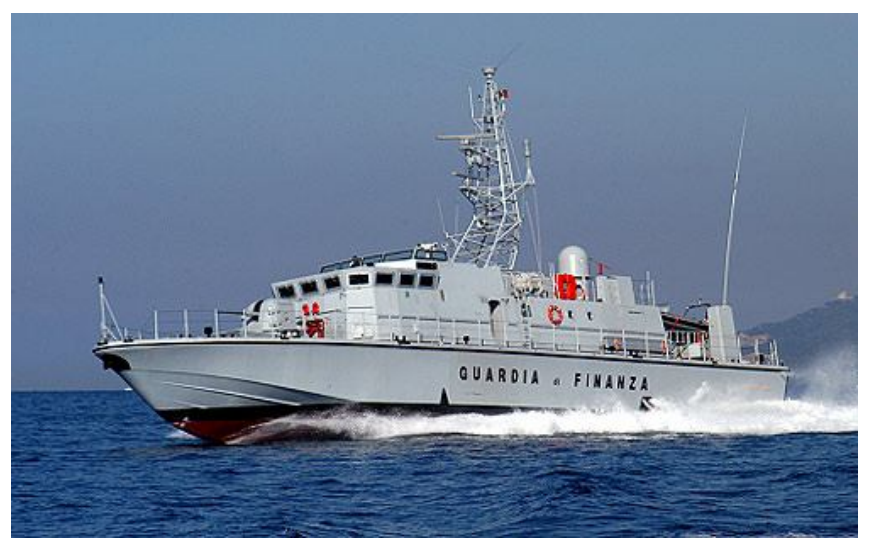

Figura 2.5 - MV115 Barco construído em compósito responsável por missões em alto mar. (Fonte: Naval Technology - www.naval-technology.com).

\subsubsection{Automotivo}

Segundo Filho (2006), as principais razões pelas quais os materiais compósitos são utilizados na indústria automotiva se devem ao fato de apresentar maior durabilidade, resistência à corrosão, vida útil à fadiga e desgaste e resistência ao impacto. De maneira geral, devido ao baixo peso os veículos apresentam uma economia significativa de consumo de combustível, melhor segurança e redução de manutenção. Algumas das peças usualmente fabricadas nestes materiais são: barras de direção, hélices do motor, molas de amortecimento, pára-choques, peças de chassis, carrocerias, peças do interior dos painéis (e o próprio painel) e peças diversas de engenharia. 
Chawla (1998) relata em uns de seus trabalhos que a grande importância da utilização dos compósitos no setor automotivo está na utilização do Gás Natural Veicular (GNV) e do Hidrogênio $\left(\mathrm{H}_{2}\right)$ como fontes de combustível veicular. $\mathrm{O}$ emprego de GNV e do $\mathrm{H}_{2}$ resultam em baixas emissões de $\mathrm{NO}_{\mathrm{X}}$ e $\mathrm{CO}_{2}$ em comparação à gasolina, além de serem mais baratos em algumas regiões. No entanto, a utilização desses componentes como combustível veicular requerem armazenamento em alta pressão, acima de $20 \mathrm{MPa}$. Para o armazenamento sob alta pressão costuma-se utilizar cilindros metálicos devido ao menor custo, porém estes cilindros acarretam aumento do consumo de combustível devido ao seu peso. Em função disso, os cilindros fabricados pelo processo de Filament Winding - FW, ou enrolamento filamentar, foram desenvolvidos como alternativa para substituir os cilindros de aço. Dessa forma houve um aumento da segurança e redução da perda de carga útil dos veículos.

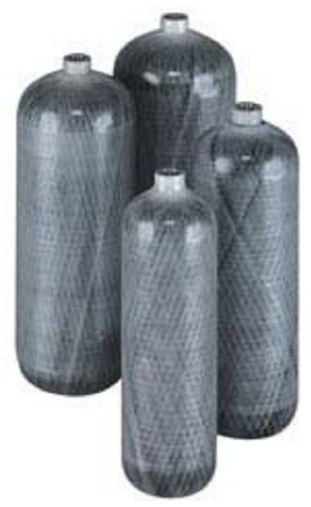

Figura 2.6 - Cilindros poliméricos reforçado com fibra de carbono. (Fonte: Luxfer).

A figura 2.6 mostra alguns cilindros de gás fabricados pelo processo de fabricação por enrolamento filamentar.

\subsubsection{Construção Civil}


As aplicações dos materiais compósitos na construção civil são encontradas em estruturas de edifícios, pontes e viadutos. As principais razões para estão na redução dos custos de instalação e manutenção, além de apresentarem melhores resultados com relação a design arquitetônicos. Outras considerações importantes são fatores como: longevidade e segurança das instalações, propriedade de resistência a altas temperaturas e resistência a substâncias químicas. Atualmente utilizam-se fibras de vidro e de aço para reforçar estruturas de concreto. As fibras formam uma malha na estrutura interna do concreto aumentando sua resistência. A figura 2.7 mostra uma estrutura deste tipo sendo reforçada por fibra de aço.

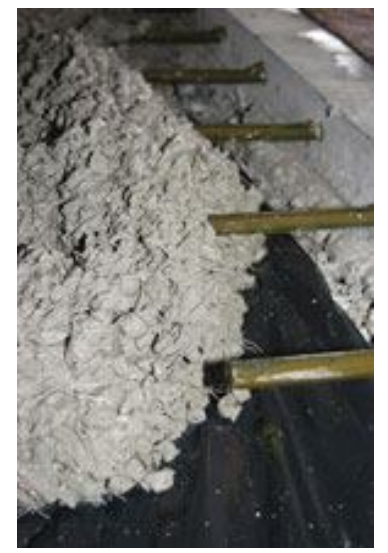

Figura 2.7 - Estrutura de concreto sendo reforçada por fibra de aço. (Fonte: www.constructalia.com).

\subsubsection{Elétrico Eletrônico}

No setor elétrico, a maior utilização dos compósitos está na fabricação de caixas de alimentação, isoladores de linhas de transmissão, postes de transmissão de energia, pás de turbinas eólicas, cabos e outros componentes. Isso devido ao fato dos MCR apresentarem boa proteção contra interferência eletromagnética, bom isolamento elétrico, boa adesão a revestimentos, propriedades antimagnéticas e resistência à temperatura elevada. 
$\mathrm{Na}$ indústria eletrônica, estes materiais têm sido empregados na construção de processadores de computadores, conectores, circuitos integrados dentre outros componentes eletrônicos. Nestes casos são empregados materiais compósitos laminados híbridos construídos por lâminas que apresentam diferentes funções. Uma dessas funções é suportar a alta temperatura gerada pelo microprocessador sem a ocorrência de delaminação. A figura 2.8 mostra a estrutura das turbinas de uma usina de energia eólica marítima.

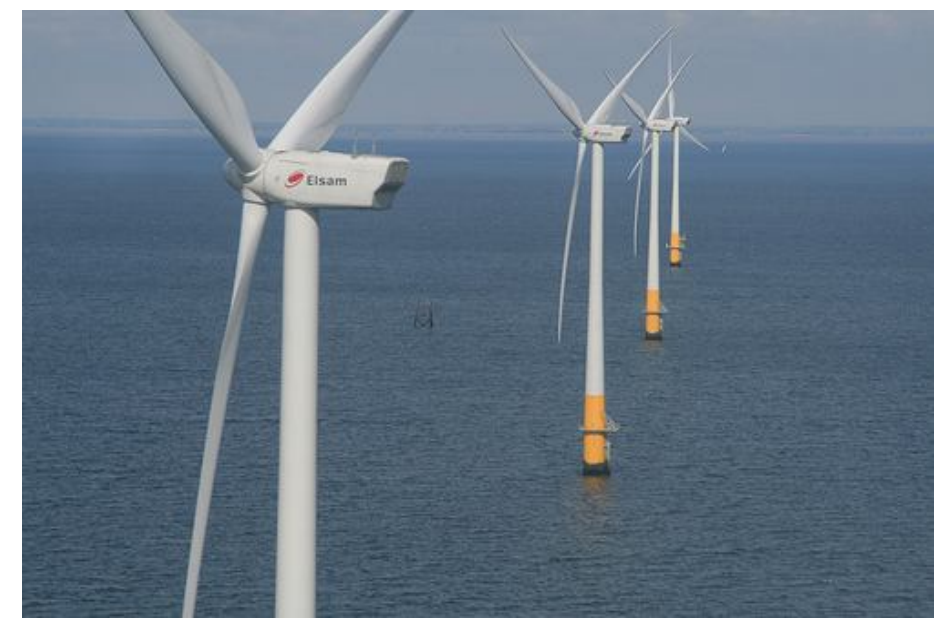

Figura 2.8 - Turbinas para obtenção de energia eólica. (Fonte: www.greenpeace.org).

\subsubsection{Equipamentos Esportivos}

Outro setor que vem se beneficiando do uso de materiais compósitos é o setor de materiais esportivos, sendo muito otimizados na fabricação de equipamentos. Os produtos fabricados com esse tipo de material apresentam melhor desempenho devido à alta resistência, alta rigidez, flexibilidade e baixa densidade o que os tornam altamente competitivos no mundo do esporte. Como exemplos pode-se citar: raquetes de tênis, tacos de golfe e beisebol, capacetes, esquis aquáticos, varas de pescar, squeites, patins, arcos-e-flexas, pranchas em gerais, canoas e remos, carros de corrida, bicicletas, cilindros de ar comprimido para 
mergulho etc. A figura 2.9 mostra um quadro de bicicleta fabricado de material compósito polimérico revestido por fibra de carbono que pesa aproximadamente $0,88 \mathrm{Kg}$, segundo a especificação técnica do fabricante.
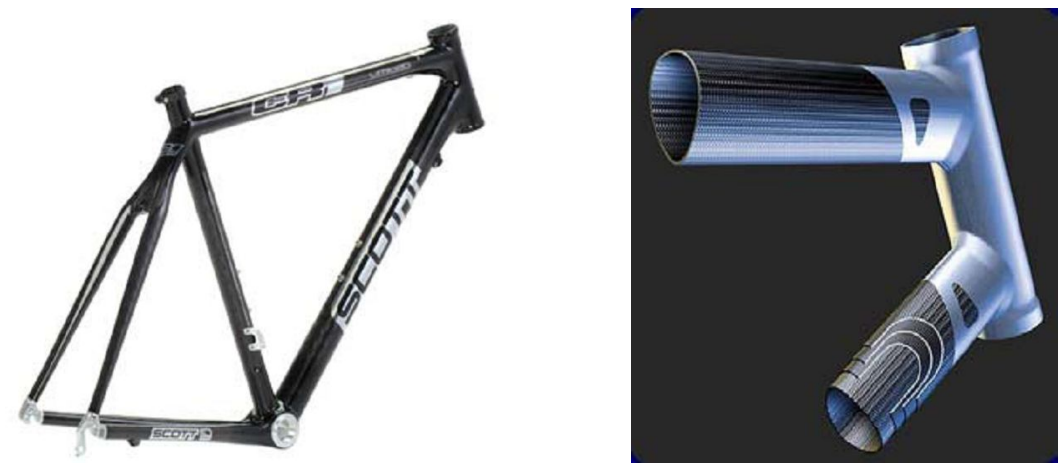

Figura 2.9 - Quadro de bicicleta fabricado por material compósito revestido por fibra de carbono.

(Fonte: Scott - www.scottusa.com).

\subsubsection{Médico}

Segundo Filho (2006), os MCR têm auxiliado em diversos setores na área médica. A finalidade dos materiais compósitos na área média é a redução do peso e a durabilidade que apresentam estes materiais além de sua compatibilidade biológica. Existem várias aplicações envolvendo a fabricação de equipamentos médicos tais como: cadeiras de roda, muletas, órteses, entre outras. Uma aplicação considerável que tem sido bastante pesquisada é a utilização de compósitos em próteses e orteses, como por exemplo, próteses de articulação do quadril. A possibilidade destes materiais em se combinar resistência e rigidez representa uma vantagem decisiva sobre os materiais convencionais. A figura 2.10 mostra um projeto de haste femoral desenvolvida por polímero reforçado por fibra de carbono. 


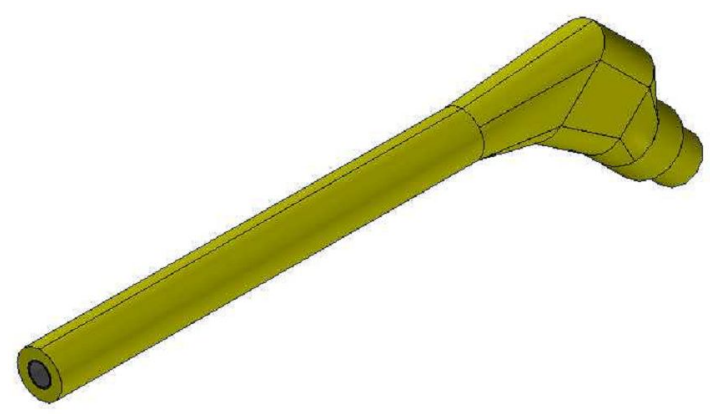

Figura 2.10 - Projeto de uma haste femoral produzida por material compósito reforçado. (Fonte: FILHO, 2006).

\subsubsection{Vantagens e Desvantagens}

Comparando a utilização dos materiais compósitos com a dos materiais convencionais em algumas aplicações, podemos chegar a diferentes conceitos de seleção. Ao escolher um determinado material para uma aplicação, algumas variáveis devem ser consideradas. As mais importantes são o custo e a eficiência estrutural, esta última prove da combinação entre rigidez e o peso especifico. Em geral, quanto menor o peso especifico do material, maior será sua eficiência estrutural e seu custo. Assim ao optar pelo o uso de um determinado material, com custos elevados como os compósitos, deve-se considerar que a resistência estrutural necessária, para uma aplicação que compense seus custos.

Noton (1987), explica que os materiais compósitos reforçados apresentam inúmeras vantagens sobre os materiais convencionai,s e quando isso não ocorre é devido à erros na escolha adequada fibra/matriz ou no processo de fabricação inadequado. De uma maneira geral, pode-se enumerar as vantagens dos materiais compósitos em relação aos materiais convencionais: 
- Atender aos requisitos em diversas fases do projeto devido a seu aspecto multifuncional;

- Baixa densidade em relação aos materiais metálicos convencionais;

- Ótimos resultados estruturais na combinação de rigidez e peso específico;

- Resistência à corrosão e oxidação;

- Ótimos resultados em aspectos de fadiga e fraturas;

- Excelentes características de tolerância a impactos e a danos;

- Ótimos resultados em relação à estética;

- Resistência a temperaturas elevadas, dependendo da matriz utilizada;

- Isolantes térmicos e acústicos;

Por outro lado, alguns fatores podem retardar a aceitação destes materiais, tais como:

- Alto custo do material para algumas aplicações em grande escala;

- Processos de fabricação mais complexos e caros;

- Conhecimento insuficiente sobre as condições do comportamento mecânico em serviço como fadiga e resistência a impacto, o que reflete na confiabilidade dos componentes fabricados;

- Preocupação com as exigências ambientais em relação a componentes químicos utilizados no processo de fabricação. Atualmente, o mercado exige certificações como ISO 14000. Conseqüentemente as empresas que não seguirem essas determinações eliminando os resíduos de forma ecologicamente correta, poderão ser excluídas do mercado.

Com relação às desvantagens apresentadas pelos materiais compósitos reforçados em relação aos custos de produção e manufatura, esses custos tendem a diminuir com o avanço tecnológico. A utilização de compósitos pela indústria atual, tem despertado o 
interesse de muitos pesquisadores visando contribuir com processos mais rápidos, flexíveis e de menor custo que os torne mais competitivos em relação aos materiais convencionais.

\subsection{PROJETO E FABRICAÇÃO EM COMPÓSITOS}

O ciclo de projeto em compósitos deve incluir toda atividade relacionada ao processo global da peça a ser fabricada. O componente final deve satisfazer requisitos de projeto que atendam a: resistência mecânica, rigidez, custo, matéria prima, fabricação e manutenção.

\subsubsection{Projeto de Materiais Compósitos}

De acordo com Carvalho (1996), a utilização de materiais compósitos em aplicações estruturais possibilita aos engenheiros manipular as propriedades do material ao longo da fabricação da peça, de modo a satisfazer os critérios do projeto. A escolha preliminar da combinação fibra e resina baseiam-se nas especificações de projeto para uma determinada

aplicação. É importante ressaltar que a escolha da melhor fibra e da melhor resina não necessariamente conduzirá ao melhor compósito, mas sim se analisar a melhor combinação do conjunto fibra e resina. Para escolher a melhor combinação fibra e resina devem-se observar aspectos mecânicos, físicos, químicos, térmicos, econômicos e de segurança. No caso de materiais laminados, após a escolha da combinação é ainda necessário escolher o ângulo (Ply Angles), que forma cada camada e a seqüência com que essas camadas são preenchidas (Stacking sequence), para atingir as propriedades do material. 


\subsubsection{Fibras}

As fibras são responsáveis pela propriedade de resistência e rigidez dos materiais compósitos, que varia em função do tipo, tamanho, grau de concentração e disposição das mesmas na matriz. Matheus \& Rawlings (1994) classifica as fibras em duas formas: Fibras contínuas e fibras descontínuas, sendo que ambas têm a função de suportar esforços provenientes da matriz (resina), porém com características distintas que influenciam o desempenho mecânico dos compósitos.

A característica mecânica dos materiais reforçados por fibras não depende somente das propriedades das fibras, mas também da intensidade com que o carregamento é transmitido às fibras por meio da matriz (Callister, 1994). Assim, para cada combinação fibramatriz é necessário estabelecer um comprimento mínimo da fibra capaz de garantir efetivamente a rigidez e resistência do compósito. Este fenômeno de transferência de carregamento é ilustrado na Figura 2.11.

Sobre esse contexto, Matthews \& Rawlings (1994) definem o comprimento crítico da fibra $\left(l_{c}\right)$ como sendo o comprimento mínimo da fibra necessário para que um determinado diâmetro de fibra alcance a tensão de ruptura a tração da fibra em lugar de tensão de ruptura ao cisalhamento da interface, ou seja, o comprimento mínimo de fibra necessário para que a tensão transmitida alcance a tensão de ruptura `a tração da fibra. 


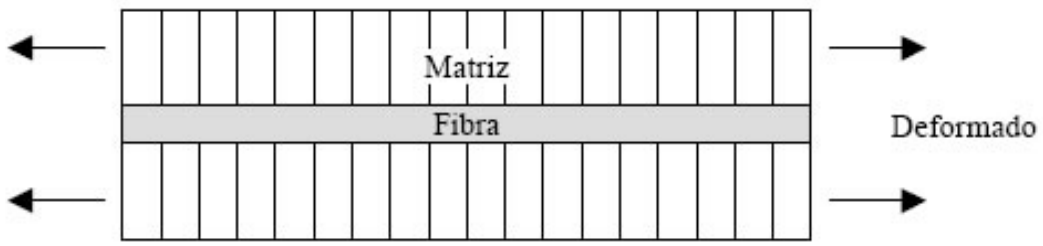

(a)

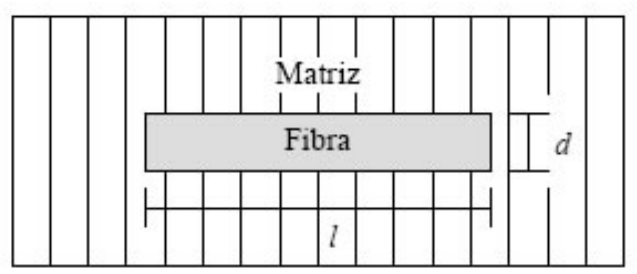

Não Deformado

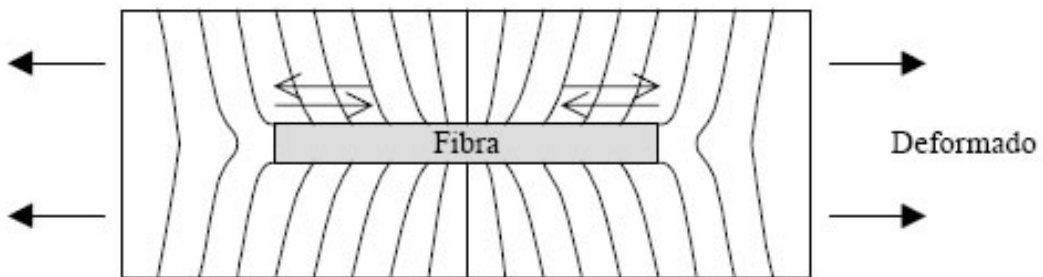

(b)

Figura 2.11 - Efeito da deformação ao redor da fibra na matriz sob tensão: (a) fibra contínua; (b) fibra descontínua (Fonte: MATHEUWS \& RAWLINGS, 1994).

Então:

$l_{c}=\frac{\sigma_{c} . d}{2 . \tau}$

Onde:

$l_{c}=$ comprimento crítico da fibra;

$\sigma_{c}=$ resistência à tração na ruptura da fibra;

$\tau$ I = menor resistência ao cisalhamento da matriz ou da interface;

$d=$ diâmetro da fibra. 
As fibras longas (contínuas) e de pequeno diâmetro são as mais adequadas para o reforço de estruturas em materiais compósitos pela ótima capacidade de transferência de carga e de aproveitamento de suas propriedades.

As fibras mais utilizadas atualmente são as de vidro, as de aramida e as de carbono. Matthys (2000) mostra na tabela 2.1 que as propriedades físicas e mecânicas das fibras variam consideravelmente entre os diferentes tipos de fibra e a figura 2.12 faz uma comparação do diagrama tensão x deformação das mesmas com o do aço.

\begin{tabular}{|c|c|c|c|c|c|c|}
\hline \multicolumn{2}{|c|}{ Tipo de Fibras } & $\begin{array}{c}\text { Resistência } \\
\text { attração } \\
(\mathrm{MPa})\end{array}$ & $\begin{array}{c}\text { Módulo de } \\
\text { elasticidade } \\
\text { (MPa) }\end{array}$ & $\begin{array}{c}\text { Deformação } \\
\text { última } \\
(\%)\end{array}$ & $\begin{array}{c}\text { Peso } \\
\text { especifico } \\
\left(\mathrm{kg} / \mathrm{m}^{3}\right)\end{array}$ & $\begin{array}{c}\text { Diâmetro } \\
\text { da fibra } \\
\text { (ㅆm) }\end{array}$ \\
\hline \multirow{3}{*}{$\begin{array}{l}\text { Carbono } \\
\text { (C) }\end{array}$} & $\begin{array}{c}\text { tipo } \text { PAN }^{\star} \text { - } \\
\text { com alta resistência } \\
\text { (HS) }\end{array}$ & $3500-5000$ & $200-260$ & $1.2-1.8$ & $1700-1800$ & $5-8$ \\
\hline & $\begin{array}{l}\text { tipo PAN }{ }^{*}- \\
\text { com alto modulo de } \\
\text { elasticidade }(\mathrm{HM})\end{array}$ & $2500-4000$ & $350-700$ & $0.4-0.8$ & $1800-2000$ & $5-8$ \\
\hline & $\begin{array}{l}\text { tipo Pitch } \\
\text { com alto módulo de } \\
\text { elasticidade }(\mathrm{HM})\end{array}$ & $3000-3500$ & $400-800$ & $0.4-1.5$ & $1900-2100$ & $9-18$ \\
\hline \multirow{2}{*}{$\begin{array}{l}\text { Aramida } \\
\text { (A) }\end{array}$} & $\begin{array}{l}\text { com módulo de } \\
\text { elasticidade } \\
\text { intermediário (IM) }\end{array}$ & $2700-4500$ & $60-80$ & $4.0-4.8$ & $1400 \cdot 1450$ & $12-15$ \\
\hline & $\begin{array}{l}\text { com alto módulo de } \\
\text { elasticidade }(\mathrm{HM})\end{array}$ & $2700-4500$ & $115-130$ & $2.5-3.5$ & $1400-1450$ & $12-15$ \\
\hline \multirow{2}{*}{ Vidro (G) } & $\begin{array}{c}\text { aluminoborosilicato } \\
\text { de cálcio }(E)\end{array}$ & $1800-2700$ & $70-75$ & $3.0-4.5$ & $2550-2600$ & $5-25$ \\
\hline & $\begin{array}{c}\text { aluminosilicato de } \\
\text { maqnéslo (S) }\end{array}$ & $3400-4800$ & $85-100$ & $4.5-5.5$ & $2550-2600$ & $5-25$ \\
\hline
\end{tabular}

*PAN = fibras obtidas por pirólise e oxidação de fibras sintéticas de Poliacrilonitrila

**Pitch $=$ fibras obtidas pela pirólise do petróleo destilado ou do piche convertido em cristal líquido

Tabela 2.1 - Propriedades típicas dos principais tipos de fibra (Fonte: MATTHYS, 2000). 


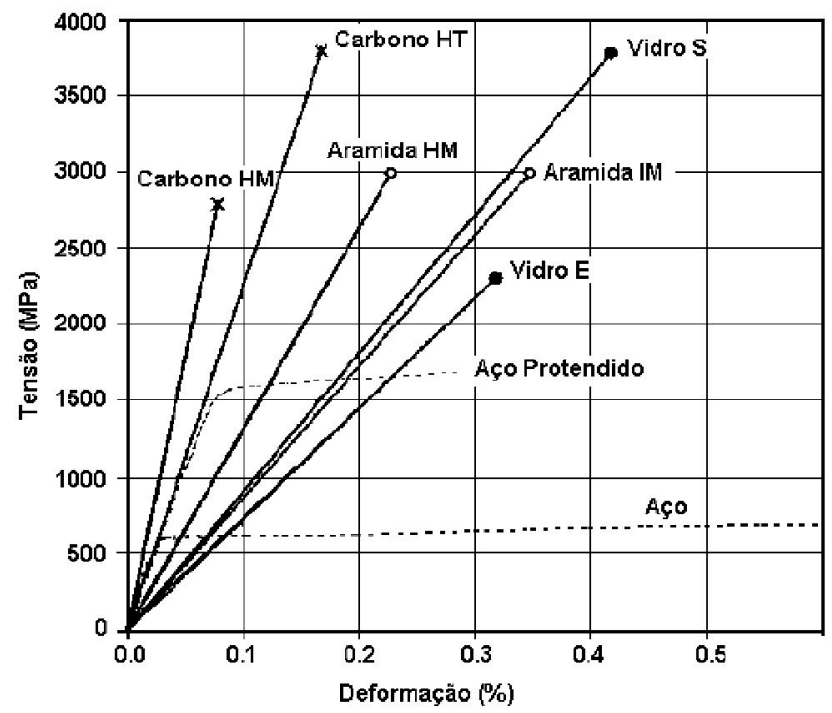

Figura 2.12 - Diagrama tensão-deformação dos principais tipos de fibra (Fonte: MATTHYS, 2000).

\subsubsection{Matriz}

Segundo Filho (2001), as matrizes podem ser materiais poliméricos, metálicos ou cerâmicos. O fator que determinará a escolha do material da matriz é a propriedade física, mecânica e térmica exigida pelo processo de fabricação e do custo estipulado pelo projeto.

Reinhart \& Clements (1987), afirma que a função da matriz é manter a integridade estrutural do compósito, através da sua união simultânea com as fibras em virtude de suas características adesivas. Além disso, tem a função de transferir o carregamento para as fibras, protegê-las contra ataques ambientais como corrosão e abrasão, e de danos relativos ao manuseio. Por isso, Callister (1994) ressalta a importância da resistência das forças adesivas referentes à interface fibra-matriz.

De acordo com Filho (2001), as matrizes mais utilizadas são as poliméricas devido ao baixo custo, fácil modelagem, boa resistência química e baixo peso específico, embora 
apresentem baixa resistência mecânica, baixo módulo de elasticidade e baixa temperatura de serviço comparadas às matrizes metálicas e cerâmicas. Outro fator negativo das matrizes poliméricas se dá através da degradação referente à exposição prolongada a luzes ultravioleta e alguns solventes. Os polímeros utilizados como materiais de matrizes são usualmente chamados de resinas. As resinas exercem muitas funções essenciais, além daquelas mencionadas anteriormente: elas mantêm as fibras na posição e orientação adequada de modo que possam suportar as cargas desejadas, servem como barreira de propagação de trincas e garantem a resistência ao cisalhamento interlaminar do compósito.

As matrizes poliméricas podem ser classificadas como: resinas termoplásticas e termofixas. Shackelford (1996) mostra que, a principal diferença entre os polímeros termoplásticos e os termofixos está no comportamento quando aquecidos, ou seja, os termoplásticos se fundem e se transformam em um líquido viscoso capaz de sofrer processos de extrusão, enquanto os termofixos, ao invés de sofrerem processo de fusão, começam a se decompor termicamente.

As resinas termoplásticas são caracterizadas por macromoléculas mais lineares e podem ser repetidamente fundidas quando aquecidas e endurecidas quando resfriadas. Em outras palavras, as resinas termoplásticas podem "amolecer" sob aplicação de calor e pressão e "endurecer" novamente quando resfriadas. Já as resinas termofixas passam por uma reação química irreversível durante a polimerização, conhecido como processo de cura. Durante esse processo, são formadas ligações cruzadas covalentes entre as cadeias moleculares adjacentes, desenvolvendo uma estrutura tridimensional. Essas ligações cruzadas, à medida que se formam, causam diminuição da mobilidade das cadeias moleculares, provocando solidificação. Portanto o processo de cura pode ser acelerado com aplicação de calor e pressão em condições controladas, por meio de autoclaves, ou ainda por catalisador (hardener). Quando se solidificam, assim permanecem e mesmo reaquecidos, não se fundem. Sob a 
exposição a temperaturas elevadas, o material sofrerá combustão, o que descarta a possibilidade de sua reutilização.

Segundo Tita (1999), as resinas termofixas são mais comuns para o uso estrutural em materiais compósitos, devido ao enorme número de aplicações e características finais mais desejáveis como menor custo comparado às resinas termoplásticas. Smith (1993) descreve as vantagens dos polímeros termofixos para uso na engenharia como:

- $\quad$ Alta estabilidade térmica;

- $\quad$ Alta rigidez;

- $\quad$ Alta estabilidade dimensional;

- $\quad$ Resistência à fluência e a deformação sob carregamento;

- $\quad$ Baixo peso específico;

- Boas propriedades de isolamento térmico e elétrico.

Uma das resinas mais utilizadas é a epóxi, devido à extensa gama de propriedades físicas e mecânicas do material. Para manipular esse tipo de resina é preciso respeitar alguns detalhes de processos tais como: o período em que a resina mantém suas características de aderência e pode ser manipulada sem dificuldade é conhecido como tempo de utilização (potlife). Quanto maior a temperatura e quantidade de material a ser preparado, menor o tempo de utilização. Isto ocorre em função da maior quantidade de calor e conseqüente aceleração das reações. Outro processo é o tempo de endurecimento, necessário para que a resina adquira o estado sólido. É o intervalo no qual o compósito deve ser colado para que suas propriedades se desenvolvam satisfatoriamente. Este tempo é influenciado pelas temperaturas do ambiente, do compósito e da superfície a ser reforçada. 
Para aumentar a resistência da matriz e facilitar a fabricação do compósito, vários tipos de aditivos podem ser usados. Os mais comuns são os inibidores da ação de raios ultravioleta, os antioxidantes, os catalisadores e os desmoldantes.

\subsubsection{Fibra/Matriz}

Segundo Filho (2001), a interface entre fibra e matriz é o "coração" dos materiais compósitos. A estrutura e as propriedades da interface fibra-matriz são igualmente responsáveis pelo desempenho mecânico e pela integridade estrutural dos compósitos reforçados por fibra, uma vez que as tensões atuantes na matriz são transmitidas para as fibras através da interface, HULL (1981). Algumas hipóteses normalmente aceitas, mas que nem sempre são verdadeiras na prática, são:

- A matriz e a fibra se comportam como materiais elásticos;

- A interface é infinitamente delgada;

- A interação fibra-matriz é perfeita de forma que não ocorra descontinuidade de deformação ao longo da interface;

- A interface que se forma ao redor da fibra tem as mesmas propriedades que um material no estado sólido;

\subsubsection{Ciclo de Projeto com Materiais Compósitos}

De acordo com Carvalho (1996), o ciclo de projeto com MCR deve abranger todas as atividades necessárias para obtenção um produto satisfatório em termos de custo-beneficio, como mostra a figura 2.13 . 


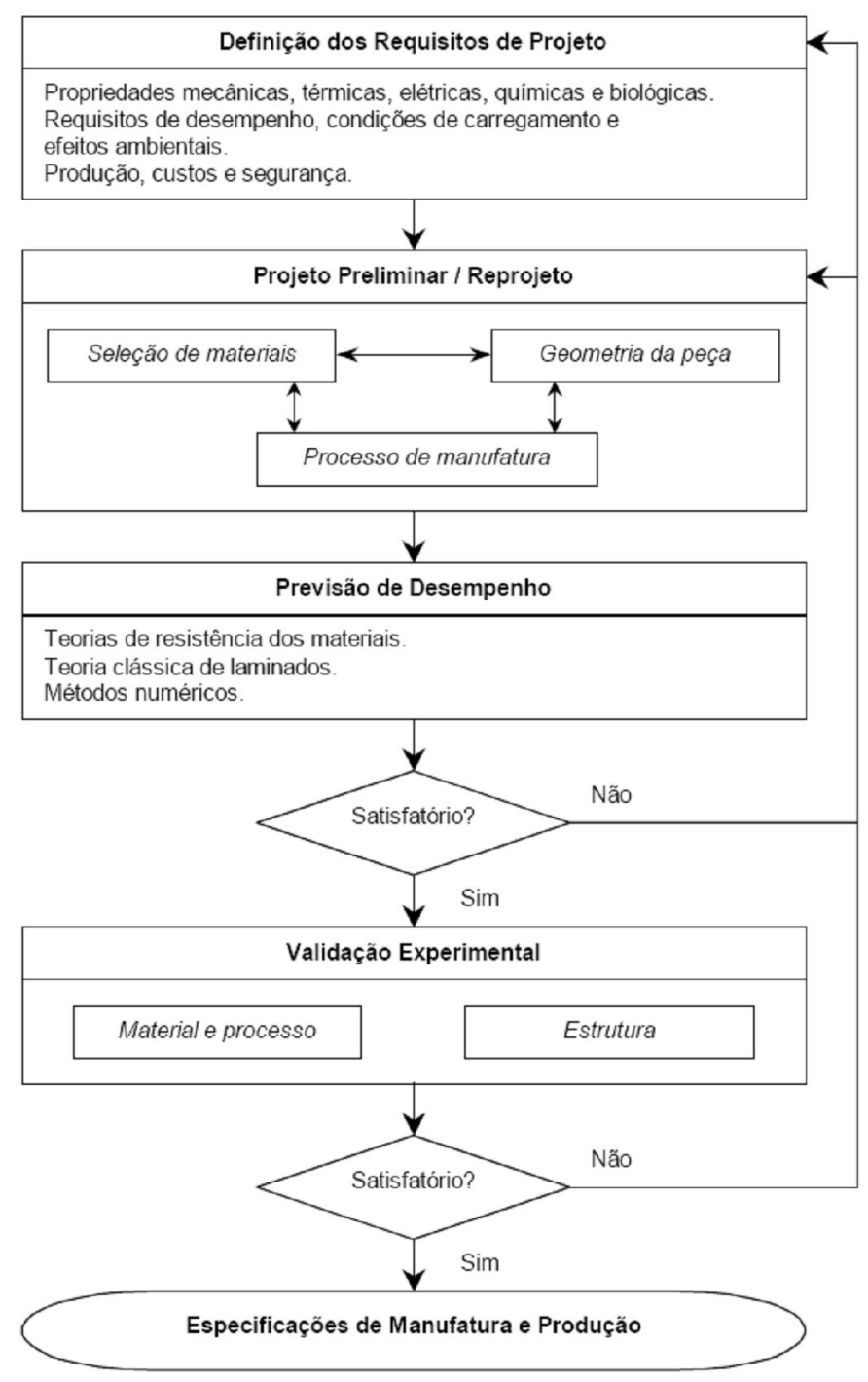

Figura 2.13 - Ciclo de projeto com materiais compósitos (CARVALHO, 1996).

\subsection{Definição dos requisitos do projeto}

Na primeira fase do projeto, é necessário realizar um levantamento de informações referentes às especificações da aplicação e aspectos de custos. Essas especificações incluem requisitos de funcionalidade como: propriedades mecânicas, térmicas, elétricas, químicas e biológicas, bem como as condições de carregamento e efeitos ambientais. 


\subsection{Projeto preliminar / reprojeto}

Após o levantamento das informações da primeira fase, estabelece-se o projeto preliminar, que se dá pela escolha inicial do material, geometria, processo de manufatura e características macromecânicas básicas da peça.

- Seleção de material: envolve todas atividades relacionadas à escolha dos materiais constituintes do material compósito;

- Geometria da peça: Recomenda-se a utilização do sistema CAD, pois o mesmo possibilita a descrição matemática da geometria da peça que poderá ser utilizada em aplicações especificas como, por exemplo: análise de escoamento, cálculo da trajetória da fibra no processo de enrolamento de filamento, entre outras.

- Processo de manufatura: Refere-se praticamente a duas atividades seqüenciais. Primeiro escolhe-se um processo de manufatura e suas limitações são tomadas em consideração para verificar a manufaturabilidade da geometria da proposta e do material. Em seguida, calculam-se as características macromecânicas como fração volumétrica e orientação das fibras, espessura e sequiência de empilhamento das camadas.

\subsection{Previsão de desempenho}

Nessa fase recomenda-se proceder à simulação numérica da estrutura e realizar a validação experimental quando tal simulação conduzir a resultados satisfatórios. Dos métodos disponíveis atualmente, o método dos elementos finitos é certamente o mais utilizado. Dessa 
simulação obtém-se informações relacionadas à distribuição de tensões, deformações e ao comportamento dinâmico, que são comparadas com as especificações do projeto.

\subsection{Validação experimental}

A validação experimental deve incluir dois aspectos principais do ciclo de projeto, a avaliação do material e do processo e a avaliação da estrutura. A avaliação do material e do processo tem por objetivo verificar se o processo escolhido conduz às propriedades dos materiais desejados com qualidade aceitável. Para obter um método de fabricação que seja eficiente, vários fatores de processamento devem ser definidos e controlados. Para avaliação da estrutura deve-se verificar se os requisitos estruturais são satisfatórios como, por exemplo, a resistência mecânica, resposta dinâmica, flambagem, impacto dentre outros.

\subsection{Especificações de manufatura e produção}

Após todas as etapas acima forem realizadas e apresentarem resultados satisfatórios, a peça estará pronta para ser produzida.

\subsubsection{Técnicas de Fabricação dos Materiais Compósitos}

Segundo Hull e Clyne (1996), as propriedades finais de componentes e estruturas em MCR não são apenas dependentes das propriedades da fibra e resina, mas também do modo pelo qual são processadas. As possibilidades de otimização e customização dos MCR é o maior atrativo para aplicações e ao mesmo tempo um problema desafiador. 
Atualmente muitos processos de fabricação de MCR estão tecnicamente e comercialmente desenvolvidos. A exploração comercial do MCR está relacionada ao aprimoramento do rendimento da produção. Bannister (2001) realizou um estudo sobre os níveis de tecnologia envolvidos nos processos de manufatura tais como: enrolamento filamentar (Filament Winding), pultrusão (Pultrusion), entrelaçamento (Braiding) dentre outros.

\subsubsection{Dificuldades do processo de fabricação}

A grande gama de possibilidade de combinações de fibras e resinas, bem como a disponibilidade de vários métodos de fabricação, dão origem a dúvidas com relação à escolha do material e do processo de fabricação. O desenvolvimento dos MCR é um processo complexo e requer considerações importantes sobre vários aspectos que influenciam na seleção tais como: dimensões e forma do componente de estrutura, volume de produção, resistência e rigidez exigida, qualidade microestrutural, custo de produção etc.

A fabricação de estruturas e produtos em MCR passa por um processo de evolução deste a laminação manual até os métodos de manufaturas automatizados. Essa evolução resulta em novos métodos de monitoramento das condições de cura, otimização do ciclo de processo e mudanças microestruturais no componente, todos baseados nas condições de fabricação.

\subsubsection{Autoclave}


Segundo Filho (2006), uma autoclave é um vaso hermético destinado ao controle da temperatura e da pressão utilizado para a cura de materiais compósitos poliméricos laminados. O material destinado à autoclave é preparado por um processo de laminação. Esse processo pode ser feito manualmente ou por equipamentos automatizados. Após a laminação, o material é colocado na autoclave e submetido a um ciclo controlado de temperatura e pressão. As propriedades do material são geradas em função da escala de temperatura e pressão proporcionada pela autoclave. A figura 2.14 ilustra uma autoclave de grande porte.

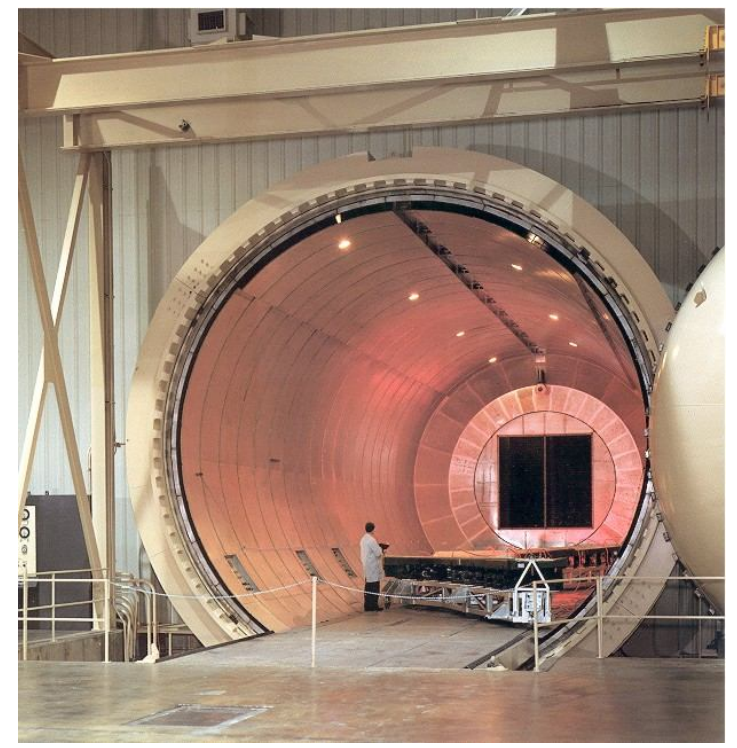

Figura 2.14 - Autoclave de grandes dimensões. (Fonte: www.bobscherer.com).

\subsubsection{Enrolamento de filamento (Filament Winding)}

O enrolamento filamentar é o processo de manufatura de materiais compósitos onde as fibras (reforço) são impregnadas na resina e "enroladas" sob tração sobre um mandril, que tem a geometria da peça desejada, em trajetórias previamente calculadas e controlada. A figura 2.15 mostra um processo de enrolamento filamentar em um vaso de pressão. Nesse 
trabalho será desenvolvido um sistema computacional para o cálculo da trajetória da fibra neste processo, melhor descrito no item 2.2.3.

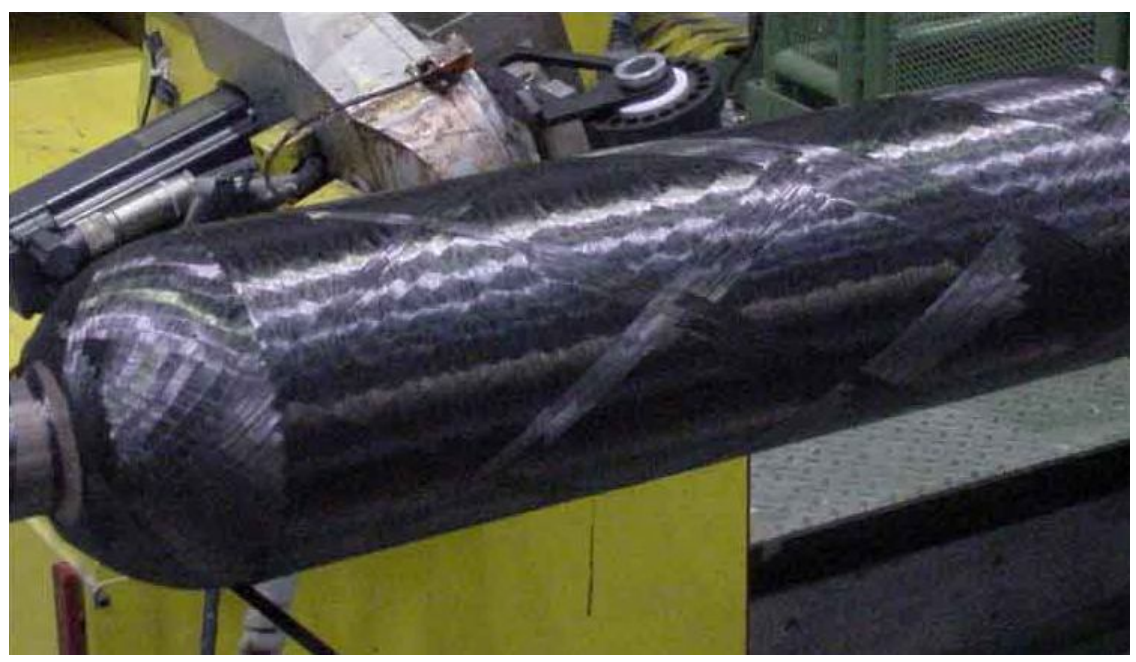

Figura 2.15 - Processo de enrolamento de filamento. (Fonte: http://dev.wilsoncomposites.com).

\subsubsection{Pultrusão (pultrusion)}

A pultrusão é um processo de fabricação em compósitos que utiliza fibra contínua e é utilizado para gerar perfis lineares tais como: barras, vigas, tubos, etc. Essa técnica se inicia com a impregnação das fibras contínuas através de um banho de resina termofixa. Estas são estiradas através de um molde de aço que pré-conforma o material na forma desejada e o excesso de resina é removido para estabelecer a razão fibra/resina. O material passa através de um molde que é usinado com precisão, de modo a conferir ao perfil a forma final desejada. Esse molde é aquecido com o objetivo de iniciar o processo de cura. Um dispositivo de puxar estira o material através dos moldes e determina a velocidade da produção. No final do processo, o produto pultrudado é cortado no tamanho desejado. Os principais reforços utilizados nesse processo são as fibras de vidro, carbono e aramida. A pultrusão é um processo contínuo e automatizado, as taxas de produção são relativamente altas o que torna 
esse processo muito eficaz em termos de custos. A figura 2.16(a) mostra esquematicamente o processo e a figura 2.16(b) mostra uma máquina de pultrusão.
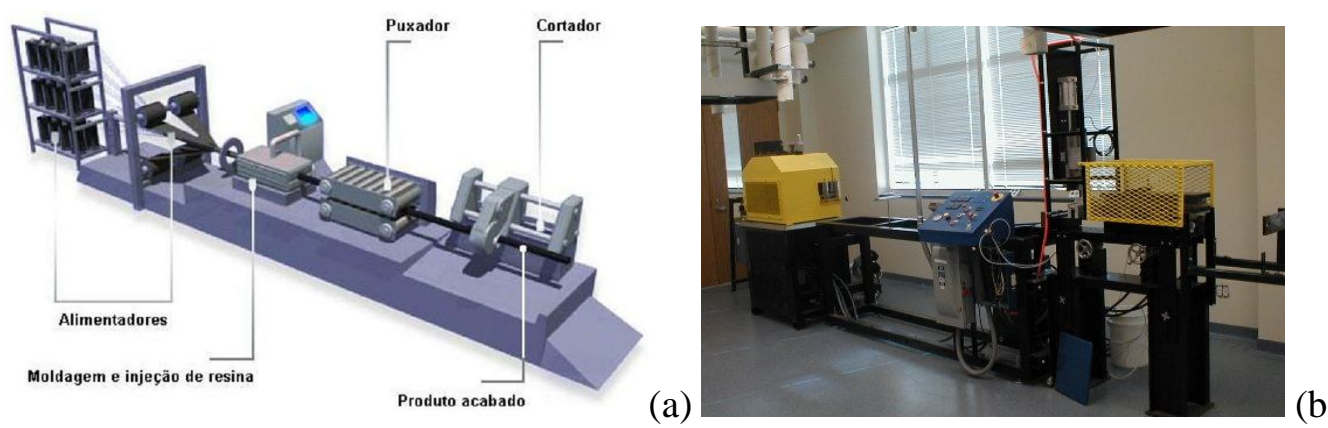

Figura 2.16 - (a) Desenho esquemático do processo de pultrusão; (b) Máquina de pultrusão (Fonte: Exel Industry - www.exelindustry.com.br).

\subsubsection{Entrelaçamento (braiding)}

O entrelaçamento é uma técnica utilizada para o revestimento de peças com formas tubulares. Filho (2006) descreve o processo de funcionamento da máquina em um anel que se localiza no interior de várias bobinas presente na máquina. Essas bobinas giram em relação a um mandril, e este se movimenta paralelamente através do anel. O sincronismo do movimento de rotação do anel com o movimento de translação do mandril determinam o ângulo de entrelaçamento das fibras, ou seja, definem a cobertura do traçado sobre a superfície do mandril.

Uma das vantagens desse processo com relação ao processo de enrolamento filamentar é que esta técnica permite revestir peças com superfícies mais complexas em tempo reduzido, embora não tenha a mesma capacidade para otimização do ângulo de orientação da fibra. A figura 2.17(a) mostra um desenho esquemático do processo de entrelaçamento e a figura 2.17(b) mostra uma máquina em funcionamento. 

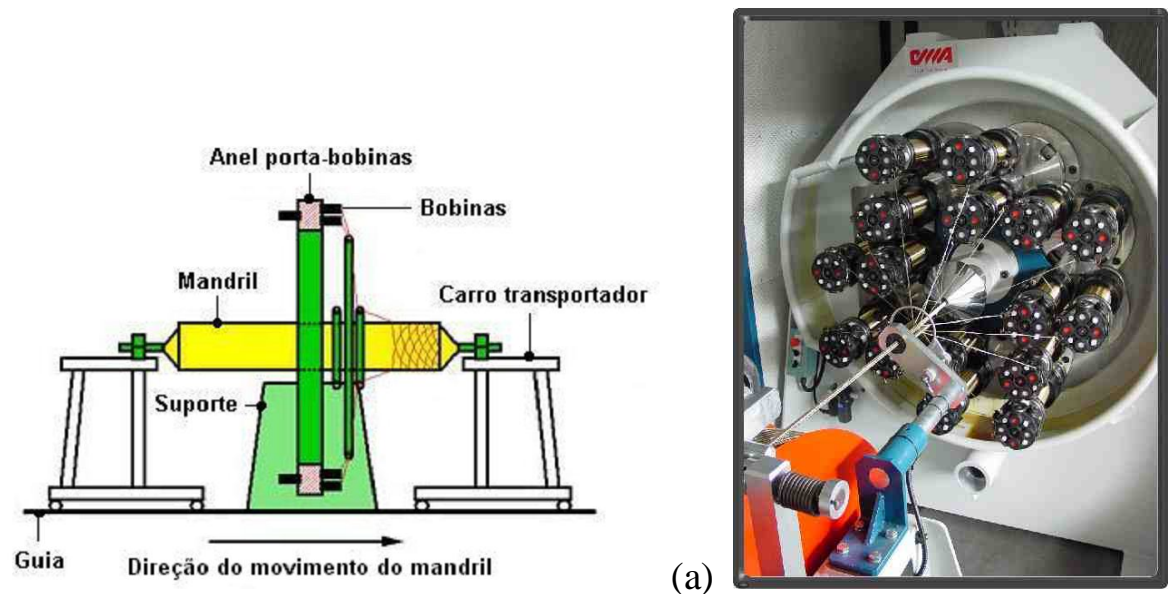

(b)

Figura 2.17 - (a) Desenho esquemático do processo de entrelaçamento; (b) Máquina de entrelaçamento. (Fonte: (a) Intelligent Systems Laboratory/Michigan State University www.islnotes.cps.msu.edu; (b) http://www.omabraid.com)).

\subsubsection{Modelagem por transferência de resina (Resin Trasnfer Molding - RTM)}

Neste processo uma resina líquida é injetada sob pressão para dentro da cavidade de um molde fechado que contem a pré-forma em fibra da peça desejada. Após o processo de cura, obtém-se o produto final solidificado. Esse processo requer o uso de resinas de baixa viscosidade, o suficiente para que as fibras sejam facilmente impregnadas. Também é exigido que os moldes tenham orifícios que permitam a saída de ar durante a transferência de resina. O esquema do processo é mostrado na figura 2.18 . 


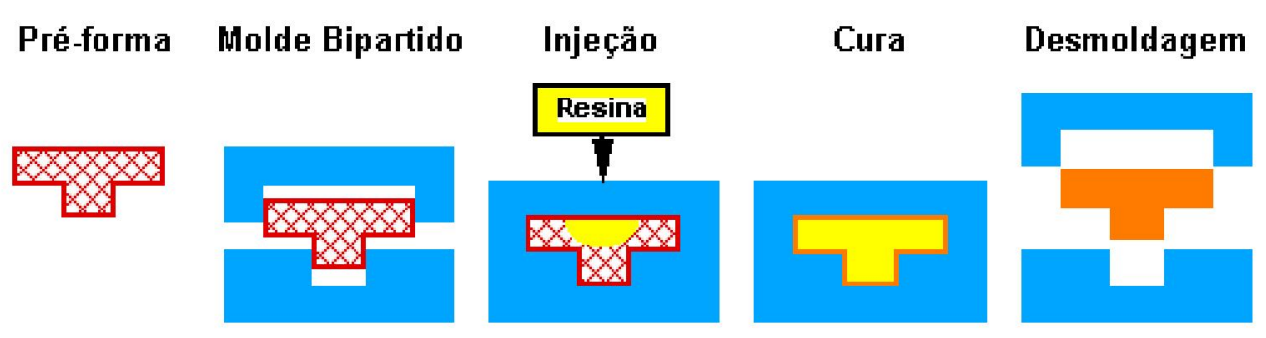

Figura 2.18- Esquema do processo de moldagem por transferência de resina. (Fonte: FILHO, 2006).

As vantagens principais desse processo incluem bom rendimento de produção, obtenção de peças grandes com formas complexas, bom acabamento superficial, boa produtividade e habilidade de incluir um grande número de insertos de molde.

\subsubsection{O processo de Enrolamento Filamentar (Filament Winding)}

O processo de fabricação em materiais compósitos conhecido como "Filament Winding” consiste na manufatura destes materiais através de fibras impregnadas em resinas, com uma trajetória definida sobre uma superfície de um mandril.

Scholliers (1992) descreve o processo como: "Processo de fabricação de estruturas em compósitos reforçados na qual a fibra é impregnada continuamente com resina e guiada através de um olho em movimento linear ao longo de um mandril com uma trajetória previamente determinada”.

De acordo com Carvalho (1996), a trajetória da fibra deve ser calculada por um software que determinará o movimento do olho, ou alimentador, durante o processo. Com a utilização de um software que calcule a otimização da trajetória da fibra, é possível determinar a melhor rotação para o mandril, o tempo e a estratégia de revestimento e o 
comprimento total da fibra a ser utilizada. A figura 2.19 ilustra esquematicamente o processo de Filament Winding.

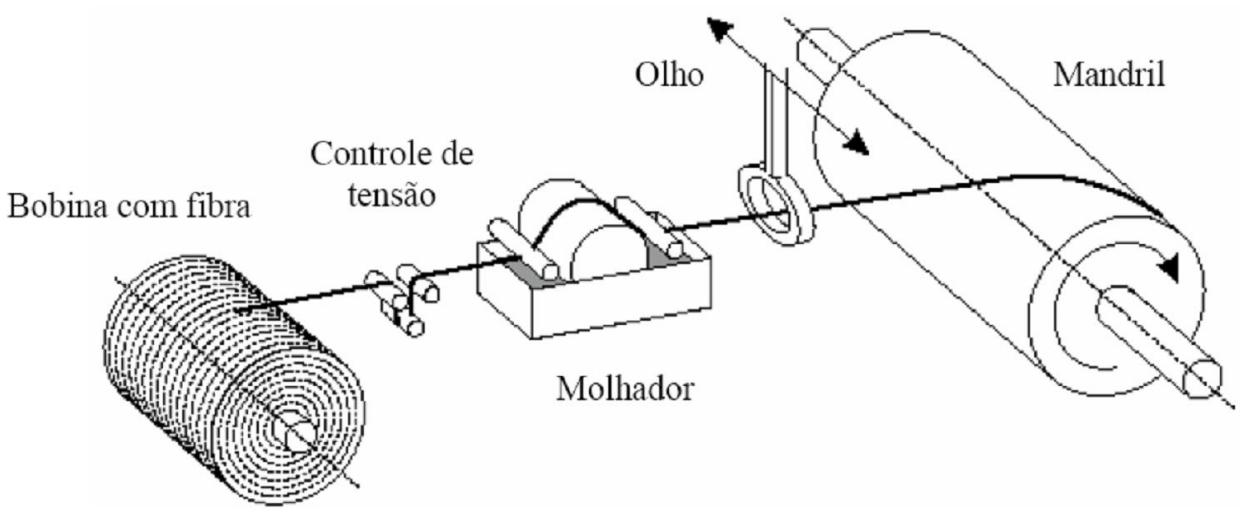

Figura 2.19 Representação esquemática de Enrolamento Filamentar(Filament Winding)

Neste processo, a fibra passa pelo controlador de tensão que tem a finalidade de mantê-la esticada durante o processo; em seguida passa por um rolo de impregnação que contém um recipiente com a resina, muitas vezes aquecida. Ao passar sobre o rolo, a fibra torna-se impregnada, sendo então guiada para o mandril, através do olho (do inglês: "payout eye"), figura 2.20. O olho tem a liberdade de movimento longitudinal, porém em alguns casos como em peças não geodésicas, pode possuir o movimento de rotação para melhor direcionar a fibra. O mandril é fixado em um eixo que gira continuamente, dessa forma a fibra é depositada na superfície da peça formando as diferentes camadas de laminação. No final do processo, o mandril deve continuar sua rotação para evitar a concentração de resina e formação de gotas. Caso haja concentração de resina no mandril, é necessário realizar a remoção através de pás ou raspadores plásticos. Para finalizar o ciclo, a peça passa pelo processo de cura, onde é submetida a altas temperaturas por meios de fornos de autoclave ou através de lâmpadas infravermelhas. 


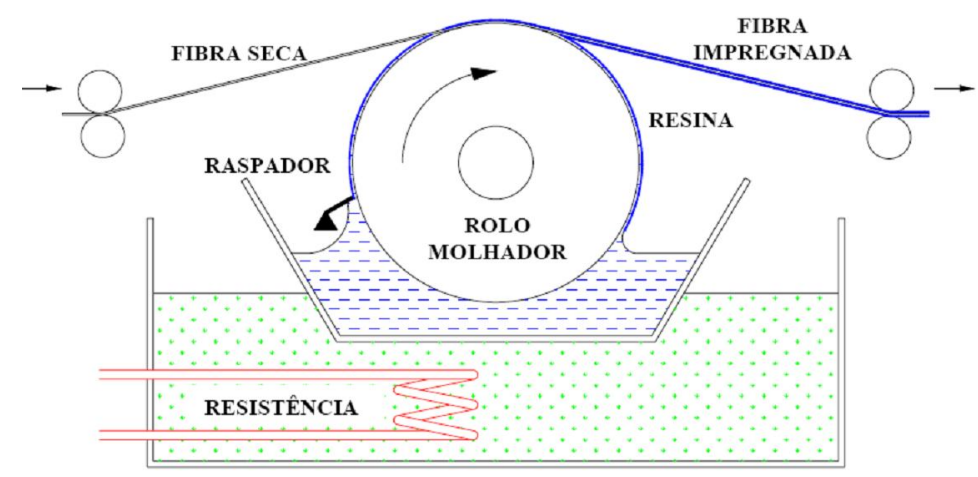

Figura 2.20 - Rolo Molhador. (Fonte: JOHAN, 1992).

\subsubsection{Ciclo De Projeto Para O Processo de Enrolamento Filamentar ( Filament Winding)}

Segundo Carvalho (1996), para o projeto e fabricação de peças pelo processo de enrolamento filamentar são necessárias algumas etapas, ilustradas na metodologia apresentada na figura 2.21 .

- Concepção preliminar: Após o levantamento dos dados gerados através da análise dos requisitos, uma concepção preliminar é feita para definição da geometria e propriedades dos materiais que serão utilizados na fabricação da peça. Para a definiç̧ão da geometria são utilizados sistemas CAD, que facilitam a manipulação de superfícies geometrias. Com a definição da superfície da peça, pode-se fabricar o mandril que apresenta o mesmo formato geométrico;

- Análise isotrópica de tensões: Para proporcionar um ponto de partida para o cálculo dos ângulos da trajetória, uma simulação é realizada com o material escolhido. A partir dessa simulação podem-se obter dados para geração da trajetória da fibra; 
- Geração da trajetória da fibra: Com base nos dados da fase anterior os pontos da trajetória da fibra são computados. Infelizmente devido às restrições imposta pelo processo, o ângulo ideal para a formação da trajetória nem sempre será alcançado desviando o melhor caminho. Por isso é importante ter um algoritmo computacional ou software que considere essas restrições, a fim de viabilizar a fabricação da peça;

- Seqüência Lay-up: Após a definição da trajetória é preciso definir a sequiência pela qual as diferentes trajetórias serão depositadas na peça. Essa seqüência formará as camadas (plies) do laminado, fator muito importante para garantir a resistência mecânica da peça final. Em caso de superfícies simétricas, uma única trajetória pode ser definida até o termino do revestimento. Já para superfícies assimétricas, diferentes trajetórias devem ser definidas para garantir um bom revestimento.

- Análise de tensões no material compósito: Após definir a seqüência o laminado (lay-up) precisa ser analisado. Essa análise pode ser feita através de elementos finitos a fim de obter informações sobre resistência e estrutura do material.

- Dados da máquina: Uma vez que os dados da trajetória tenham sido definidos, o próximo passo é a geração dos dados para controlar a máquina. Nessa fase que engloba o software desenvolvido em nosso trabalho. Os dados obtidos nas fases anteriores, são informados ao nosso sistema, que calcula os pontos da trajetória podendo ser interpretados pelas máquinas. Embora algumas restrições tenham sido consideradas em etapas anteriores, restrições adicionais podem ser relacionadas decorrentes do funcionamento da máquina.

- Validação Experimental: A validação experimental envolve a fabricação de protótipos, a fim de avaliar o desempenho global do componente, bem como o os parâmetros relacionados com o processo, fibra, impregnação, controle de tensão, sistemas orientadores, sistema de entrega e o processo de cura. 


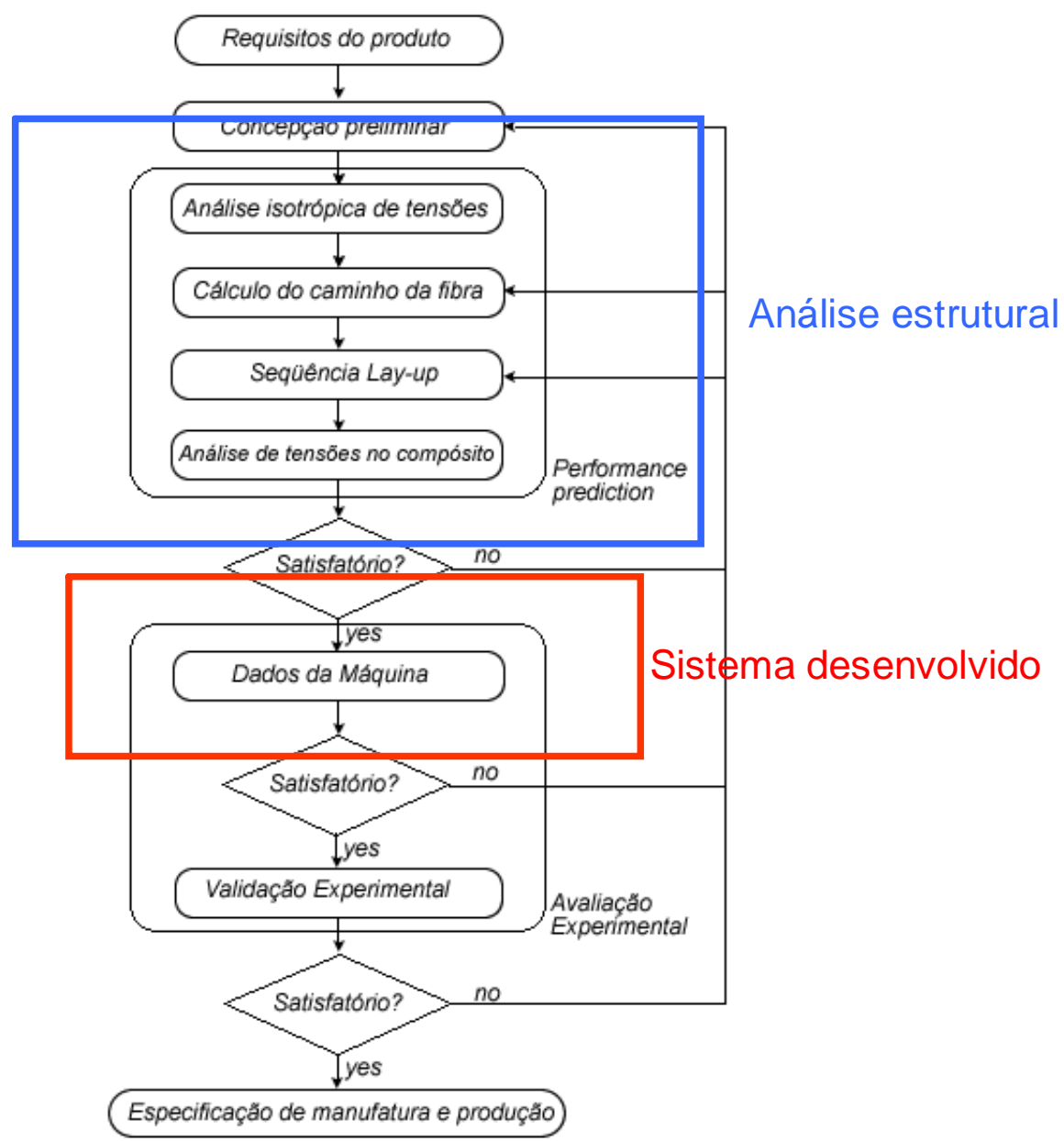

Figura 2.21 - Metodologia utilizada no processo de Filament Winding. (Fonte: CARVALHO, 1996).

Existem diferentes padrões que podem ser utilizados para revestir completamente as superfícies das peças. A figura 2.22 mostra três padrões básicos que serão utilizados pelo sistema computacional a ser desenvolvido neste trabalho:

- Revestimento polar (“Polar Winding”): Neste caso o caminho da fibra é um plano tangencial para ambos os pontos polares do mandril. A maior vantagem deste revestimento é a simplicidade e a possibilidade de manter constante a velocidade de revestimento; 
- Revestimento helicoidal (“Helical Winding”): A rotação do mandril e a velocidade de alimentação da fibra são sincronizadas, de tal forma que a hélice desejada e o ângulo sejam gerados. Este tipo de revestimento é muito mais versátil do que o revestimento polar, tendo um largo número de combinações de diâmetro, comprimento e ângulos de revestimento. O conceito básico do revestimento helicoidal tem sido estendido aos formatos não simétricos. Algoritmos especiais determinam a seqüência adequada, para o revestimento de superfícies mais complexas.

- Revestimento circular (“Hoop Winding”): Revestimento circular ou em forma de aro é basicamente o revestimento helicoidal, em um ângulo fechado próximo a 90 graus, o caminho das fibras é quase que totalmente perpendicular ao eixo da peça a ser revestida. Revestimento circular é geralmente combinado com revestimento polar ou helicoidal de maneira a encontrar um grau adequado de compactação e uma distribuição uniforme de tensões.

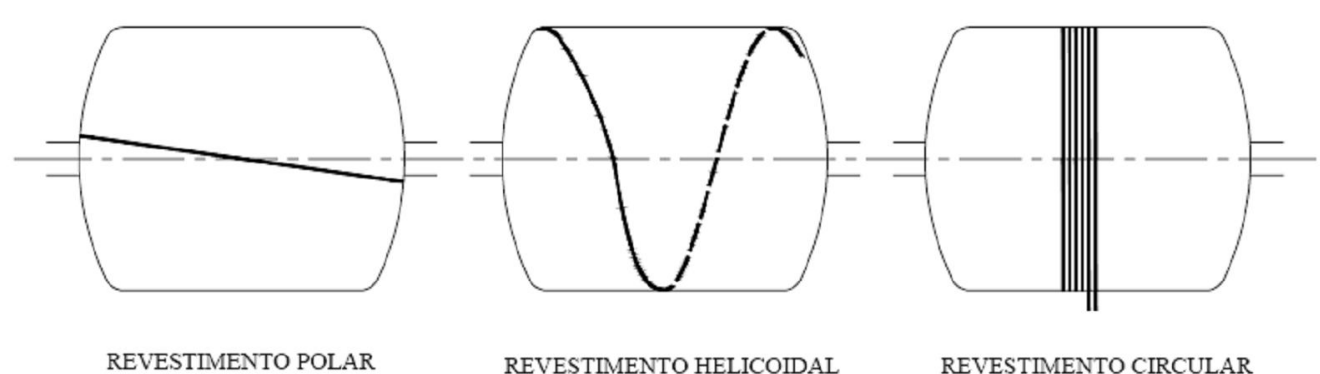

Figura 2.22 Exemplo de padrões de revestimento (CARVALHO, 1996).

\subsubsection{Trajetória}


A trajetória da fibra em uma superfície assimétrica é caracterizada pelo enrolamento com o ângulo $\alpha$, ou seja, o ângulo entre a tangente do caminho da fibra e a geratriz da superfície de revolução, como mostra a figura 2.23.

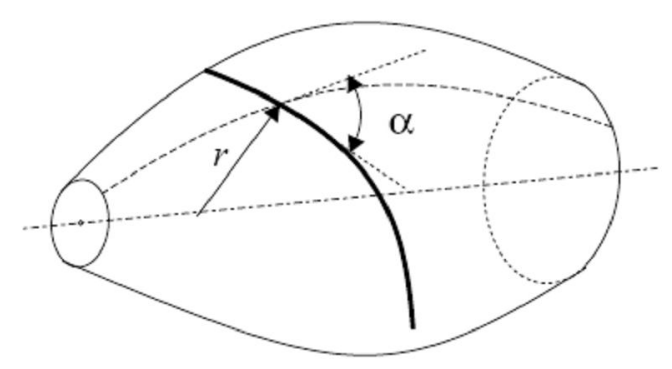

Figura 2.23. Ângulo do enrolamento sobre uma superfície de revolução. (Fonte JOHAN, 1992).

O caminho geodésico da fibra em uma superfície de revolução pode ser satisfeito pela equação:

$\mathrm{r} \sin \alpha=\mathrm{Cc}$

onde sendo:

r é o raio do cilindro,

$\alpha$ é o ângulo do enrolamento,

Cc é uma constante para geodésica.

\subsubsection{Estratégia de revestimento}

A seqüência percorrida pela fibra deve ser combinada, de modo que cubra toda a superfície da peça depositada em várias camadas. A trajetória percorrida pela fibra pode ser 
determinada por diversas estratégias: Na primeira etapa, a fibra deve sair do ponto inicial que está em uma das extremidades do mandril e percorrer toda a trajetória até o ultimo ponto situado na outra extremidade. Na próxima etapa do circuito, a fibra deve percorrer o mesmo caminho, mas com um deslocamento ao longo da circunferência do mandril, definido pela estratégia de revestimento adotada. A figura 2.24 mostra uma estratégia de revestimento aonde os pontos formam uma trajetória que percorre toda a superfície da peça.
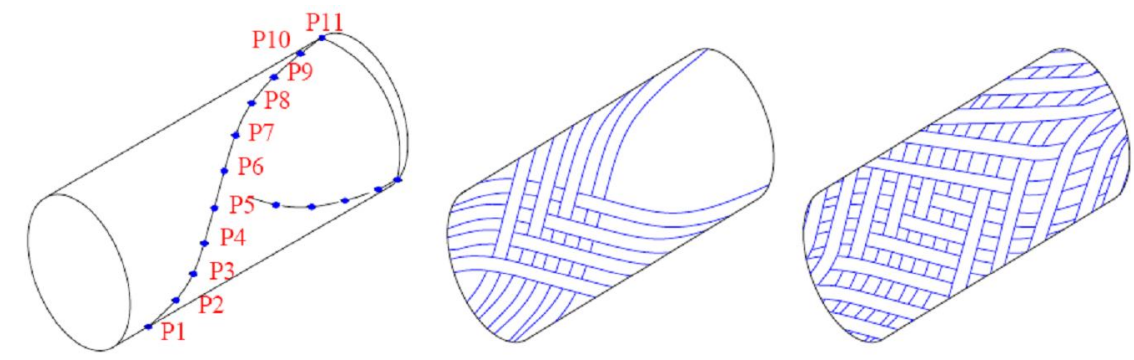

Figura 2.24 - Estratégia de Revestimento para preenchimento de camadas.

\subsubsection{Máquina de Filament Winding}

Segundo Johan (1992), uma máquina de Filament Winding consiste de:

- Sistema controlador de tensão da fibra;

- Sistema de banho de impregnação;

- Olho guia ( payout eye);

- Sistema de eixos transversais;

- Estrutura de apoio e movimentação do mandril.

De acordo com Carvalho (1996), as primeiras máquinas de Filament Winding possuíam dois eixos sendo limitadas a dois graus de liberdade, como mostra a figura 2.24. 
Estas máquinas são utilizadas no mercado de manufatura, uma vez que, são ideais para peças simples e alta produção.

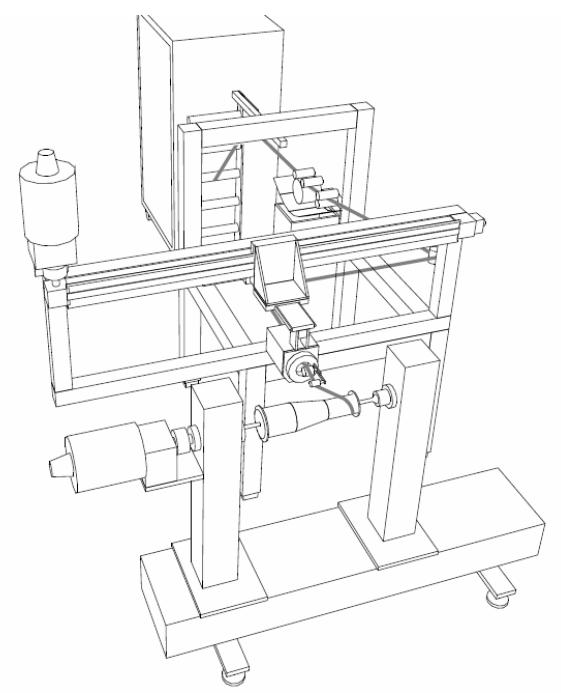

Figura 2.25 - Máquina de Filament Winding cartesiana. (Fonte: CARVALHO, 1996).

Durante os últimos anos, a necessidade de fabricação de peças com superfícies complexas tem aumentado gradativamente, o que tornou indispensável o surgimento das máquinas controladas por comandos numéricos (CNC). A utilização de computadores em máquinas de Filament Winding permitiu o controle de até sete eixos trabalhando de forma independente a rotação de mandril, o que tornou estas máquinas flexíveis e automatizadas. As máquinas $\mathrm{CNC}$ podem ser programadas para otimizar o ciclo de produção. Esse tipo de máquina pode ser visto na figura 2.26 .

Atualmente têm-se utilizado maquinas robotizadas, para o processo de revestimento em materiais reforçados por fibra. O robô articulado substitui o carro transversal cartesiano. 


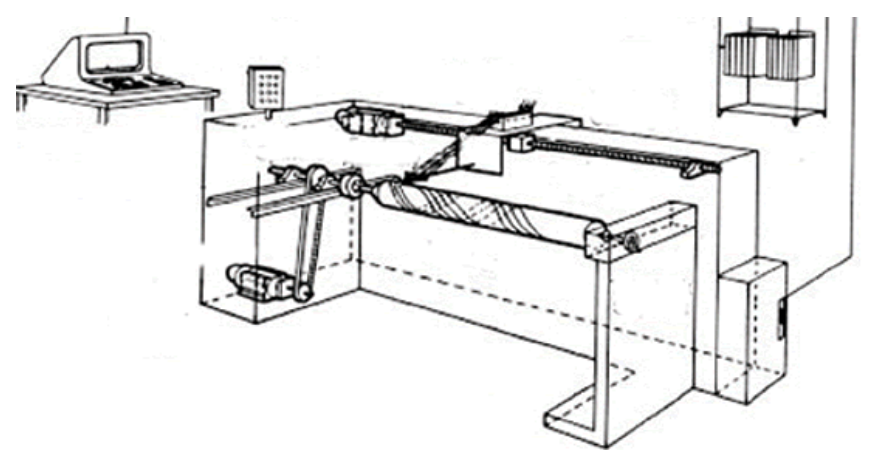

Figura 2.26 - Máquina de Filament Winding controlada por comandos numéricos (CNC). (Fonte: www.globalsecurity.org).

Essas máquinas apresentam algumas vantagens em relação às máquinas cartesianas apresentadas anteriormente como: melhor adaptação à geometria de peças assimétricas, automatização do processo de produção aumentando a qualidade do compósito, aumento da velocidade de produção e redução de custo. Apesar das vantagens apresentadas com relação à otimização do processo, algumas desvantagens são notáveis em relação às máquinas cartesianas como, por exemplo, menor precisão de posicionamento e espaço limitado por parte da articulação do robô. A figura 2.27 mostra um esquema de máquina robotizada.

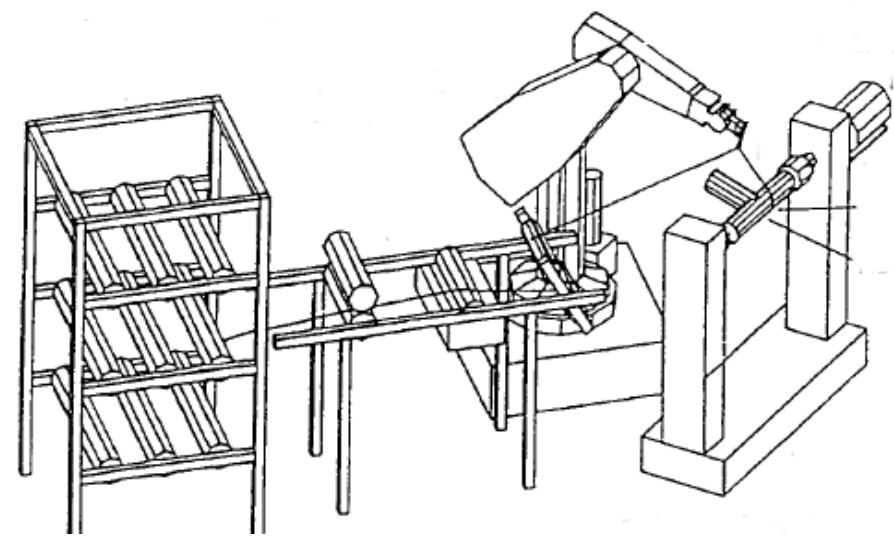

Figura 2.27 - Máquina de Filament Winding Robotizada. (Fonte: CARVALHO, 1996). 


\subsubsection{Aplicações de Filament Winding}

Alguns setores nos quais o processo de Filament Winding tem sido utilizado:

- Aeronáutica: fuselagens de aviões (Boeing 787 e Airbus A350). O Airbus A350 é uma nova família de aeronaves wide-body, atualmente em desenvolvimento, destinada a competir com o Boeing 777 e 787. O A350 será o primeiro avião da Airbus com fuselagem e a estrutura das asas constituídas principalmente por plástico reforçado de fibra de carbono, como mostra a figura 2.28. A sua entrada em serviço está prevista para 2013;

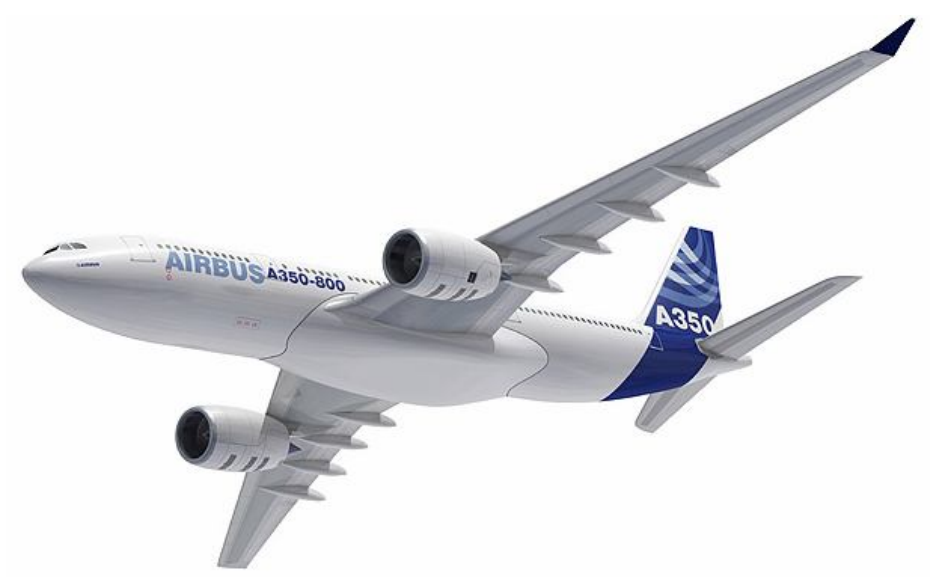

Figura 2.28 - Avião Airbus A350. (Fonte: www.thea350.com).

- Aeroespacial: caixa para motores de foguetes ("motor cases"), tanques de combustíveis, peças de satélites, tubos de condutores elétricos fabricados em material isolante termo-elétrico;

- Automotiva: cilindros para GNV e tanques de combustíveis citados anteriormente;

- Construção Civil: tubos e conexões, formas para pilares e estacas, vigas e pilares sujeitos a ataques químicos; 
- Energia: tubos e dutos para indústrias do setor sucoalcooleiro e petroquímico, pás de turbinas eólicas, e vasos de pressão em geral;

- Naval: dutos condutores de arrefecimento, mastros, retrancas de embarcações, guarda - mancebos;

- Militar: cápsulas de mísseis e bombas, protetores de ogivas, invólucros para materiais de resíduos radioativos;

- Médica: próteses e órteses.

\subsubsection{Vantagens e desvantagens}

Segundo Carvalho (1996) as principais vantagens do processo de Filament Winding são:

- Alto grau de repetibilidade e precisão no posicionamento da fibra;

- A capacidade, embora limitada, de posicionar a fibra em muitas e apropriadas direções;

- O alto grau de automação que pode ser obtido direcionando para um baixo custo de manufatura e larga escala de produção;

- Baixo custo relativo ao material da fibra e da resina a ser impregnada na fibra;

- Baixo peso associado à alta tensão admissível e rigidez dos componentes;

- Desempenho aprimorado devido à habilidade de ser revestido por fibras e alto potencial na redução de custos;

- Melhor resistência, maior rigidez, melhor resistência à compressão;

- Melhor distribuição de cargas e protegem o mesmo contra efeitos ambientais.

Entretanto algumas desvantagens são inerentes ao processo: 
- Um mesmo mandril pode não atender todas as necessidades de revestimento dependendo do formato da peça a ser revestida. Haveria a necessidade de que houvesse vários mandris intercambiáveis;

- Dificuldade em revestir peças com formatos côncavos devido ao problema do deslizamento no contato entre a fibra e o mandril;

- Limitações de projetos e trajetórias, no qual o deslizamento pode limitar o posicionamento das fibras na posição apropriada. Também a inabilidade de mudar a trajetória da fibra em um mesmo ciclo;

\subsection{SOFTWARES EXISTENTES PARA FILAMENT WINDING}

Atualmente poucas empresas desenvolvem e comercializam sistemas computacionais (softwares) comerciais para cálculo das trajetórias no processo de Filament Winding. No Brasil, não há empresas específicas que realizem tal trabalho. A falta de conhecimento, equipamento e materiais são fatores que contribuem para inexistência de sistemas comerciais disponíveis no Brasil. Dessa forma, ficamos dependentes dos recursos e do custos referentes às ferramentas existentes em outros paises, o que limita o desenvolvimento de estudos nessa área em nosso país.

Alguns estudos referentes ao desenvolvimento de sistemas de cálculo de trajetórias no processo de Filament Winding são descritos na literatura.

O software CAWAR desenvolvido na Bélgica por Scholliers (1992) foi elaborado através da linguagem de programação $\mathrm{C}$, tendo sido desenvolvido na plataforma VMS (Virtual Machine System) da empresa Digital Co. O mesmo autor deu inicio às técnicas dos cálculos da trajetória das fibras que logo após, foi aprimorado por Carvalho (1996). SILVA (2005), propôs o desenvolvimento de um protótipo que calculasse a trajetória das fibras 
através de uma interface amigável para o usuário. Seu objetivo foi desenvolver um software semelhante ao CAWAR utilizando uma linguagem de programação visual C++ em plataforma Windows. O protótipo desenvolvido por Silva (2005) apresenta algumas carências com relação ao cálculo da trajetória como, por exemplo, a escolha da técnica para realização dos cálculos e a estratégia para realizar o preenchimento em múltiplas camadas.

Atualmente existem diversos softwares para controle de processos de Filament Winding. Geralmente esses softwares são compostos de pacotes que calculam desde superfícies cilíndricas, até superfícies mais complexas. Alguns apresentam diferenciais como: suporte à análise de elementos finitos (CAE), sistema de visualização bidimensional e tridimensional, disposição para controle de seis eixos, possibilidade de mudança de ângulo nas diversas camadas de revestimento, importação e exportação de diversos tipos de arquivos de superfícies, dentre outros recursos essenciais que possibilitam um bom sistema para Filament Winding.

A seguir são listados alguns sistemas comercialmente utilizados para o revestimento em materiais compósitos utilizando a técnica de enrolamento filamentar.

\subsubsection{Cadfil}

CADFIL® é um software desenvolvido pela Crescent Consultants Limited, empresa fundada em 1983, que tem a finalidade de controlar máquinas de Filament Winding. O software permite a criação de compósitos reforçados por fibra de alto desempenho em tempo reduzido. Alguns recursos merecem destaques como: visualização da superfície da peça no formato bidimensional e tridimensional, sistema de segurança contra colisão do mandril, alteração do ângulo winding entre o preenchimento das camadas, auto ajuste a superfícies cônicas, ferramentas para analise de elementos finitos, saída para comando numérico 
computadorizado (CNC) e controle de máquinas com cinco olhos (pay-out) totalizando até seis eixos de revestimento. A figura 2.29 mostra algumas telas de funcionamento do software CADFIL.

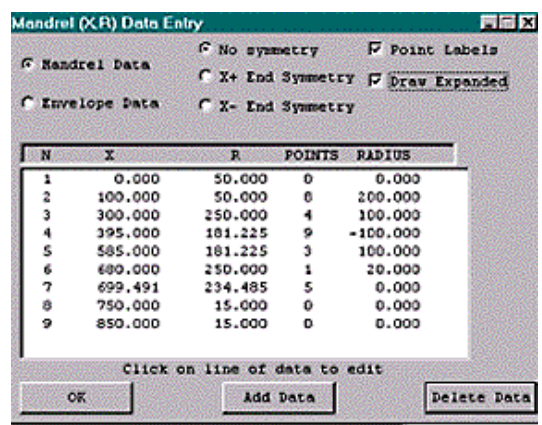

(a)

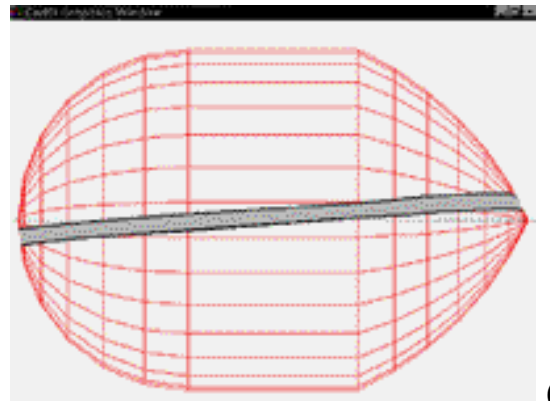

(b)
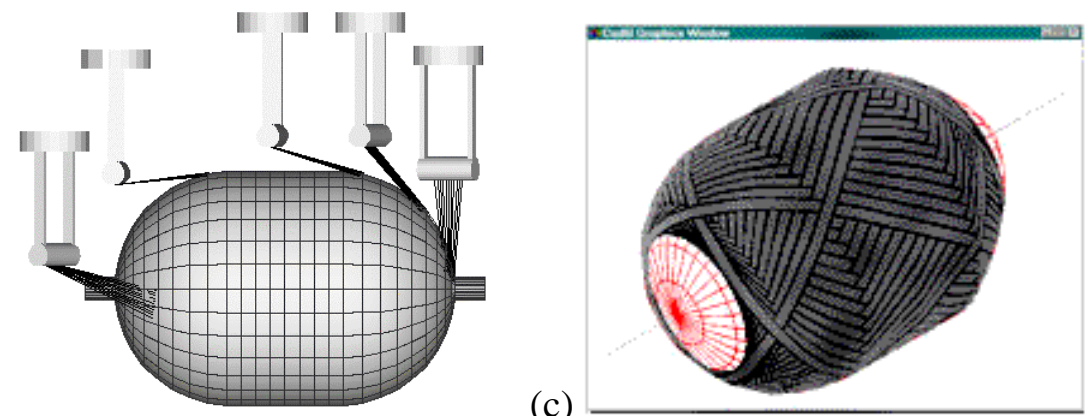

(c)

(d)

Figura 2.29 (a) Dados de entrada do mandril, (b) trajetória da fibra no mandril, (c) visualização 3D do mandril com cinco olhos, (d) visualização 3D da peça revestida. (Fonte: Crescent Consultants Limited - www.cadfil.com).

\subsubsection{Fiber grafix}

FIBER GRAFIX é um software desenvolvido pela Entec Composites Machines®. Assim como o CADFIL, o FIBER GRAFIX possui vários recursos interessantes para o processo tais como: acompanhamento visual da trajetória da fibra no formato 3D, posicionamento do mandril durante o revestimento, tempo restante para o termino do 
processo, possibilidade de mudanças de ângulo nas diversas camadas de revestimento, importação de dados de superfícies representadas por outros softwares como, por exemplo, a geometria de um mandril desenhado no AUTOCAD, exporta dados das trajetórias em diferentes formatos, podendo ser analisadas por outros softwares.
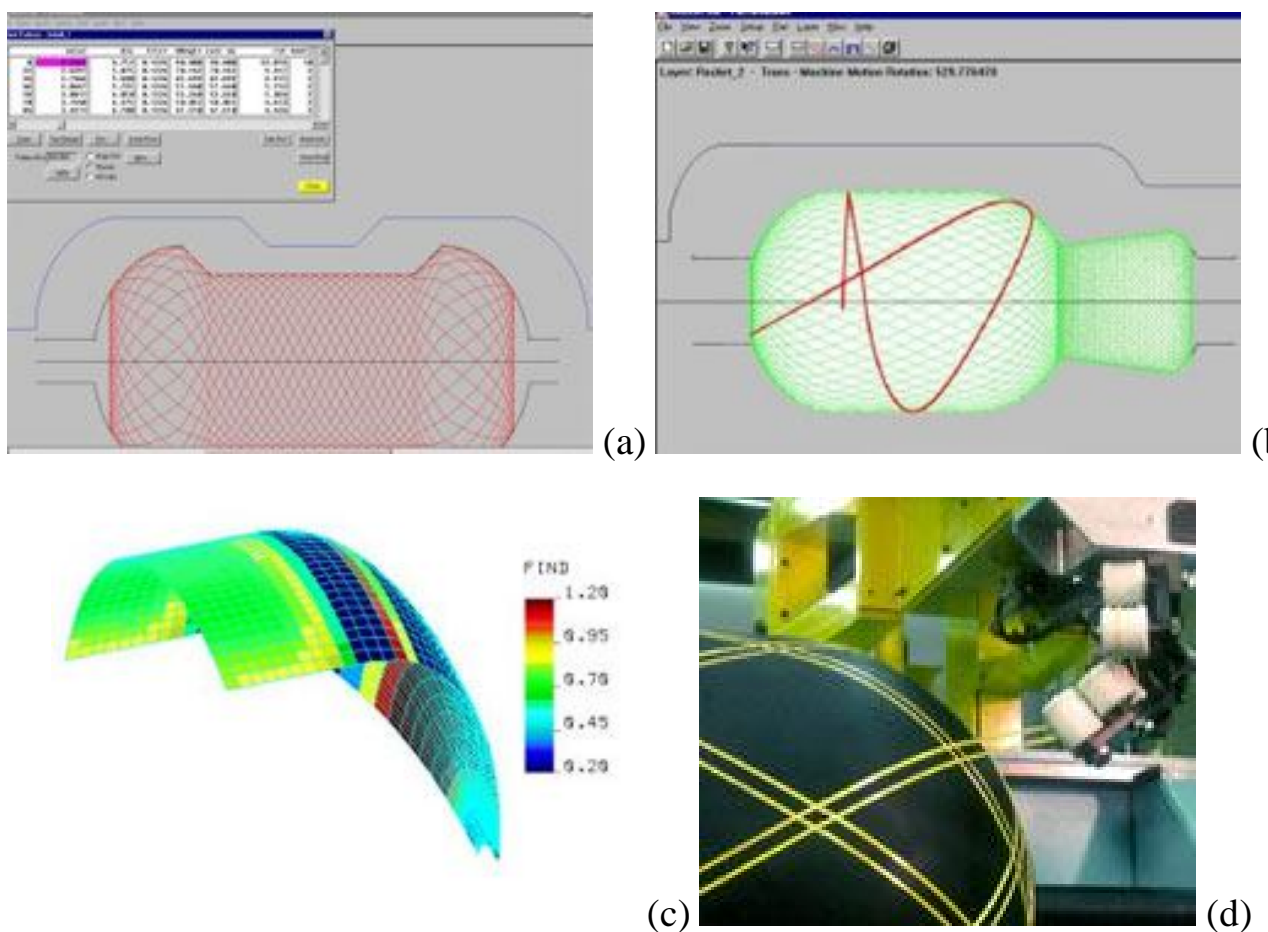

(b)

(c)

(d)

Figura 2.30 (a) Tela de gerenciamento de projeto, (b) tela de gerenciamento de padrões, (c) tela de do módulo FEA, (d) peça sendo revestida pela máquina. (Fonte: Entec Composites Machines Www.entec.com).

Um outro fator interessante do FIBER GRAFIX é o módulo para análise de elementos finitos dentro do próprio programa chamado de FEA (Finite Element Analysis). O usuário não necessita exportar os dados resultantes para um outro programa específico de análise de elementos finitos como o Ansis, Abaqus, Nastran, Isto poupa tempo e facilita o trabalho do engenheiro. Este módulo permite o engenheiro realizar uma análise sistemática, o que ajuda 
reduzir o tempo e o custo de desenvolvimento do projeto. Na figura 2.30, pode-se visualizar algumas telas do software em execução.

\subsubsection{Cadwin}

CADWIND é um sofisticado software de simulação de processos de revestimento de materiais compósitos reforçados por fibra desenvolvida pela Material. Esse software realiza simulações com base em modelos físicos reais a partir da importação dos dados da geometria. Possui um módulo de simulação de atrito entre a fibra e o mandril permitindo percorrer a distância mais curta entre dois pontos das superfícies como mostra a figura 2.31.

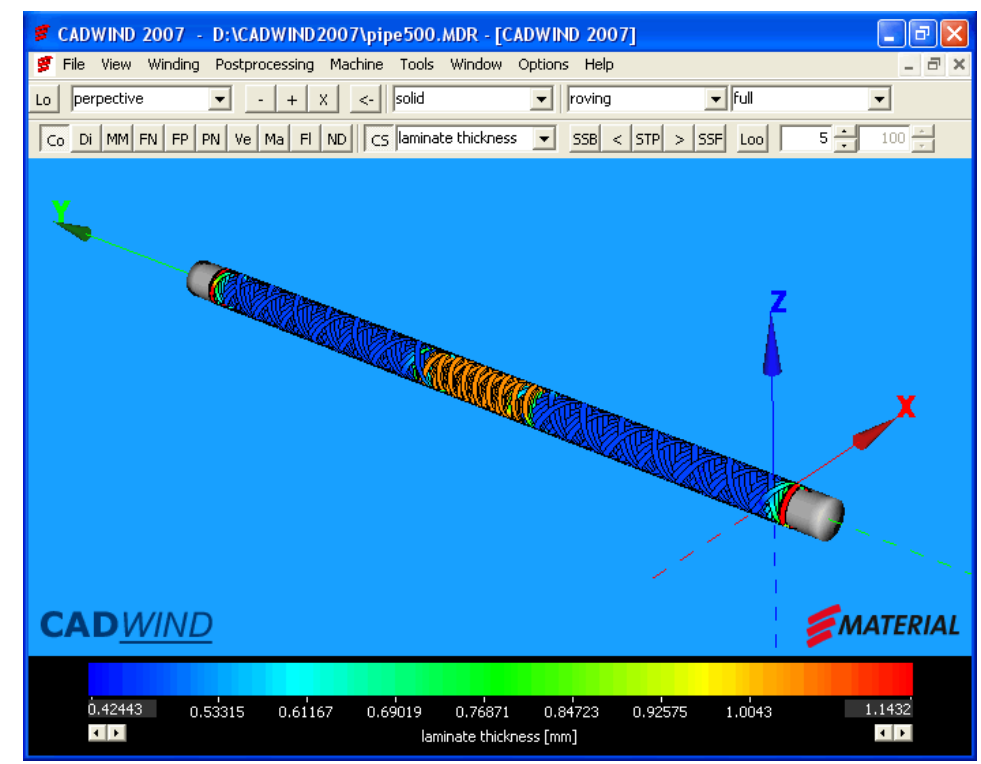

Figura 2.31 - Simulação de atrito. (Fonte: Material - www.material.be).

A modelagem do atrito permite mudanças dos ângulos alterando a suas cores conforme podemos ver na escala da figura 2.31 . 
Outro aspecto interessante do software é a simulação da trajetória de peças simétricas como tubos e vasos de pressão e peças não simétricas como cotovelos e outros acessórios. A figura 2.32 mostra a simulação da trajetória da fibra em diferentes tipos de peças.
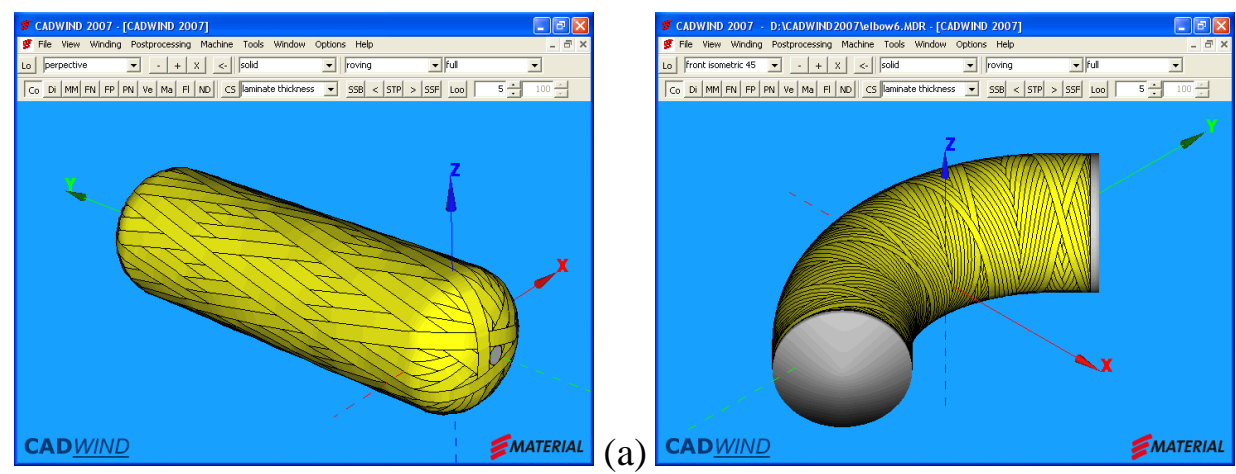

(b)

Figura 2.32 Simulação da trajetória em peças simétricas e assimétricas. (Fonte: Material www.material.be).

O CADWIND controla a dinâmica do movimento da máquina. Isso permite a otimização de controle de dados de acordo com diferentes aspectos com a redução da produção.

Pode-se verificar na figura 2.33 o gráfico da análise dinâmica da máquina com a variação de tempo, velocidade de aceleração e diagramas de deslocamento.

Outros fatores interessantes que podemos destacar do CADWIN é a possibilidade de mudança de ângulo nas diferentes camadas de revestimento, um excelente módulo de análise de elementos finitos (FEA), importação e exportação de diferentes tipos de dados, ferramentas gráficas para visualização do tempo de deslocamento, velocidade de aceleração da máquina, alem da ótima interface com o usuário. Atualmente o CADWIN é portável nas plataformas Windows 98, ME, NT, 2000, XP e Vista. 


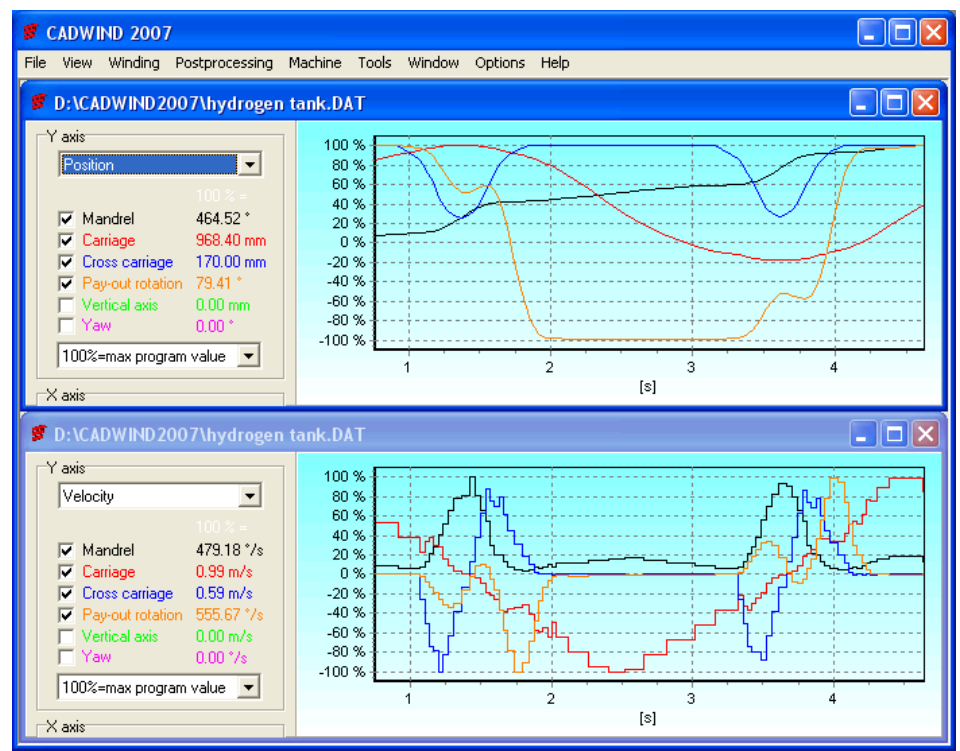

Figura 2.33 - Analise de otimização dinâmica da máquina. (Fonte: Material - www.material.br).

Silva (2005), desenvolveu um trabalho cujo objetivo foi implementar um protótipo de uma plataforma para cálculos da trajetória da fibra em materiais compósitos. Esse protótipo calcula a trajetória de um cilindro simples com diâmetro, comprimento, ângulo, espessura da fibra, fornecidos pelo usuário. Após o fornecimento dos dados, o protótipo calcula os dados dos pontos (X,Y e Z) do primeiro quadrante do cilindro e logo depois os dados dos demais quadrantes conforme mostra a figura 2.34 .

O protótipo desenvolvido por Silva (2005), embora possa ser utilizado para cálculo de trajetórias circulares, não atendia ao calculo das trajetórias helicoidais, bem como não apresentava recursos suficientes para manipulação de estratégias de revestimento em múltiplas camadas, fatores significativos no processo de revestimento em materiais compósitos reforçados por fibra. 


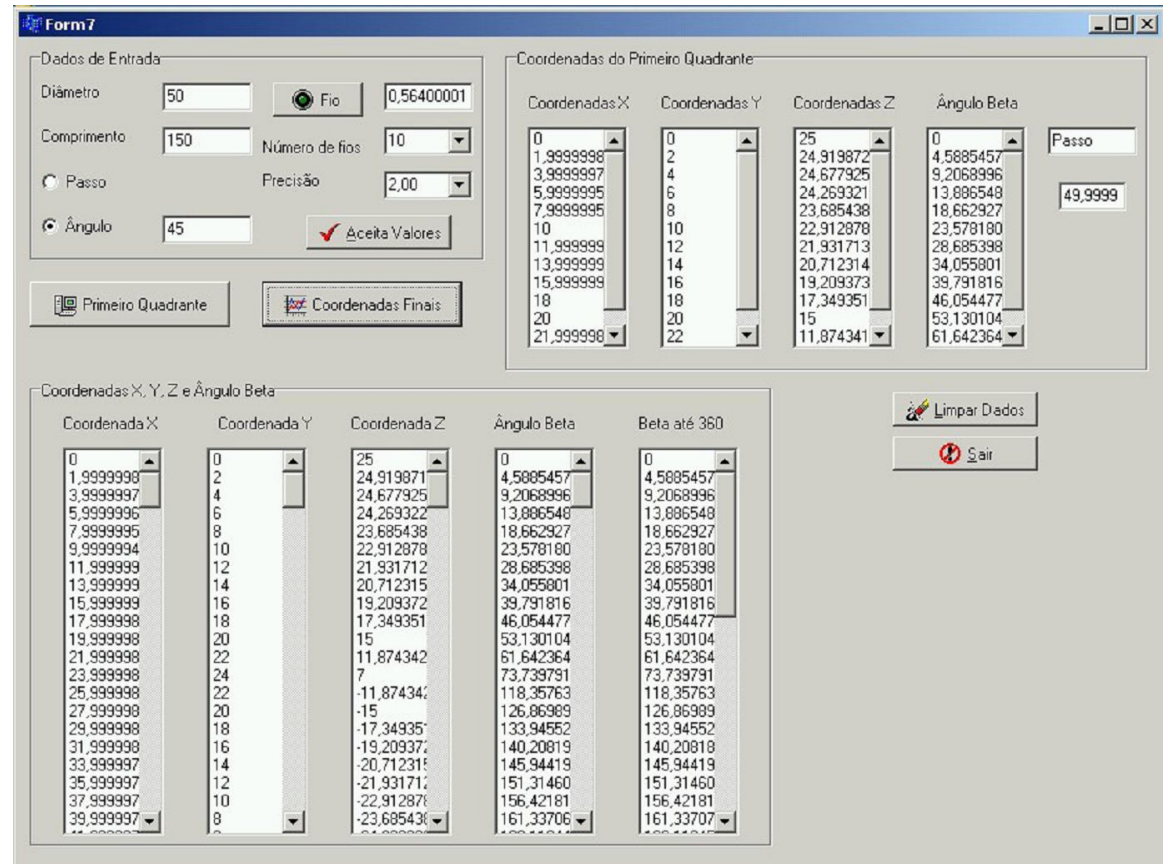

Figura 2.34 - Tela do protótipo. (Fonte: SILVA, 2005).

\subsection{RECURSOS COMPUTACIONAIS}

Nos últimos anos com o avanço da tecnologia digital, milhares de empresas e pessoas puderam ter acesso a pacotes de informações provenientes de computadores interligados não somente em unidades físicas locais, mas também mundialmente pela Internet. Esse volume de acesso de informações fez com que surgisse o conceito de tecnologia da informação, que engloba recursos computacionais como: redes de computadores, arquitetura cliente/servidor, sistema gerenciador de banco de dados (SGBD), sistemas de informações administrativos, ambientes operacionais gráficos, Internet dentre outros recursos que permite a inclusão de informação.

Dentro desse conceito, surgiu a necessidade de automação na industria para auxilio no processo de fabricação. Ferramentas como CAD, CAE, CAM, começaram ser utilizadas para manipulação de superfícies e análise de dados de projeto, maquinas de manufatura puderam 
ser auxiliadas por computadores visando à otimização dos processos de produção para diminuição dos custos.

\subsubsection{Interfaces Gráficas com o Usuário (GUI’s)}

Com o avanço das ferramentas computacionais, surge um grande desafio para os desenvolvedores de softwares: proporcionar ao usuário uma interface amigável. Segundo Pressman (2002), uma das áreas da computação que tem se desenvolvido rapidamente, é o projeto de interfaces com o usuário final (HCI) (Human-Computer Interface), decorrente do número de pessoas que utilizam os microcomputadores. Muitas pessoas sentem dificuldade em se relacionar com interfaces confusas e inflexíveis. A interface com o usuário é o mecanismo pelo qual, se estabelece a conexão entre a máquina e a pessoa. Se os fatores que contribuem para essa comunicação forem explícitos, um fluxo continuo de interação entre o usuário e a máquina é permitido.

Segundo Pressman (2002), muitos recursos contribuem para o desenvolvimento de uma boa interface com o usuário como por exemplo, bibliotecas de componentes visuais. Esses componentes auxiliam a visão e fazem com que o cérebro possa captar e receber informações com referência a tamanho, forma, cor, orientação, movimento e outra características de identificação visual. Os objetos gráficos assumem formas de botões, janelas, menus, ícones que são utilizados para apresentar os aplicativos em execução e sequiência de comandos.

\subsubsection{Linguagem de Programação C}


Desenvolvida pela Bell Laboratory no inicio dos anos 70, a linguagem C visava à implementação do sistema operacional UNIX. A linguagem C pode ser considerada uma evolução da linguagem de programação BCPL criada por Martin Richards. Em 1970, Ken Thompson efetuou algumas melhorias na linguagem BCPL e a chamou de linguagem B. Em 1972, Dennis M. Ritchie, implementou diversas melhorias na linguagem B, que considerada uma sucessora da linguagem $B$ foi chamada de linguagem $C$, sendo executada pela primeira vez num computador DEC PDP-11 no sistema operacional UNIX (MAIA e MORELLI, 2003).

A linguagem $\mathrm{C}$ obteve grande sucesso nos meios acadêmicos e nos desenvolvedores de sistemas operacionais, devido a várias características como: facilidade de programação em "baixo nível” ou seja, linguagem de máquina assembly, geração eficiente de código, amplo conjunto de operadores que geram uma interface amigável com o usuário final.

Mais tarde, a linguagem $\mathrm{C}$ sofreu uma evolução e foi chamada de linguagem $\mathrm{C}++$. A linguagem $\mathrm{C}++$ é fornecida por diversos fabricantes como Microsoft@ (Visual C++), Borland ${ }^{\circledR}(\mathrm{C}++$ Builder$)$, Intel Softwares ${ }^{\circledR}$, entre outros. A linguagem $\mathrm{C}++$ permite ser executada nas mais variadas configurações, como o desenvolvimento de aplicações orientadas a objeto é uma linguagem multiplataforma, ou seja, pode ser executada em vários sistemas operacionais como Windows, Linux, Unix.

\subsubsection{Sistema Gerenciador de Banco de Dados (SGBD)}

Durante vários anos os sistemas de bancos de dados foram utilizados nas áreas comerciais, tais como: controle de estoque, sistema de vendas, controle de produção, etc. Com o avanço tecnológico e o aumento de informações a serem armazenadas, a utilização dos Sistemas de Gerenciamento de Banco de Dados (SGBD), direcionaram-se para outras áreas de 
desenvolvimento como, por exemplo, engenharia, educação, medicina dentre outras. Segundo Costa (1996) os elementos básicos que compõem os Sistemas de Gerenciamento de Banco de Dados, são:

- Banco de Dados: é uma coleção de dados inter-relacionados e armazenados;

- Arquivos de Dados: são estruturas utilizadas para armazenar o próprio banco de dados. Um arquivo consiste em conjunto de registros;

- Registros: são estruturas de dados compostas por uma seqüência de campos.

Segundo Korth \& Silberschatz (1989) um Sistema de Gerenciamento de Banco de Dados, é uma coleção de dados inter-relacionados em um conjunto de programas que os acessam e os manipulam. A coleção organizada e inter-relacionada de dados é chamada de Banco de Dados, que contém informações especificas de uma determinada aplicação.

De acordo com Costa (1996), uma das vantagens de utilizar banco de dados em aplicações de softwares é possuir um único deposito de dados, que são definidos uma única vez, padronização entre os usuários de uma mesma organização, flexibilidade de alteração em sua estrutura, redução do tempo de desenvolvimento das aplicações, informações atualizadas, economia de pessoal e equipamentos.

\subsection{CONSIDERAÇÕES SOBRE ENGENHARIA DE SOFTWARE}

Segundo Pressman (2002), a preocupação com o estudo do software ultrapassou o hardware, uma vez que este possui uma evolução maior em função dos avanços tecnológicos. O software se tornou algo indispensável para os sistemas baseados em computador.

Algumas experiências realizadas mostram que conceber um software não resume somente em escrever seu código-fonte. Mesmo não havendo uma metodologia definida para 
projetar um software, há várias técnicas, critérios de qualidade e notações específicas que podem ser aplicadas às várias atividades de seu desenvolvimento.

Um software pode ser definido como: (i) instruções/programas de computador que quando executados, produzem a função e desempenho desejados; (ii) estruturas de dados que possibilitam que os programas manipulem adequadamente a informação; (iii) documentos que descrevem a operação e a utilização de programas. Uma definição mais ampla define o software como: programa de computador, estruturas de dados e documentação correlata que servem para efetivar o método, processo ou controle lógico necessário.

A figura 2.35 mostra o ciclo de vida de um software segundo Pressman (2002).

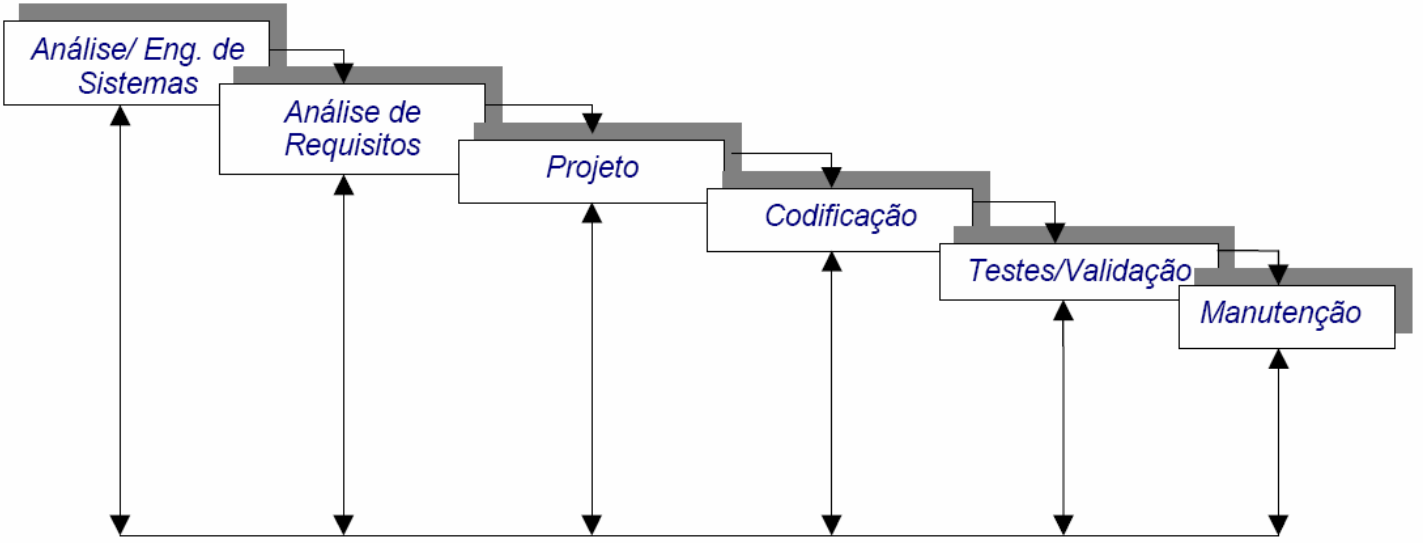

Figura 2.35 - Ciclo de vida de um software. (Fonte: PRESSMAN, 2002).

O desenvolvimento do software se inicia com a analise de requisitos, projeto, codificação, testes e manutenção.

Análise e engenharia de sistemas: $O$ software fará parte de um sistema computacional mais amplo. Nesta etapa são estabelecidos e coletados os requisitos para todos os elementos do sistema e atribuições.

Análise de requisitos: para que sejam bem definidos os programas, os engenheiros analistas, devem compreender o domínio da informação para o software tais como: suas 
funções, desempenho e interfaces necessárias. Os requisitos necessários para o software e o sistema devem ser documentados e revistos junto ao cliente.

Projeto: o projeto é dividido em quatro etapas: estrutura de dados, arquitetura de software, detalhes procedimentais e caracterização da interface. O processo de construção do processo transmite as exigências numa representação do software que pode ser avaliada à qualidade, anteriormente à codificação. O projeto é documentado.

Codificação: é a tradução do projeto para códigos que a máquina entende. Geralmente essa fase é bem mecânica.

Teste: nessa fase verificam-se todos os aspectos de funcionamento do software a fim de levantar possíveis erros.

Manutenção: um software sempre sofre mudança e adaptações quando é finalizado e executado. A manutenção do software se aplica, para cada uma das etapas anteriores do ciclo de vida de um software existente. 


\section{CAPÍTULO 3}

\section{METODOLOGIA E IMPLEMENTAÇÃO DO SOFTWARE}

No Capítulo 2 foi abordado alguns tópicos focados no processo de revestimento em materiais compósitos e algumas ferramentas, que auxiliam no processo de Filament Winding. Neste Capítulo são descritos os materiais (ferramentas) e os métodos utilizados para desenvolver o software SISCAWIND, no qual serão implementadas as rotinas para cálculo da trajetória da fibra no processo de Filament Winding.

\subsection{COLETA DOS DADOS}

Nessa primeira etapa do trabalho foi realizado um estudo sobre o assunto, tais como: a evolução dos materiais compósitos, a importância de sua aplicação no processo de manufatura, técnicas de projeto de fabricação, características do processo de Filament Winding e alguns softwares existentes utilizados para cálculo e controle de dos dados de processo. Esse estudo foi realizado para coletar informações necessárias para o desenvolvimento do protótipo de software SISCAWIND, proposto neste trabalho.

\subsection{ANÁLISE DOS DADOS}


Em seguida, foi realizada uma análise detalhada sobre o processo de revestimento em compósitos como: estudo da técnica do cálculo da trajetória da fibra, estudo dos tipos de revestimento para superfícies cilíndricas, estratégia de preenchimento das camadas de revestimento nos tipos circular, helicoidal e polar e uma análise referente os recursos computacionais utilizados para desenvolver o sistema, tais como: linguagem de programação utilizada para realizar a interface com o usuário, banco de dados utilizado para armazenar as informações e a forma de validação dos resultados.

\subsection{PRODUÇÃO DO SOFTWARE "SISCAWIND”}

Com base na reflexão feita na análise dos dados, foi criado um software de otimização do cálculo da trajetória das fibras no processo de revestimento em materiais compósitos seguindo os seguintes passos:

\subsubsection{Modelagem dos Dados}

Nessa fase foi criado um modelo de projeto ilustrado na figura 3.1. Primeiramente foram estudados os supostos relacionamentos que cada entidade do sistema teriam entre si. Como por exemplo, a entidade revestimento circular se relaciona com a entidade cálculo. Feito esse estudo, foi questionado qual o tipo de relacionamento caberia para cada entidade, sendo necessário para isso perguntas do tipo: O revestimento circular pode possuir um único cálculo ou deve possuir vários cálculos? Esse tipo de pergunta possibilita saber se o relacionamento é de um para vários, de um para um ou de vários para vários. 


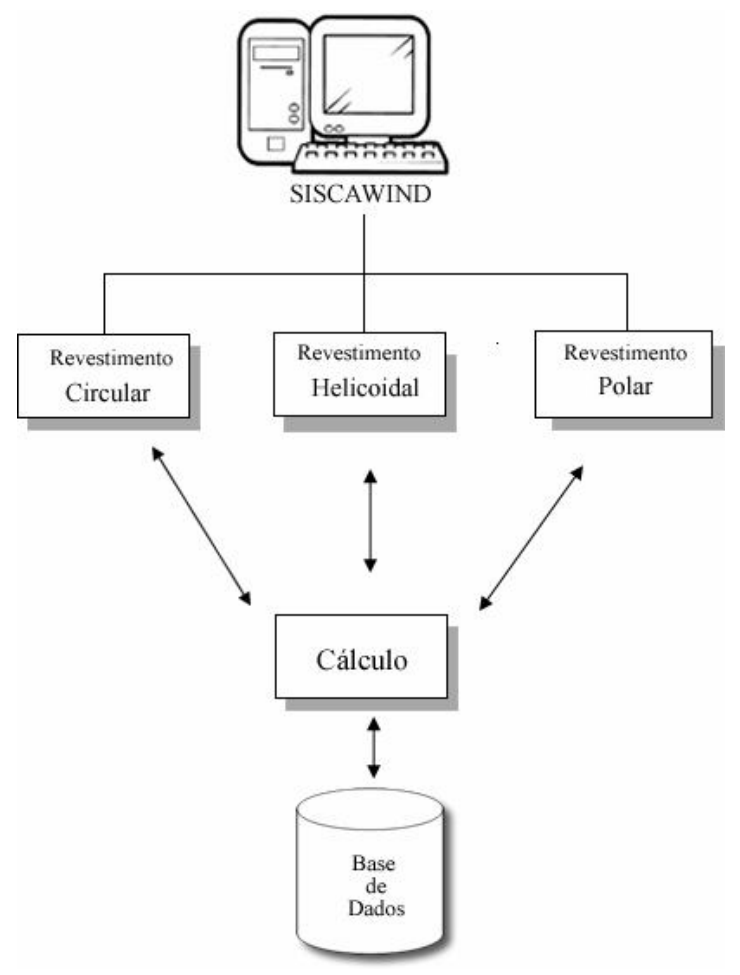

Figura 3.1 - Esquema do Software SISCAWIND.

\subsubsection{Implementação}

Com base no modelo criado, foi desenvolvido um protótipo de software através da linguagem de programação C++. Essa linguagem de programação foi escolhida devido a sua facilidade de manipulação de dados em "baixo nível" ou seja, apresenta bons resultados de integração com relação software/hardware, como programação das rotinas e agilidade no envio dos dados para a máquina de filament winding, além de proporcionar uma interface gráfica amigável para o usuário final. $\mathrm{O}$ ambiente de programação escolhido para escrever o código fonte do protótipo foi Borland $\mathrm{C}++6.0$ como mostra a figura 3.2. 


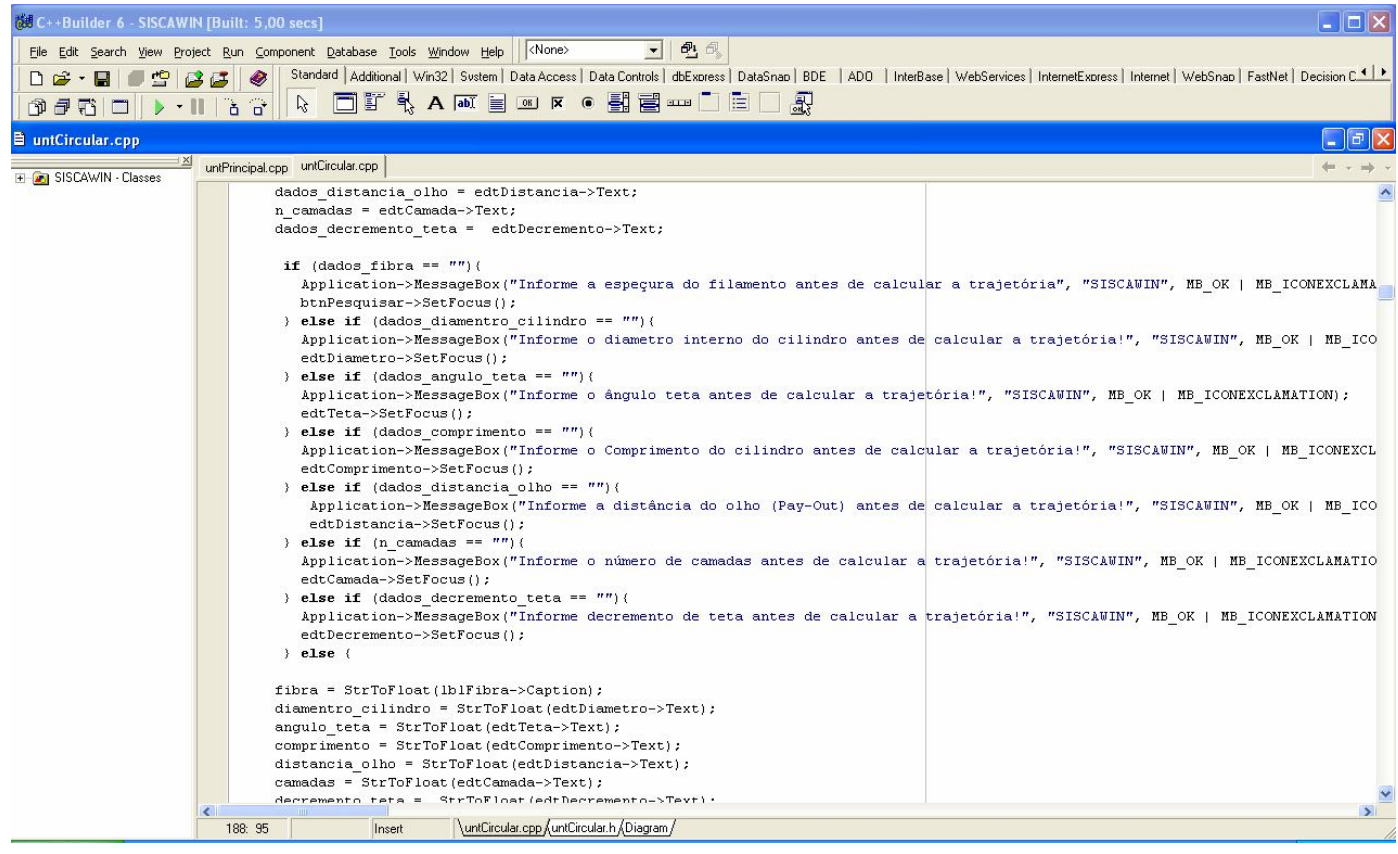

Figura - 3.2 Ambientes de programação Borland C++ 6.0.

O sistema de banco de dados escolhido para armazenar os dados gerados pelo sistema foi o Microsoft Access. Foram realizados testes de consulta, inclusão, alteração e exclusão nos bancos de dados Firebird 1.5, MySq1 6.0 e Access. Os três bancos de dados apresentaram resultados satisfatórios com relação à velocidade do tempo de pedido e resposta decorrente da quantidade de dados manipulados. O banco de dados Access foi escolhido devido à facilidade de exportação dos registros para o formato de arquivos *.xls, formato reconhecido pelo software CAD Solid Edge. Com o Solid Edge pode-se verificar os resultados obtidos no sistema implementado no formato 3D como mostra a figura 3.3. 


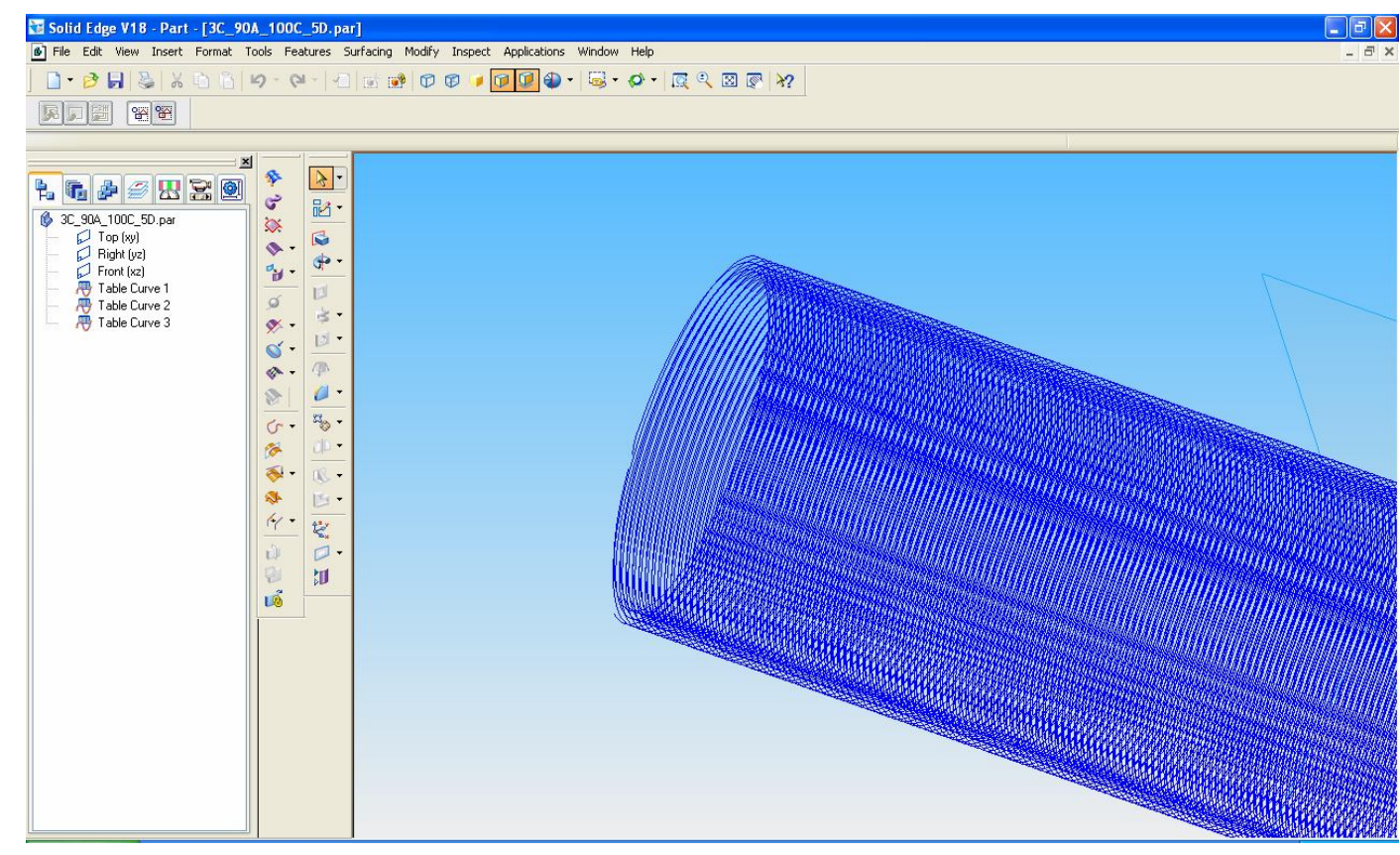

Figura 3.3 - Software Solid Edge.

\subsection{APLICAÇÃO DE TESTES PARA VALIDAÇÃO}

Após a implementação das rotinas de cálculo, foram realizados uma série de testes com a intenção de descobrir possíveis erros gerados pelo sistema. De acordo com Pressman (2002), “Testar um software envolve executar o programa com um conjunto de dados e comparar os resultados obtidos com os esperados". Com base nesse conceito, o software foi "forçado" a passar por situações anormais como, por exemplo, entrar com valores negativos em dados que somente poderiam assumir valores positivos, forçar o cálculo da trajetória sem nenhuma entrada pelo usuário, deixar algum valor de entrada em branco, etc.

\subsubsection{Teste de Caixa Branca}


Segundo Pressman (2002), os testes de caixa branca são métodos utilizados em caso de estruturas de controle de projetos orientados à objeto. Utilizando esse método de teste, o programador do sistema deve derivar casos de teste que garantam a execução de todo o caminho dos algoritmos como laços de repetições e decisões lógicas. Nesse caso, foram aplicados casos de testes forçando a leitura de todo código fonte do programa pelo compilador, eliminando possíveis erros de sintaxe.

\subsubsection{Teste de Sistema}

Conforme ainda Pressman (2002), o software não está sozinho em um sistema computacional. Com isso foram realizados casos de testes interagindo o software projetado com o sistema operacional, monitores, redes, hardwares, a fim de observar seu funcionamento com os demais equipamentos do ambiente.

\subsubsection{Testes de Desempenho}

Os testes de desempenho servem para verificar o run-time, ou tempo de processamento. Com base nesse conceito foram realizados testes de cálculos verificando se o tempo de processamento, corresponde ao tempo esperado.

\subsection{MODELAGEM DO SISTEMA}


O software SISCAWIND é formado pelo módulo de revestimento circular, módulo de revestimento helicoidal e o módulo de revestimento polar. O usuário interage com o sistema informando os dados de entrada. Como resposta o sistema realiza os cálculos e apresenta os resultados ao usuário e os resultados podem ser visualizados e gravados. A figura 3.4 mostra um esquema da modelagem do sistema SISCAWIND.

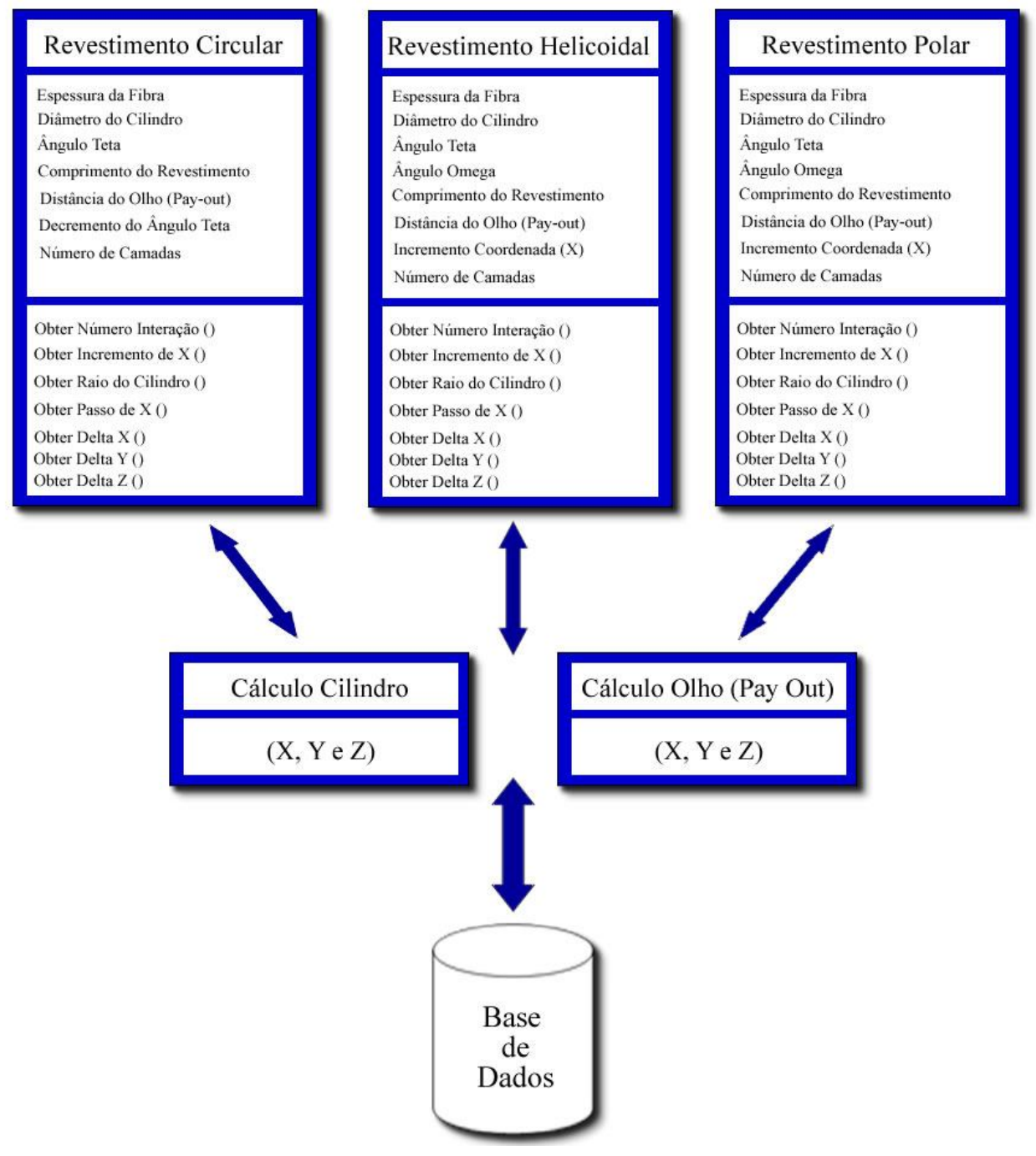

Figura 3.4 - Esquema do Sistema SISCAWIND. 


\subsubsection{Interface Gráfica Dos Módulos Do Protótipo Siscawind}

A interface gráfica do software apresenta um papel muito importante na interação com o usuário, pois é através dela que os recursos de hardware oferecidos pelo computador podem ser manuseados. Interfaces gráficas implementadas através de ícones, caixa de diálogo, figuras e gráficos, facilitam o aprendizado tornado mais agradável à interação entre o homem e a máquina.

Quando se inicia a execução do software, é apresentada a tela principal do sistema contendo os módulos de revestimento circular, helicoidal e polar para superfícies cilíndricas. A figura 3.5 mostra a tela principal do sistema.

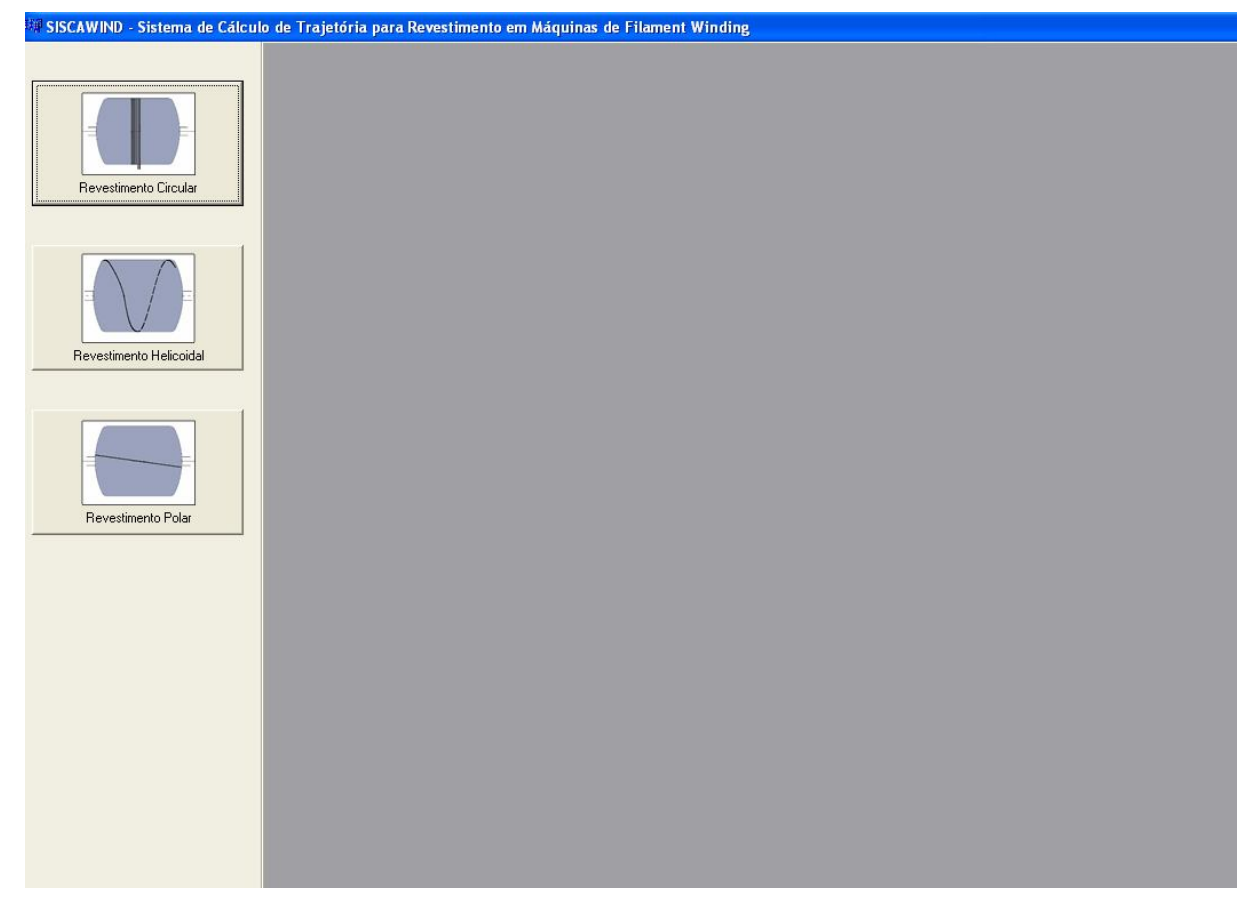

Figura 3.5 - Tela principal do software SISCAWIND.

Primeiramente é apresentado o módulo de revestimento circular, no qual são implementadas as funções para cálculo da trajetória do cilindro e do olho pay-out utilizados 
na técnica de revestimento circular. Para que isso ocorra, o usuário deve fornecer os seguintes dados ao sistema:

- Espessura do filamento: representa a medida em milímetros da espessura do fio do filamento;

- $\quad$ Número de Fios: representa a quantidade de fios agrupados que forma a malha de revestimento;

- Diâmetro do cilindro: representa a medida em milímetro do diâmetro externo do cilindro a ser revestido;

- $\quad$ Ângulo Teta: representa o ângulo em graus, do ponto inicial no qual começa o revestimento do cilindro. Este ângulo representa a posição circunferêncial do ponto inicial no cilindro;

- Comprimento do revestimento: representa o comprimento em milímetro do cilindro a ser revestido;

- Distância do olho (pay-out): representa a distância em milímetro entre o cilindro e o olho;

- Decremento do ângulo teta: representa o decremento do ângulo teta no decorrer da trajetória, na posição circunferêncial do cilindro. Esse dado aponta a precisão da seqüência dos pontos em relação ao cálculo da trajetória;

- Número de camadas: representa a quantidade de camadas que o cilindro recebe no revestimento.

A figura 3.6 mostra a tela de funcionamento do módulo de revestimento circular com suas respectivas característica. 


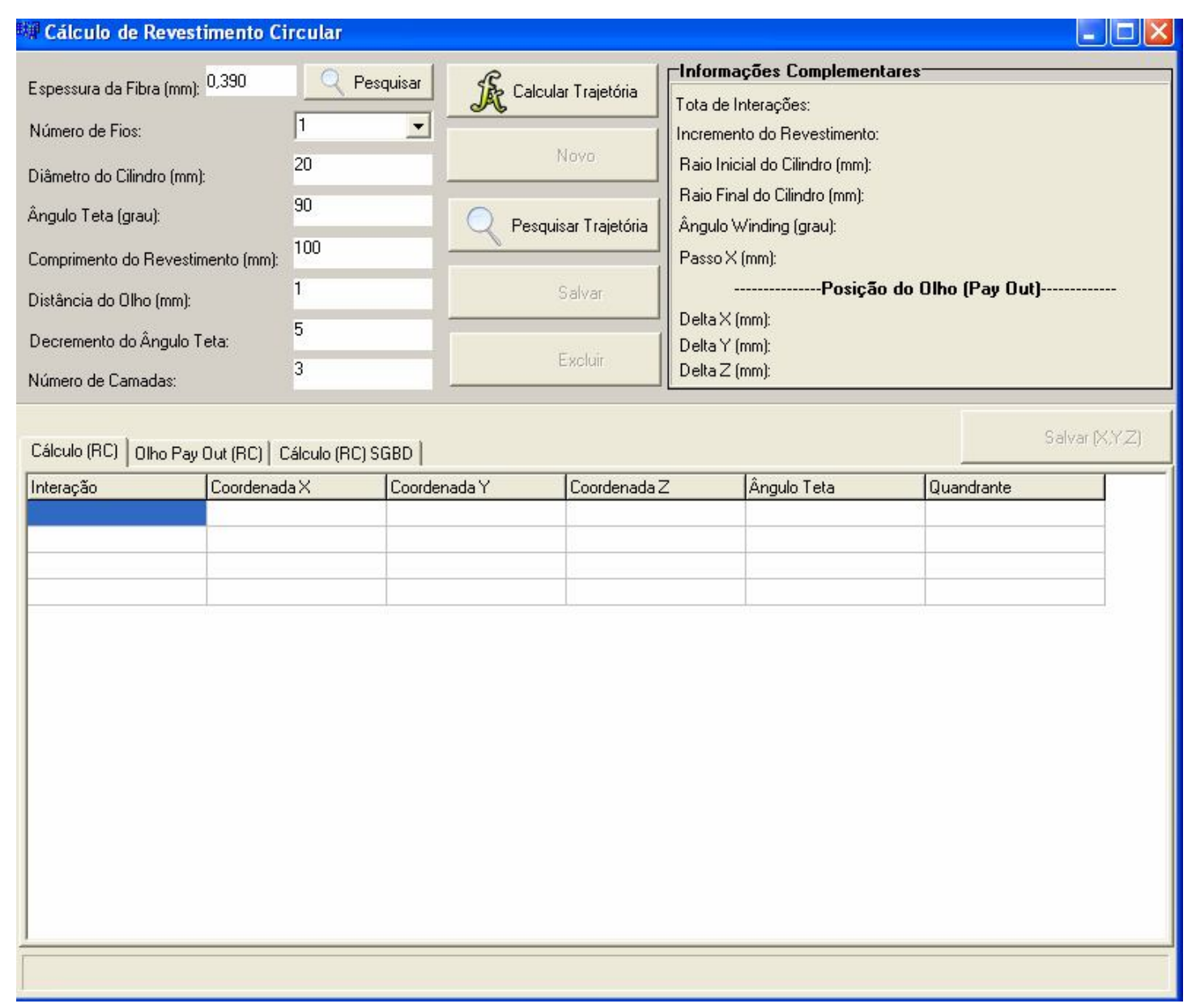

Figura 3.6 - Tela do módulo de revestimento circular.

Para realizar o cálculo, primeiramente, o usuário deve informar ao sistema o tipo de material que deseja trabalhar, para isso basta acionar o botão "pesquisar". Os valores apresentados pelo software foram obtidos, a partir fabricante do material, nesse caso HECXEL®. A figura 3.7 mostra a tela de escolha do material.

O fabricante não oferece o diâmetro do fio, porém fornece a densidade e o peso para um comprimento de 1000 metros. Com estes dados é possível calcular o diâmetro do fio usando a relação densidade, massa e volume. 


\begin{tabular}{|c|c|c|c|}
\hline \multicolumn{2}{|c|}{ Espeçura do Filamento } & 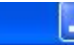 & $\square$ \\
\hline Tipo & N Filamento & \multicolumn{2}{|c|}{ Diâmetro (mm) } \\
\hline $\mathrm{AS} 4$ & 3000 & 0,390 & $r$ \\
\hline AS4 & 6000 & 0.553 & $r$ \\
\hline $\mathrm{AS} 4$ & 12000 & 0.782 & $r$ \\
\hline$A S 4 C$ & 3000 & 0,374 & $r$ \\
\hline$A S 4 C$ & 6000 & 0,529 & $r$ \\
\hline$A S 4 C$ & 12000 & 0.748 & $r$ \\
\hline$A S 4 D$ & 12000 & 0.740 & $r$ \\
\hline $1 \mathrm{M} 4$ & 12000 & 0.723 & $r$ \\
\hline IM6 & 12000 & 0.740 & $r$ \\
\hline $1 \mathrm{M} 7$ & 6000 & 0.407 & $r$ \\
\hline $1 \mathrm{M7}$ & 12000 & 0.564 & $r$ \\
\hline $1 \mathrm{M} 7$ & 12000 & 0.564 & $r$ \\
\hline $1 \mathrm{M} 7 \mathrm{C}$ & 12000 & 0,597 & $r$ \\
\hline IM8 & 12000 & 0,564 & $r$ \\
\hline IMC & 12000 & 0.597 & $r$ \\
\hline PV/36/700 & 12000 & 0.740 & $r$ \\
\hline PV $36 / 800$ & 12000 & 0.597 & $r$ \\
\hline PV $36 / 850$ & 12000 & 0,564 & $r$ \\
\hline & $0 \mathrm{OK}$ & $\times 0$ & \\
\hline
\end{tabular}

Figura 3.7 - Tela de escolha do tipo de material.

$v=\frac{m}{d}$

Sendo $v=\frac{\pi \cdot d^{2}}{4} \cdot h$

Onde: $\frac{\pi \cdot d^{2}}{4} \cdot h=$ secção do fio.

A massa e a densidade são fornecidas pelo fabricante. Com estes dados podemos calcular o diâmetro do fio. 


$$
\begin{gathered}
\frac{\pi \cdot d^{2}}{4} \cdot h=\frac{m}{D} \\
\mathrm{~d}=\sqrt{\frac{4 \cdot m}{D \cdot \pi \cdot h}}
\end{gathered}
$$

Sendo: $\mathrm{D}=$ Densidade .

$$
\begin{aligned}
& \mathrm{H}=\text { Altura } . \\
& \mathrm{m}=\text { Massa } .
\end{aligned}
$$

Após a escolha do material, o usuário deve acionar o botão "OK" para retornar a tela principal do módulo de revestimento circular. O próximo passo é informar o restante dos dados como: número de fios, diâmetro do cilindro, ângulo teta, distância do olho, decremento de teta e o número de camadas. Feito isso, deve-se efetuar o cálculo acionando o botão “calcular trajetória”.

Com o término do cálculo, alguns dados referentes ao cilindro e ao olho pay-out serão apresentados pelo software ao usuário como:

- Total de Interações: representa a quantidade de pontos (X,Y, Z) que constitui o cálculo da trajetória;

- Incremento do Revestimento: representa o valor que é incrementado a cada seqüência de cálculo no eixo X;

- Raio inicial do cilindro: representa a medida em milímetros do raio do cilindro na primeira camada de revestimento;

- Raio final do cilindro: representa a medida em milímetros do raio do cilindro na ultima camada de revestimento;

- Ângulo Winding: representa o ângulo em graus entre a fibra e a geratriz do cilindro; 
- Passo de X: representa a distância em milímetros entre as fibras em um giro de 360 graus. Geralmente no revestimento circular essa distância é marcada pela espessura da fibra;

- Delta X: representa o ponto inicial para a coordenada X do olho pay-out;

- Delta Y: representa o ponto inicial para a coordenada Y do olho pay-out;

- Delta Z: representa o ponto inicial para a coordenada Z do olho pay-out.

A figura 3.8 apresenta a tela do módulo de revestimento circular após a realização do cálculo.

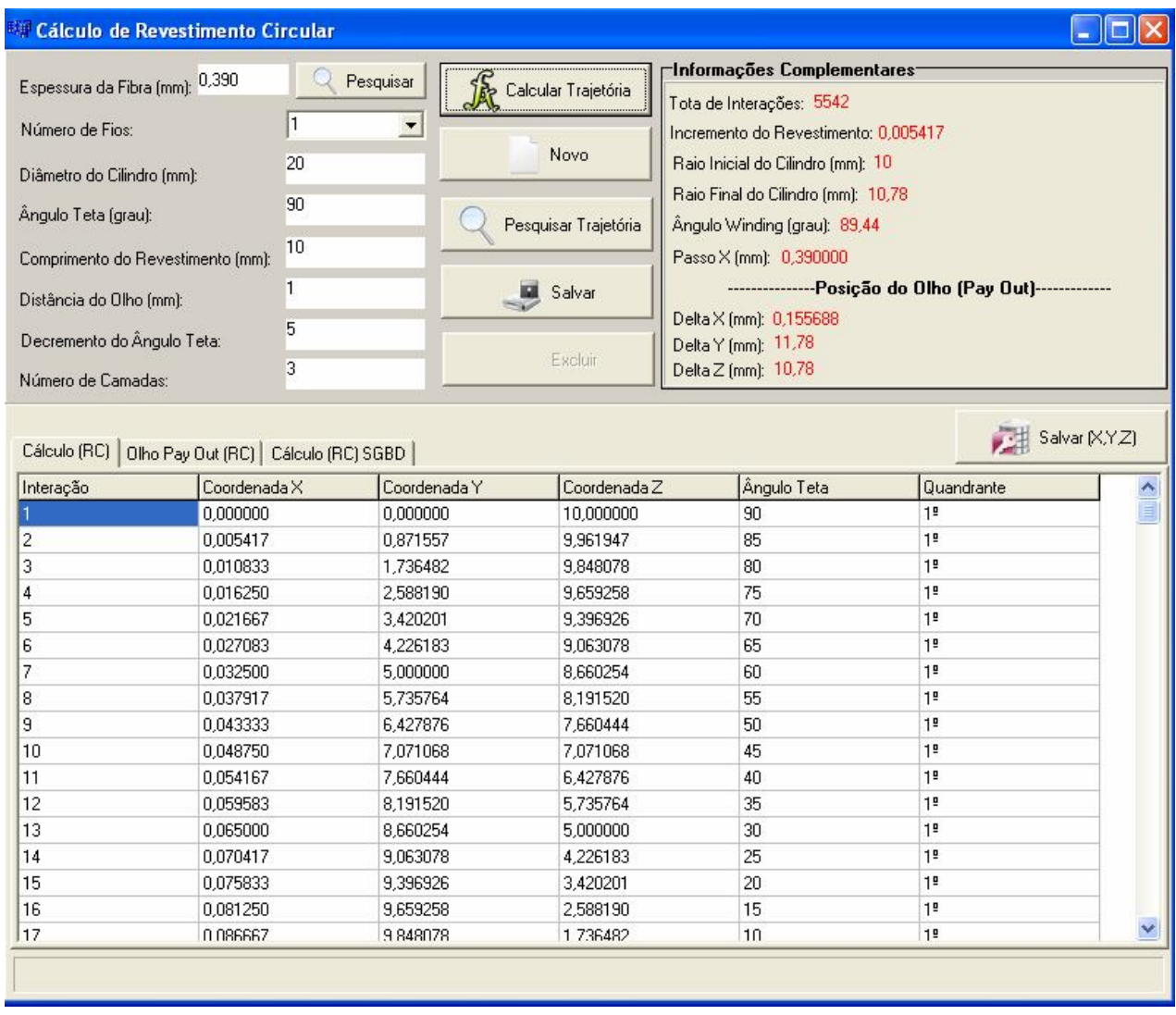

Figura 3.8 - Tela do módulo de revestimento circular após a realização do cálculo.

As informações que mencionadas anteriormente, são apresentadas ao usuário como “informações complementares”. Pede-se visualizar essas informações na figura 3.9. 


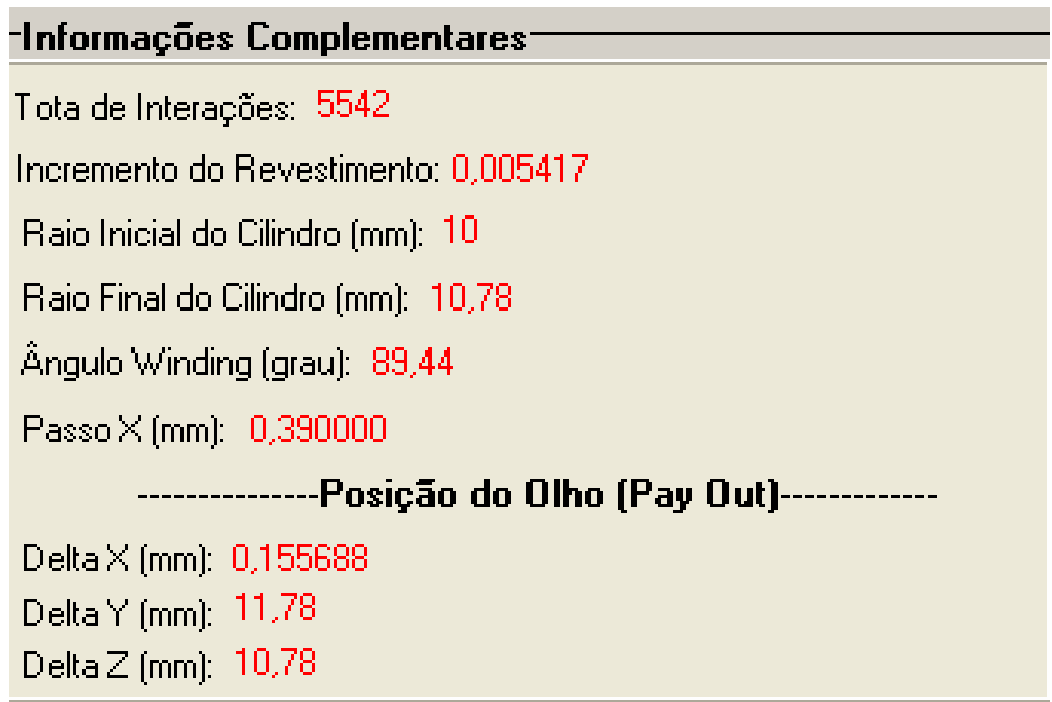

Figura 3.9 - Informações complementares.

Outro ponto que merece destaque é o acompanhamento do cálculo do cilindro que é mostrado na figura 3.10 e o acompanhamento do cálculo do olho pay-out, apresentado na figura 3.11 .

\begin{tabular}{|c|c|c|c|c|c|c|}
\hline \multirow{2}{*}{$\begin{array}{l}\text { Cálculo }[\mathrm{RC}] \\
\text { Interação }\end{array}$} & \multicolumn{4}{|c|}{ | Olho Pay Out (RC) | Cálculo (RC) SGBD | } & \multicolumn{2}{|c|}{ Fift Salvar $(X, Y Z)$} \\
\hline & Coordenada $X$ & CoordenadaY & Coordenada Z & Ângulo Teta & Quandrante & $\wedge$ \\
\hline 1 & 0,000000 & 0,000000 & 10,000000 & 90 & $1^{\underline{9}}$ & 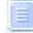 \\
\hline 2 & 0,005417 & 0,871557 & 9,961947 & 85 & $1 \stackrel{0}{a}$ & \\
\hline 3 & 0,010833 & 1,736482 & 9,848078 & 80 & $1^{\text {? }}$ & \\
\hline 4 & 0,016250 & 2,588190 & 9,659258 & 75 & 19 & \\
\hline 5 & 0,021667 & 3,420201 & 9,396926 & 70 & $1^{\underline{9}}$ & \\
\hline 6 & 0,027083 & 4,226183 & 9,063078 & 65 & $1^{19}$ & \\
\hline 7 & 0,032500 & 5,000000 & 8,660254 & 60 & $1^{\underline{9}}$ & \\
\hline 8 & 0,037917 & 5,735764 & 8,191520 & 55 & 19 & \\
\hline 9 & 0,043333 & 6,427876 & 7,660444 & 50 & $1^{0}$ & \\
\hline 10 & 0,048750 & 7,071068 & 7,071068 & 45 & $1^{9}$ & \\
\hline 11 & 0,054167 & 7,660444 & 6,427876 & 40 & $1^{0}$ & \\
\hline 12 & 0,059583 & 8,191520 & 5,735764 & 35 & 19 & \\
\hline 13 & 0,065000 & 8,660254 & 5,000000 & 30 & $1^{9}$ & \\
\hline 14 & 0,070417 & 9,063078 & 4,226183 & 25 & $1^{19}$ & \\
\hline 15 & 0,075833 & 9,396926 & 3,420201 & 20 & $1^{19}$ & \\
\hline 16 & 0,081250 & 9,659258 & 2,588190 & 15 & $1^{19}$ & \\
\hline 17 & ก nRfifif7 & 9848ก78 & 17364882 & $1 \pi$ & 19 & $\underline{v}$ \\
\hline
\end{tabular}

Figura 3.10 - Informações do cálculo do cilindro.

Cada interação de cálculo representa um ponto no espaço $\mathrm{X}, \mathrm{Y}$ e Z. Os valores correspondentes a esses pontos são apresentados ao usuário em forma de: Coordenada X, 
Coordenada Y e Coordenada Z. Outros valores também são apresentados como o ângulo teta e o quadrante correspondente ao ângulo.

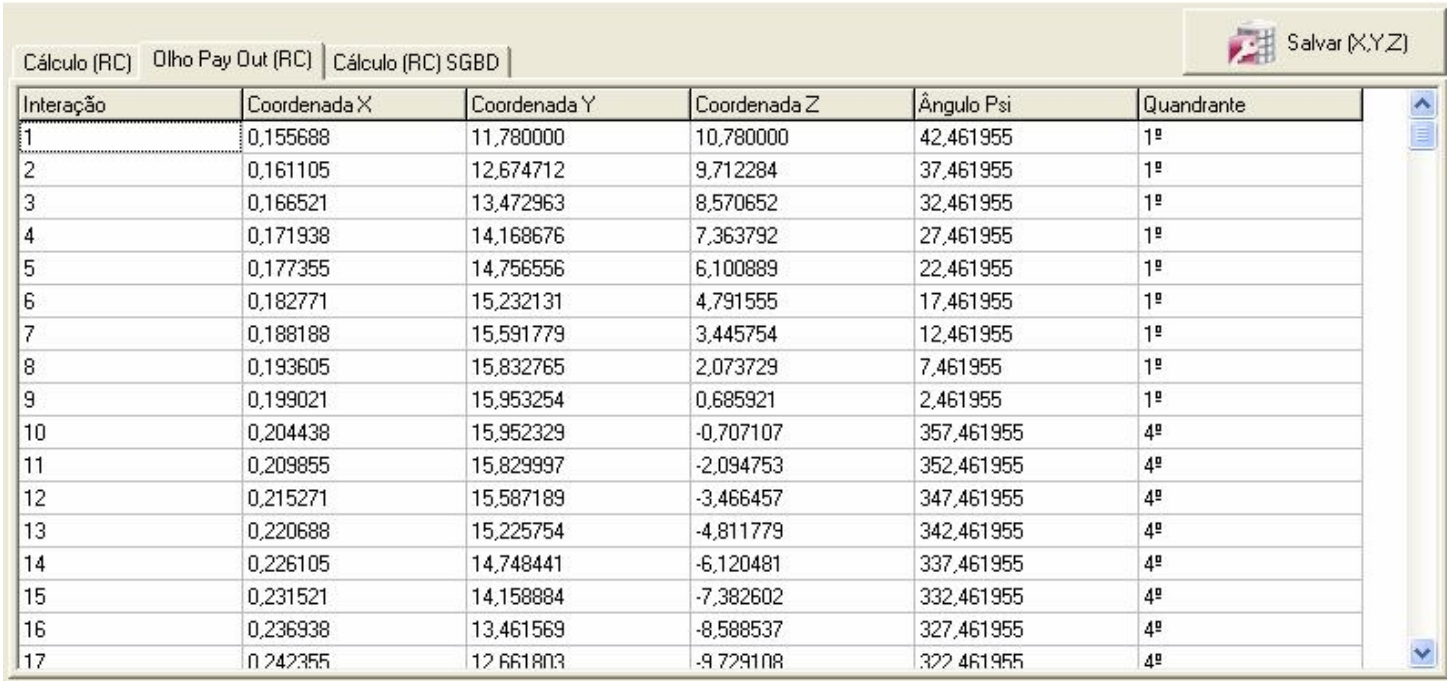

Figura 3.11 - Acompanhamento do cálculo do olho pay-out.

As mesmas informações são apresentadas para o cálculo do olho pay-out, entretanto há uma mudança do ângulo teta para o ângulo Psi, que representa a abertura entre o eixo Y e o ponto inicial do Olho.

Com o término do cálculo da trajetória, o usuário pode gravar as informações no banco de dados clicando no botão "salvar", como mostra a figura 3.8. Quando o usuário opta por essa opção, todas as informações referentes ao calculo da trajetória ficam armazenadas na base de dados, podendo ser utilizadas posteriormente. Para isso, basta acionar o botão "Pesquisar Trajetória" apresentado na figura 3.6 e escolher as opções de pesquisa no caso, diâmetro e comprimento do cilindro ou todos. Optando pela pesquisa do diâmetro, o sistema realiza um busca na base de dados por todos os registros que satisfazem a condição de busca como mostra a figura 3.12 , no caso entre $10 \mathrm{~mm}$ a $50 \mathrm{~mm}$. O mesmo acontece caso o usuário 
opte pelo comprimento do cilindro. Indicando a opção todos, o sistema busca todos os registros armazenados na base de dados referentes aos cálculos de trajetória circular.

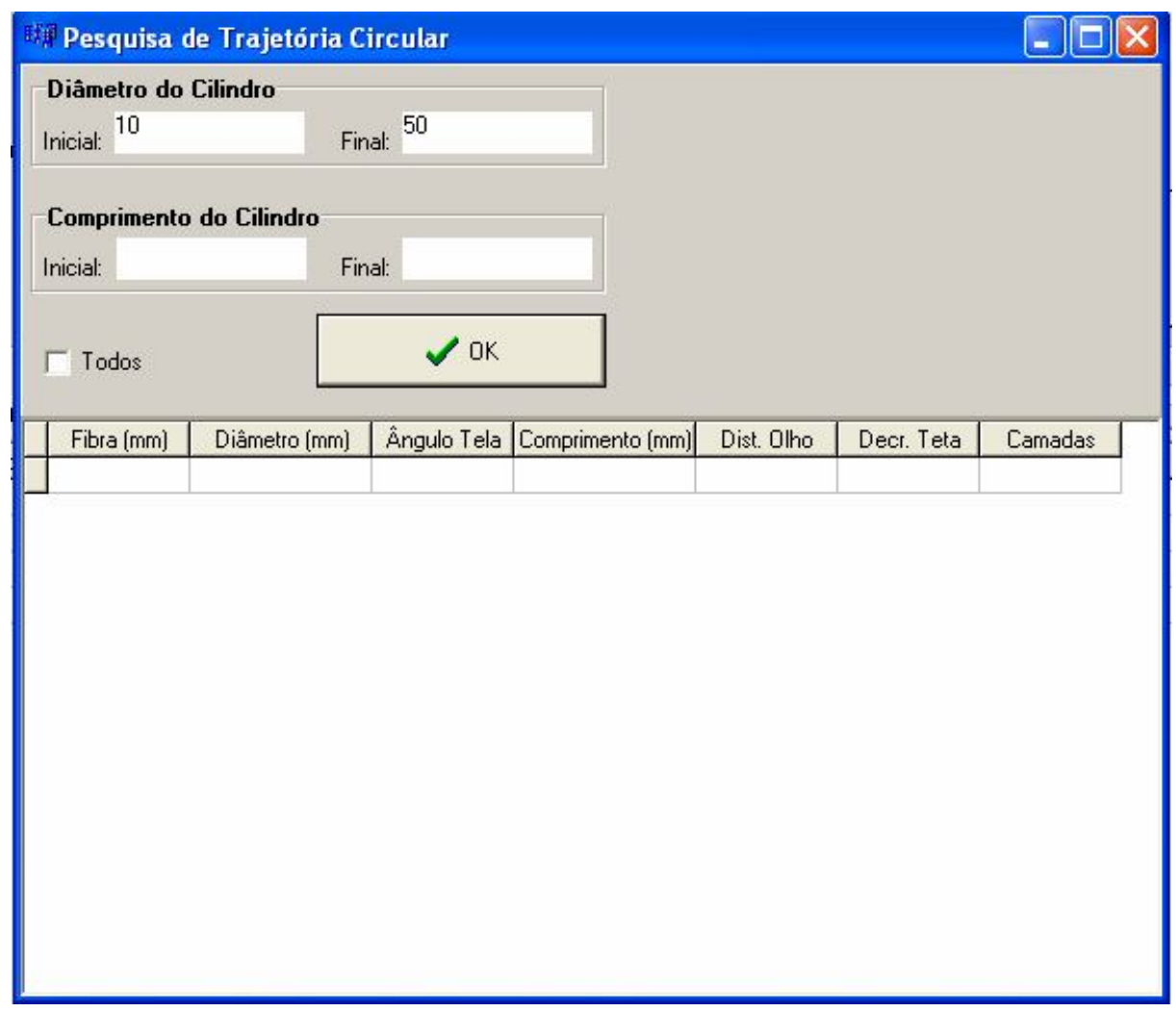

Figura 3.12 - Tela de pesquisa da trajetória.

Após definir a opção de busca, o usuário deve acionar o botão "OK" para que os dados sejam apresentados no sistema. Para escolher a opção correspondente ao cálculo desejado, basta indicar a opção, como mostra a figura 3.13 . 


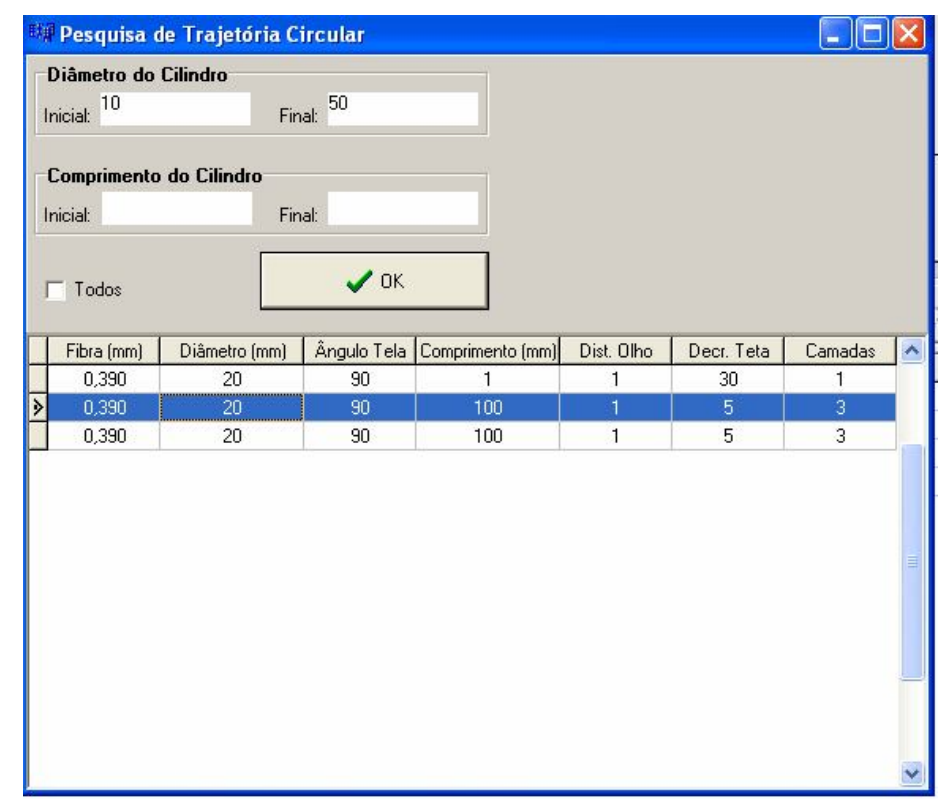

Figura 3.13 - Tela de pesquisa da trajetória com apresentação dos dados.

O cálculo indicado pelo usuário é apresentado ao sistema, podendo ser executado ou excluído, conforme mostra a figura 3.14.

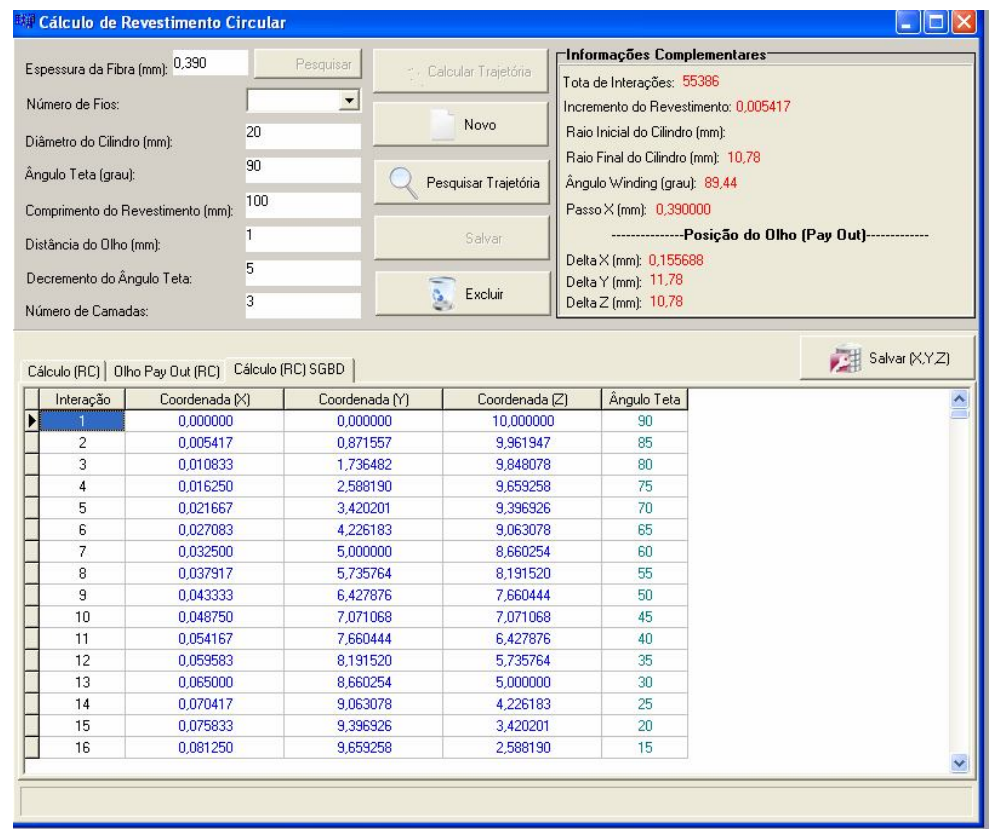

Figura 3.14 - Tela de apresentação do cálculo pesquisado. 
O software também apresenta a opção de armazenar os dados referentes às coordenadas X, Y e Z. Acionando o botão "Salvar (X, Y, Z)", o sistema armazena na base de dados somente os valores correspondentes os eixos X, Y e Z como mostra a figura 3.15.

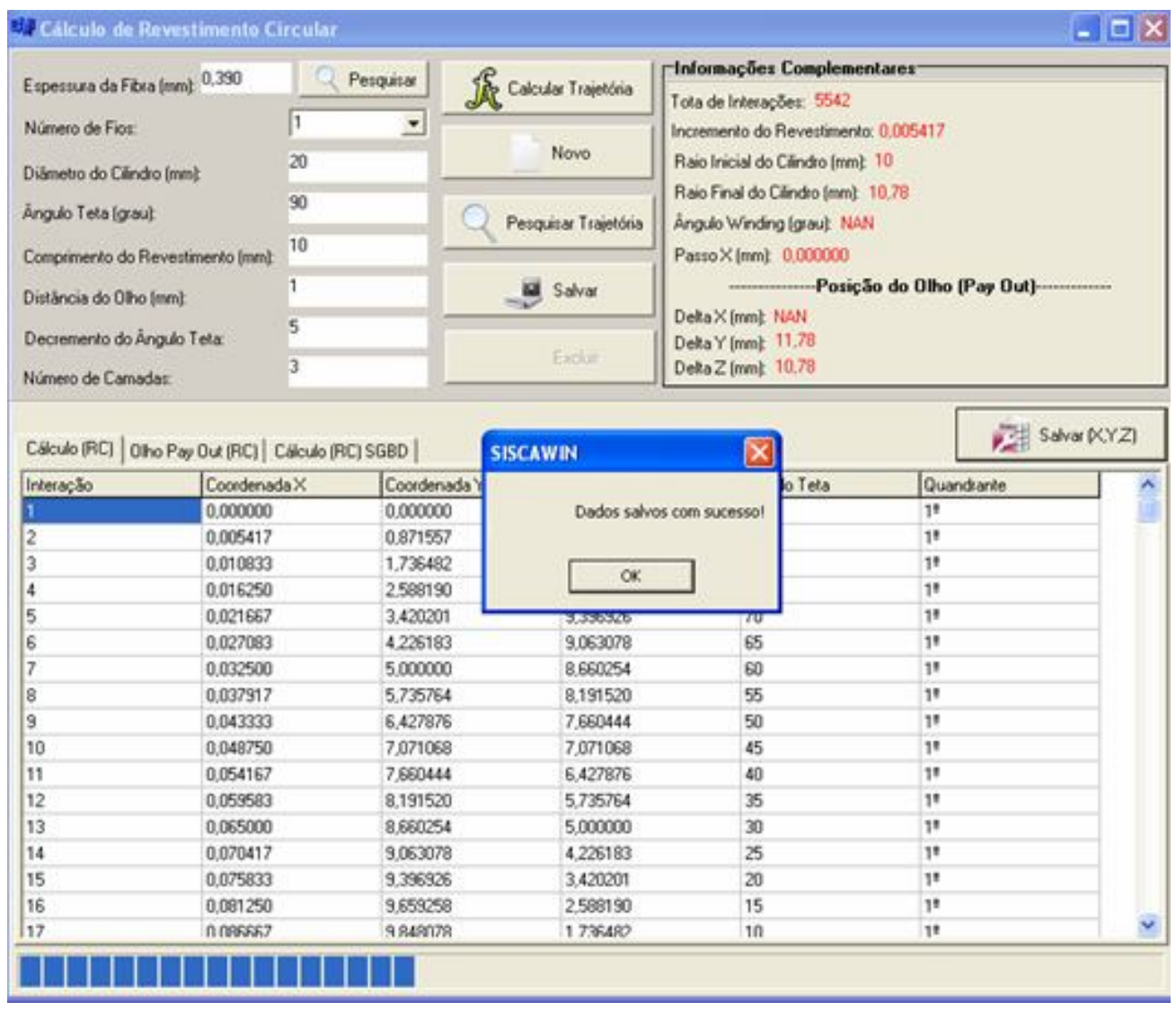

Figura 3.15 - Tela do módulo de revestimento circular demonstrando a opção Salvar (X,Y, Z).

Esses valores podem ser exportados em formato de arquivo *.xls como mostra a figura 4.13. Formato de arquivo que pode ser interpretado por softwares CAD. O Solid Edge é um software CAD que possibilita a visualização de sólidos no formato 3D. O software apresenta um recurso de importação de dados no padrão $\mathrm{X}, \mathrm{Y}, \mathrm{Z}$ em formato xls. A figura 3.16 demonstra como o arquivo pode ser importado pelo software Solid Edge. 


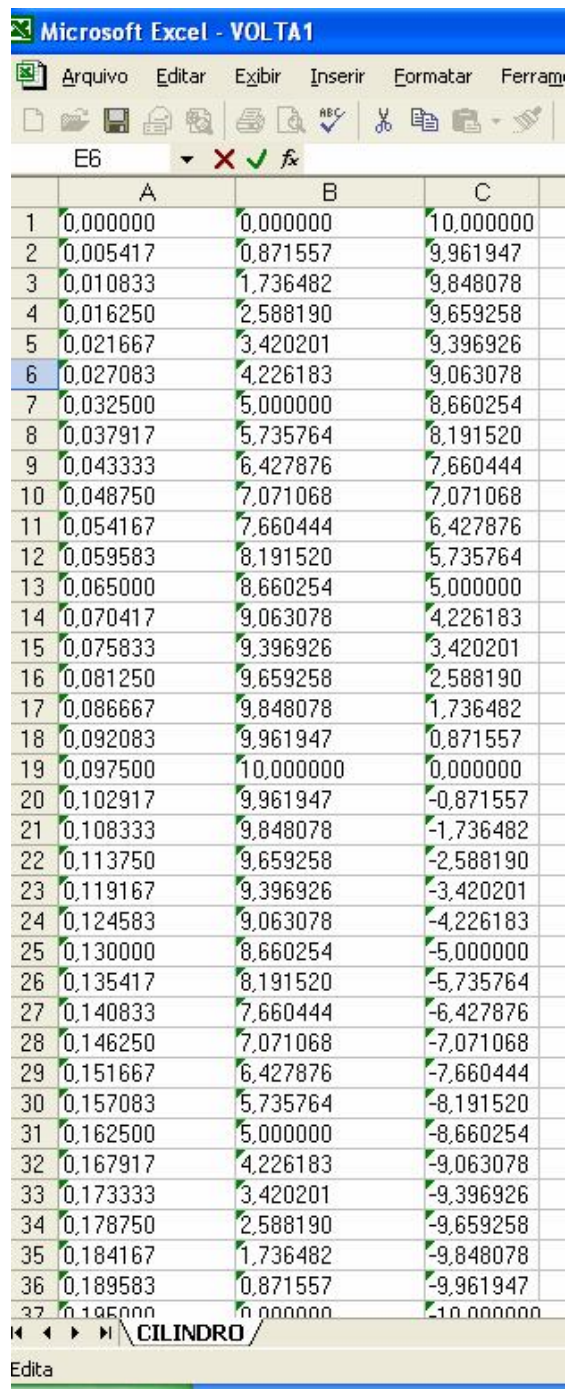

Figura 3.16 - Valores X, Y e Z no formato xls.

Após a importação dos dados, o usuário pode comprovar o resultado dos cálculos através recursos que a ferramenta apresenta para manipulação superfícies 3D como, por exemplo, o comprimento do cilindro, o diâmetro das camadas, o valor do passo, à distância do cilindro ao olho pay-out . A figura 3.17 mostra o resultado da importação de um arquivo *.xls gerado pelo software SISCAWIND. 


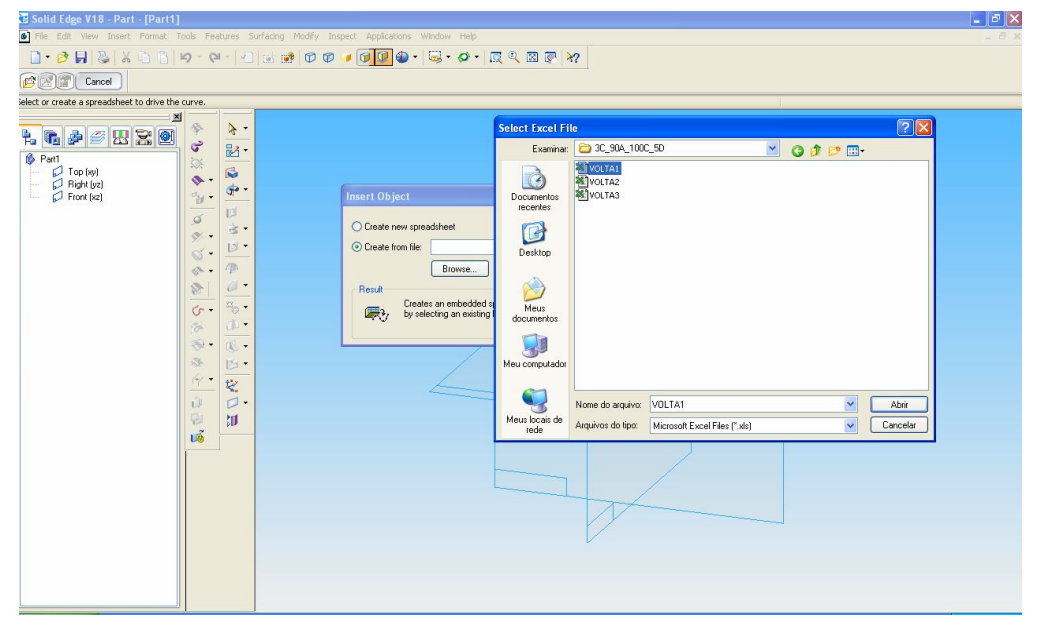

Figura 3.17 - Software Solid Edge demonstrando a importação de um arquivo xls.

A visualização do cálculo no formato 3D, apresentado na figura 3.18 , permite a verificação dos valores de entrada e saída do software SISCAWIND e apresenta ao usuário uma simulação real do revestimento do cilindro, fator indispensável para que o engenheiro possa tomar suas respectivas decisões.

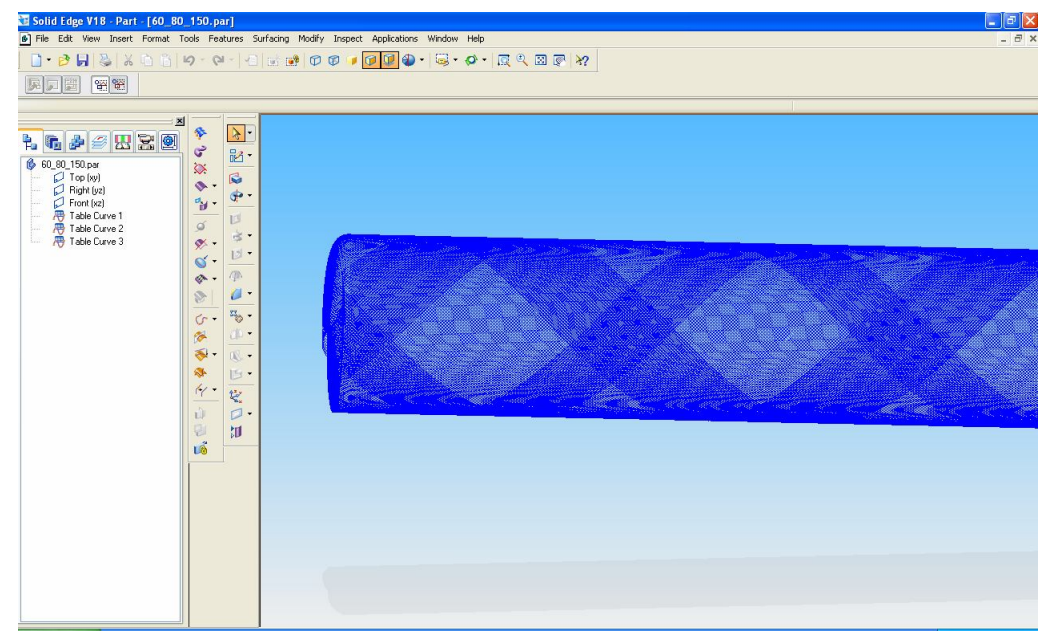

Figura 3.18 - Resultado da importação do arquivo xls no software Solid Edge.

Outro módulo apresentado pelo sistema é o módulo de revestimento helicoidal. Esse módulo possui os mesmos recursos que o módulo de revestimento circular apresentado 
anteriormente. A única diferença entre eles é que no módulo de revestimento helicoidal, o usuário fornece o valor do ângulo winding, definido aqui por Ômega, a forma de calcular o ângulo teta e o incremento de coordenada X. As técnicas utilizadas para os cálculos serão tratadas mais à frente nesse capítulo. O ângulo Omega representa em graus, o ângulo entre a fibra e a geratriz do cilindro. Pode-se visualizar a representação do ângulo winding na figura 3.19 .

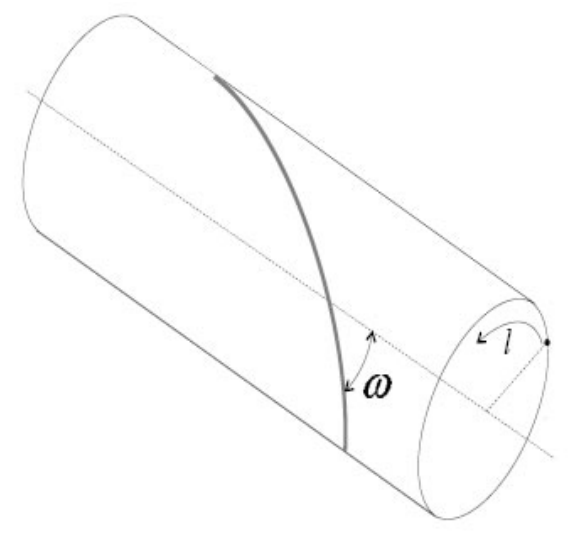

Figura 3.19 - Representação do ângulo Omega (winding) no revestimento helicoidal.

Dessa forma, o usuário pode estabelecer o formato do revestimento de acordo com o ângulo escolhido. Desde que o valor escolhido esteja dentro do limite estabelecido pela condição de revestimento helicoidal:

$\lambda<\omega<90$

Sendo:

$\lambda=\operatorname{arcotangente}\left(\frac{D}{c}\right)$

Sendo que: 
$\lambda$ é o ângulo winding limite para a condição de revestimento helicoidal.

D é o diâmetro do cilindro.

c é o comprimento do cilindro.

$\mathrm{Na}$ figura 3.20, pode-se visualizar a tela do módulo de revestimento helicoidal com suas respectivas características.

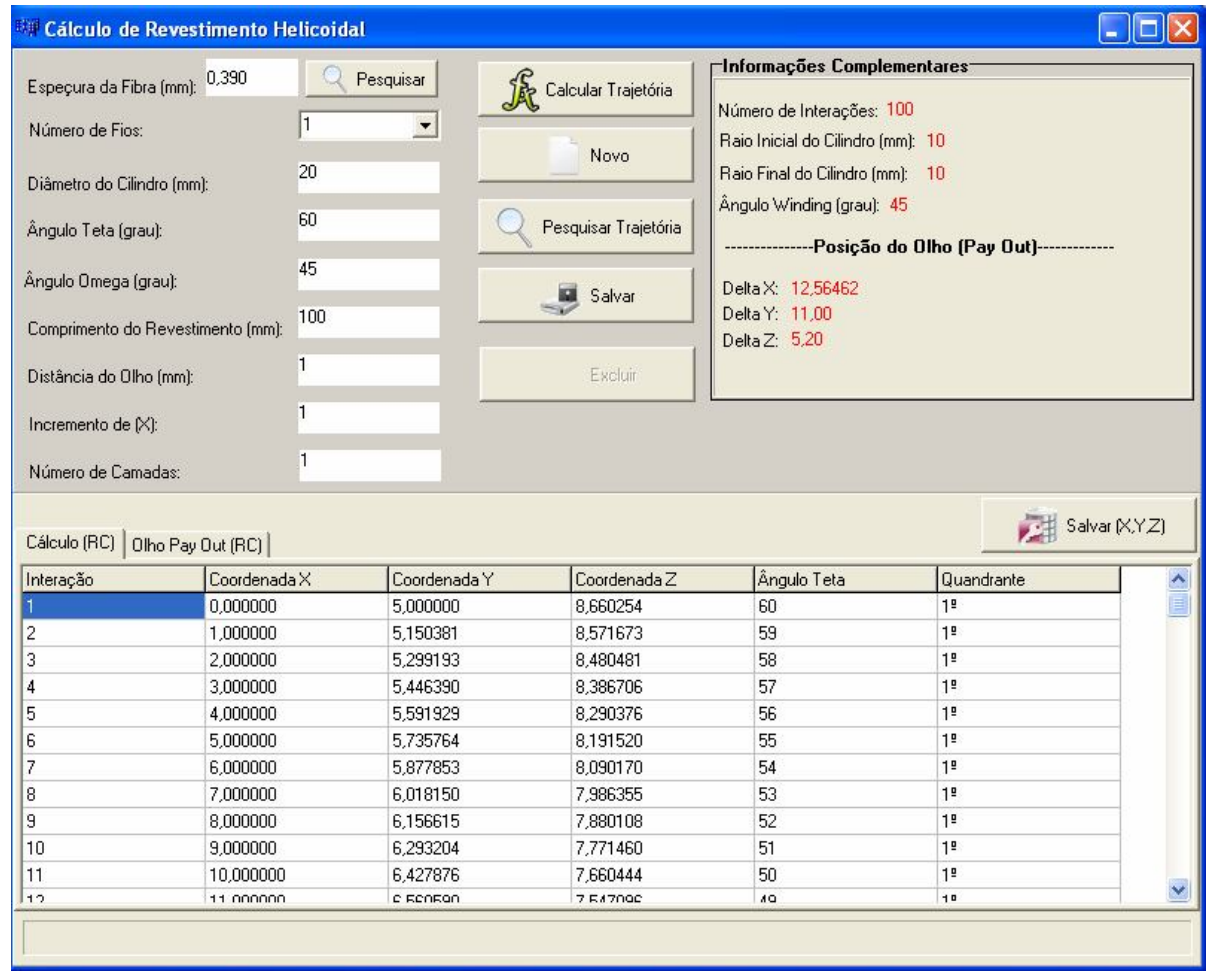

Figura 3.20 - Tela do módulo de revestimento helicoidal.

O ultimo módulo apresentado pelo sistema é o polar. Esse módulo apresenta as mesmas características que o módulo de revestimento helicoidal, porém, com limites de ângulo para satisfazer a condição do revestimento diferente. Esse limite de ângulo pode ser calculado pela seguinte pela relação: 
Onde:

$\lambda=\operatorname{arcotangente}\left(\frac{d}{c}\right)$

Sendo que:

$\lambda$ é o ângulo winding limite para a condição de revestimento polar.

d é o diâmetro do cilindro.

c é o comprimento do cilindro.

A figura 3.21 mostra a tela de revestimento polar com a função de limite de ângulo sendo executada.

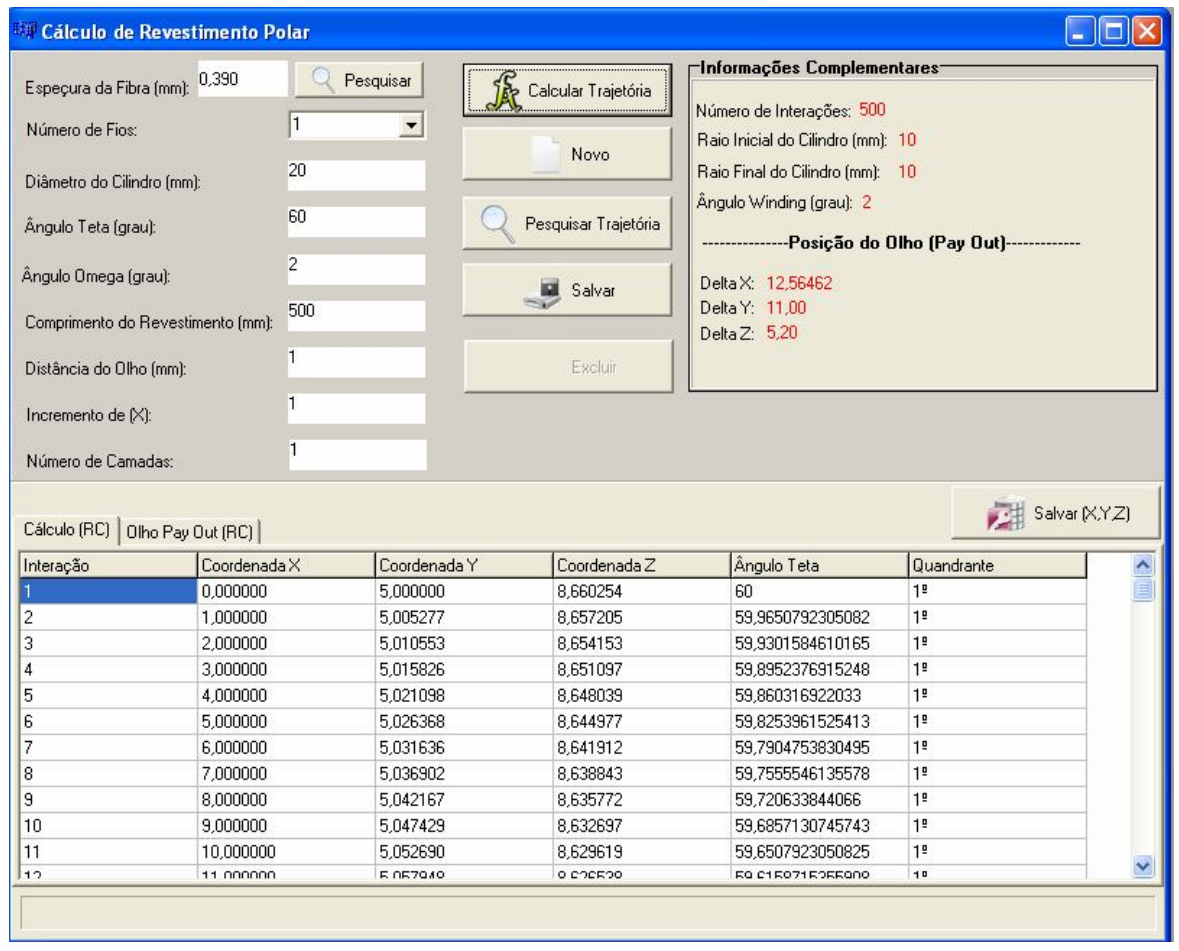

Figura 3.21 - Módulo de revestimento Polar. 


\subsection{CÁLCULO DA TRAJETÓRIA DA FIBRA}

Os algoritmos computacionais utilizados no software SISCAWIND foram elaborados através da técnica de cálculo de revestimento circular desenvolvida por Gomes (2008). Primeiramente foi elaborada uma planilha eletrônica contendo três tipos de revestimento cilíndrico: circular, helicoidal e polar.

\subsubsection{Revestimento circular}

No revestimento circular, as fibras são posicionadas, de forma precisa uma ao lado da outra preenchendo toda a superfície do mandril. Esse processo pode ser comparado a um carretel de linha, no qual a linha é enrolada na superfície do carretel formando múltiplas camadas.

Primeiramente para iniciar o processo do cálculo é preciso indicar a espessura do material que deseja trabalhar. Essa medida é obtida através do fabricante da fibra HECXEL ®. Após a escolha do tipo de filamento é necessário calcular o número de iterações através de um ciclo de $360^{\circ}(N I)$ elaborado pela fórmula:

$$
N I=360\left(\frac{1}{d_{t}}\right)
$$

No qual $d_{t}$ é o decremento de $\theta$ mostrado na figura 3.22. O ângulo formado no plano YZ determina o ponto inicial da trajetória no sentido horário. 


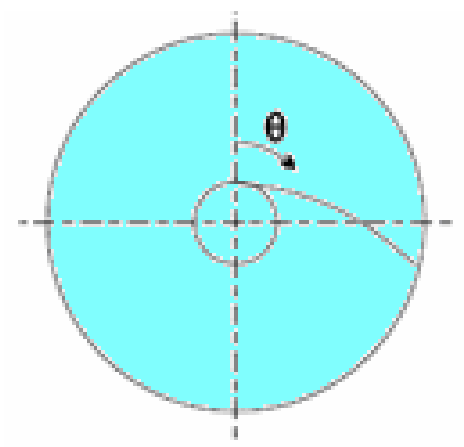

Figura 3.22 - Ângulo Teta (Fonte: GOMES, 2008).

Após determinar o número de iterações até $360^{\circ}$ é calculado o incremento do revestimento circular $\left(I_{r c}\right)$, necessário para que as fibras sejam posicionadas de forma precisa mantendo-se uma ao lado da outra sobre toda a superfície do mandril. Esse dado no revestimento circular representa sempre a espessura do filamento. O incremento é calculado da seguinte forma:

$$
I_{r c}=\frac{e f}{N I}
$$

No qual ef é a espessura do filamento escolhido para o revestimento.

Para que seja calculada a superfície, o usuário precisa fornecer ao sistema alguns dados primordiais do cilindro como: diâmetro do cilindro, Ângulo $\theta$ (Ponto Inicial da trajetória), Comprimento do Revestimento, distância do olho em relação ao Cilindro e o decremento de $\theta$. Através dos dados de entrada inseridos serão calculadas a Coordenada $\mathrm{X}$, a Coordenada Y e a Coordenada Z. A Coordenada X iniciará sempre na posição zero somado pelo incremento $\left(I_{r c}\right)$ a cada do revestimento. A Coordenada Y é calculado pela relação:

$$
Y=R \cdot \cos \theta
$$


No qual $R$ é o raio do cilindro.

O raio é calculado pela fórmula:

$$
R=\frac{D}{2}
$$

No qual $D$ é o diâmetro fornecido pelo usuário.

A Coordenada Z é calculada como:

$$
Z=R \cdot \operatorname{sen} \theta
$$

Para chegar nos valores finais das coordenadas X, Y e Z são necessários desenvolver outros cálculos. Para iniciar esses cálculos iremos descrever o "Cálculo dos Radianos". Para cada iteração o ângulo $\theta$ é subtraído um decremento de $\theta\left(d_{t}\right)$ para isso, o ângulo é transformado em radiano, através da seguinte relação:

$$
r=\frac{\pi \cdot \theta}{180}
$$

Sendo $\mathrm{r}$ é radianos e $\pi=3,14 \ldots$,

Em seguida é necessário determinar em qual quadrante cada ponto (X, Y e Z) se encontra. Para isso é calculado o ângulo $\theta$ entre $0^{\circ}$ e $359^{\circ}\left(\theta_{e}\right)$, o número da volta e o quadrante propriamente dito. Vamos iniciar mostrando como será calculado o Número da Volta $(N V)$ em que o ponto está. Para é dado:

$$
N V=I N T\left(\frac{\theta}{360}\right)
$$


No qual INT( ) é a parte inteira da divisão acima descrita.

O número da Volta $(N V)$ determina em que volta o ângulo $\theta$ esta situado. Esse número pode assumir valores negativos, pois o sentido no plano $\mathrm{YZ}$ é horário. $\mathrm{O}$ segundo passo é o cálculo do ângulo $\theta$ entre $0^{\circ}$ e $359^{\circ}\left(\theta_{e}\right)$. O ângulo $\theta$, como já mencionado, assumi valores negativos, tornando-se necessário transformar $\theta$ em ângulo entre $0^{\circ}$ e $359^{\circ}$ para que possamos determinar os quadrantes. Determinan-se $\theta_{e}$ através de:

$$
\theta_{e}=\theta-360 . N V
$$

Contendo os dados $N V$ e o $\theta_{e}$, pode-se calcular os quadrantes através da seguinte relação:

$$
Q=\left\{\begin{array}{c}
\text { se } \theta_{e}=0 ; 1^{\circ} \\
\text { se } \theta_{e}<=90 ; 1^{\circ} \\
\operatorname{se} \theta_{e}<=180 ; 2^{\circ} \\
\text { se } \theta_{e}<=270 ; 3^{\circ} \\
\text { se } \theta_{e}<=359 ; 4^{\circ}
\end{array}\right.
$$

Resumindo:

As coordenadas (X, Y e Z) que formam os pontos da trajetória utilizada para visualização 3D e enviada para máquina de Filament Winding são:

$$
\begin{aligned}
& X=0 \\
& X=X+\left(I_{r c}\right) ; \\
& Y=R \cdot \cos \theta ; \\
& Z=R \cdot \operatorname{sen} \theta
\end{aligned}
$$


Calculado o ângulo teta entre 0 e 359 e o quadrante correspondente ao ponto, é calculado o Ângulo Omega $(\omega)$ conhecido como winding angle e o Passo da trajetória (P). Dados utilizados para validação do término dos cálculos. O Ângulo Omega representa o ângulo em graus entre a fibra e a geratriz do cilindro. Pode-se obter esse valor pela fórmula:

$$
\omega=\arctan \left(\frac{\Delta y}{\Delta x}\right)
$$

Para a determinação do cálculo do passo, foi criada uma estratégia especial. Primeiramente o valor da coordenada X, é armazenado quando o ângulo teta corresponder a $180^{\circ}$ definida aqui $\operatorname{pr}\left(X_{i}\right)$ e o valor da coordenada $X$ quando o ângulo teta corresponder $540^{\circ}$ definida aqui como $\left(X_{f}\right)$. O passo representa a medida em $(\mathrm{mm})$, em relação ao posicionamento da fibra no decorrer da trajetória e pode ser definida por:

$$
P=X_{f}-X_{i}
$$

A figura 3.23 mostra o Ângulo Omega $(W)$ e o Passo $(P)$ na relação do revestimento circular.

No revestimento circular o Ângulo Omega é representado por valores próximos a 90 graus e o passo a medida da espessura do filamento. Como esses valores não são fornecidos pelo o usuário, servem basicamente para verificar se o andamento dos cálculos está caminhando de maneira satisfatória.

Terminada a etapa dos cálculos de validação do cilindro, começam os cálculos do posicionamento do olho (pay out) em relação à trajetória descrita. $\mathrm{O}$ olho é o dispositivo que 
guia a fibra impregnada na superfície do mandril. O cálculo da posição do olho é realizado automaticamente, através dos dados de entrada do programa.

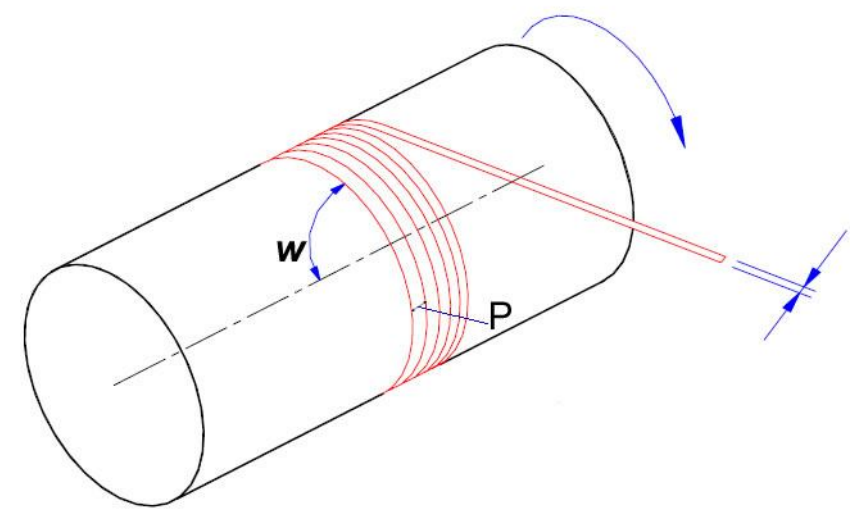

Figura 3.23 - Ângulo Omega $(W)$ e o Passo $(P)$ na relação do revestimento circular.

Para iniciar os cálculos é necessário estabelecer outras variáveis auxiliares, como por exemplo, a coordenada X', a coordenada Y', a coordenada Z', o quadrante e o Ângulo $\psi$. Inicialmente são efetuados os cálculos da coordenada X', coordenada Y' e da coordenada Z', os demais serão comentados posteriormente.

A Coordenada $X^{\prime}$ iniciará na posição inicial de $\Delta X^{\prime}$, que será descrita no decorrer desse trabalho, e para cada iteração é somado um incremento do revestimento circular $\left(I_{r c}\right)$.

A Coordenada Y' é calculada da seguinte forma:

$Y^{\prime}=R_{v} \cdot \cos \psi$

Sendo $\psi$ é denominado ângulo Psi que será demonstrado mais á frente e $R_{v}$ é o raio do Cilindro Virtual.

A Coordenada Z' é calculada é apresentada através da formula:

$Z^{\prime}=R_{v} \cdot \operatorname{sen} \psi$ 
Para determinar as coordenadas $\mathrm{X}, \mathrm{Y}$ e Z é necessário estabelecer alguns cálculos auxiliares. Esse cálculos são projetados para três estados diferentes: com o ângulo $\theta$ igual a $90^{\circ}, \theta$ maior que $90^{\circ}$ e $\theta$ menor que $90^{\circ}$.

O Cálculo da posição do Olho com ângulo $\theta$ igual a $90^{\circ}$ inicia com a determinação do raio do cilindro virtual $\left(R_{v}\right)$, que é o raio do cilindro somado a distância Olho-Cilindro indicado pelo usuário. À distância Olho-Cilindro é medida com relação ao eixo Y. Ao determinarmos os raios podemos juntamente $\Delta \mathrm{Y}^{\prime}$ igual $R_{v}$ e $\Delta \mathrm{Z}^{\prime}$ igual a $R$. O próximo passo é determinar o Ângulo $\psi_{\mathrm{r}}$ em radianos, que é responsável pelo ângulo inicial do olho. Essa relação é dada da seguinte maneira:

$$
\psi_{r}=\operatorname{arctang}\left(\frac{\Delta \mathrm{Z}^{\prime}}{\Delta \mathrm{Y}^{\prime}}\right)
$$

Para transformar o ângulo $\psi_{\mathrm{r}}$ em graus $\left(\psi_{\mathrm{g}}\right)$ é necessário utilizar a seguinte formula:

$$
\psi_{g}=\frac{180 . \psi_{r}}{\pi}
$$

A próxima variável calculada é a distância OP. Base para se calcular X'P. Como os valores de $\Delta Y^{\prime}$ e $\Delta Z^{\prime}$, já são conhecidos, pode-se aplicar o Teorema de Pitágoras.

$$
O P=\sqrt{\left(\Delta Z^{\prime}\right)^{2}+\left(\Delta Y^{\prime}\right)^{2}}
$$

Determinado a Distância OP segue-se os cálculos com a obtenção da distância X'P, responsável pela posição inicial do Olho em relação ao eixo $\mathrm{X}$ (ou $\Delta \mathrm{X}^{\prime}$ ). À distância $\mathrm{X}^{\prime} \mathrm{P}$ é obtida através da obtenção do ângulo complementar de $\omega$, que definada por $\omega$ ', calculado da seguinte forma: 
$\omega^{\prime}=90-\omega$

Para transformar $\omega^{\prime}$, que está em graus, em radianos $\left(\omega_{r}{ }^{\prime}\right)$ basta executar o seguinte cálculo:

$$
\omega_{r}^{\prime}=\frac{\pi \cdot \omega^{\prime}}{180}
$$

Com $\omega_{r}$ ' calculado em radianos segue-se a determinação de X'P da seguinte forma:

$$
X^{\prime} P=\tan \left(\omega_{r}{ }^{\prime}\right) \cdot O P
$$

$X^{\prime} P$ é o ponto inicial do Olho, em relação ao eixo $\mathrm{X}$ denotado por $\Delta \mathrm{X}^{\prime}$.

Os cálculos auxiliares do olho para o ângulo teta igual a $90^{\circ}$ podem ser visualizados na figura 3.24 .

Para os cálculos auxiliares do olho com ângulo $\theta$ maior que $90^{\circ}$ é utilizado o mesmo processo com acréscimo do ângulo $\alpha$ e das variáveis $Y \_m a i$ e $y \_m i n$, que são necessárias para determinarmos $\Delta Z^{\prime}$. Calcula-se essas variáveis da seguinte maneira:

$$
\alpha=180-\theta
$$

Transformando o mesmo em radianos $\left(\alpha_{r}\right)$ temos

$$
\alpha_{r}=\frac{\pi \cdot \alpha}{180}
$$




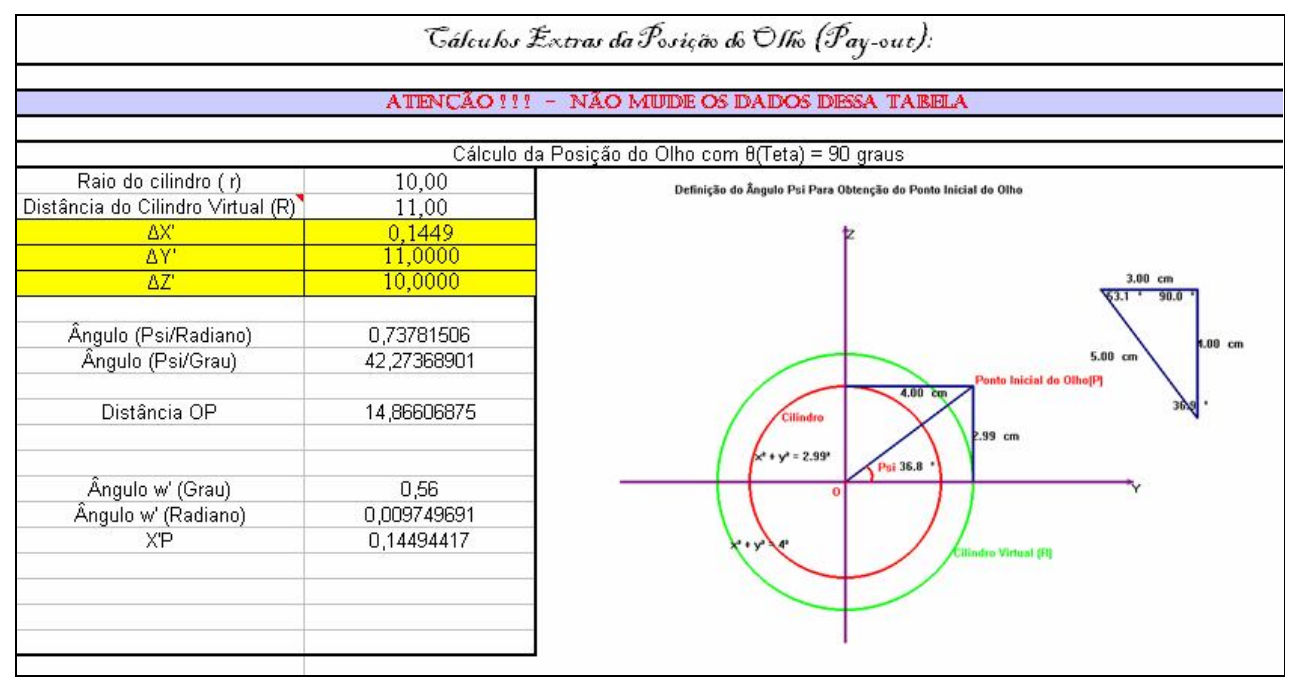

Figura 3.24 - Cálculos auxiliares do olho para o ângulo $\theta=90^{\circ}$ (Fonte GOMES, 2009).

O próximo passo é determinarmos as distâncias $y \_m i n$ e $Y \_m a i$,

$$
\begin{aligned}
& y_{-} \min =\frac{R}{\cos \alpha_{r}} \\
& Y_{-} \text {mai }=y_{-} \min +R_{v}
\end{aligned}
$$

Com os cálculos acima descritos pode-se determinar $\Delta Z^{\prime}$, da seguinte maneira:

$$
\Delta Z^{\prime}=\frac{Y_{-} m a i}{\tan \alpha_{r}}
$$

O Cálculo da posição do Olho com ângulo $\theta$ maior que $90^{\circ}$ é mostrado na figura 3.25 . 


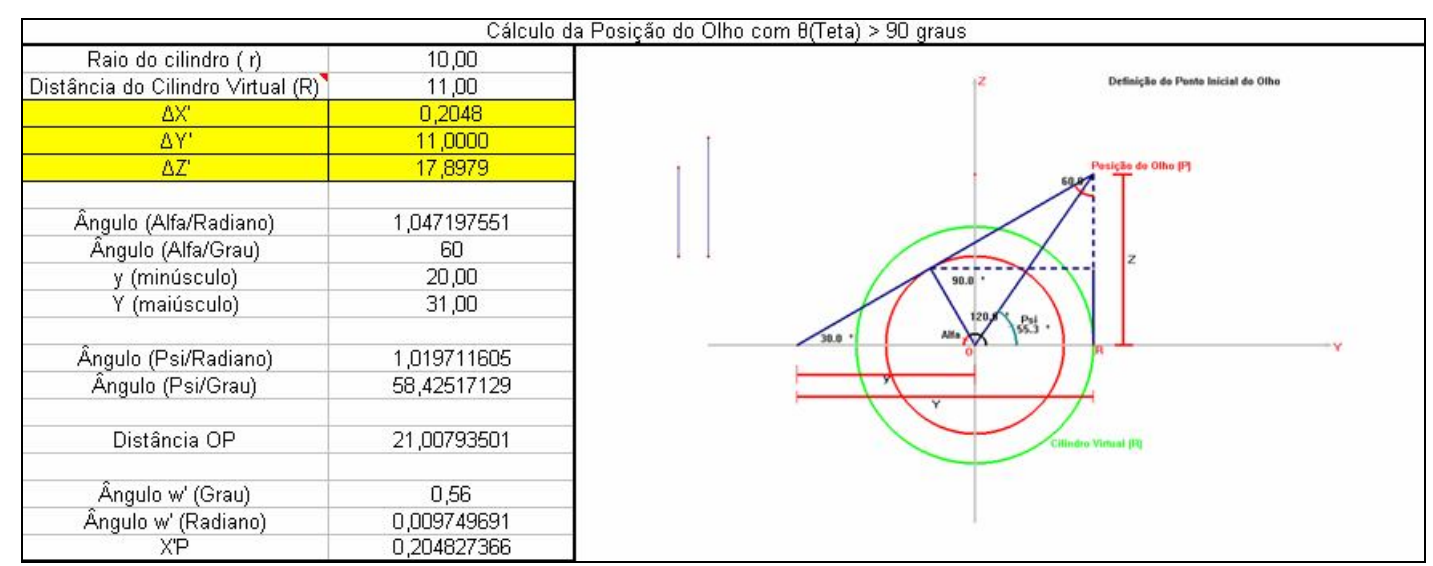

Figura 3.25 - Cálculo da posição do Olho com ângulo $\theta>90^{\circ}$ (Fonte: GOMES, 2009).

Para os cálculos auxiliares do olho com ângulo $\theta$ menor que $90^{\circ}$ é utilizado o mesmo processo que o cálculo com o ângulo $\theta$ maior que $90^{\circ}$ com acréscimo diferença nas variáveis Y_mai e $y \_$mim. Tem-se:

$$
\begin{aligned}
& Y_{-} m a i=\frac{R}{\cos \theta_{r}} \\
& y_{-} \min =Y_{-} m a i+R_{v} \\
& \Delta Z^{\prime}=\frac{y_{-} \min }{\tan \theta_{r}}
\end{aligned}
$$

O Cálculo da posição do Olho com ângulo $\theta$ menor que $90^{\circ}$ é mostrado na figura 3.26 . 


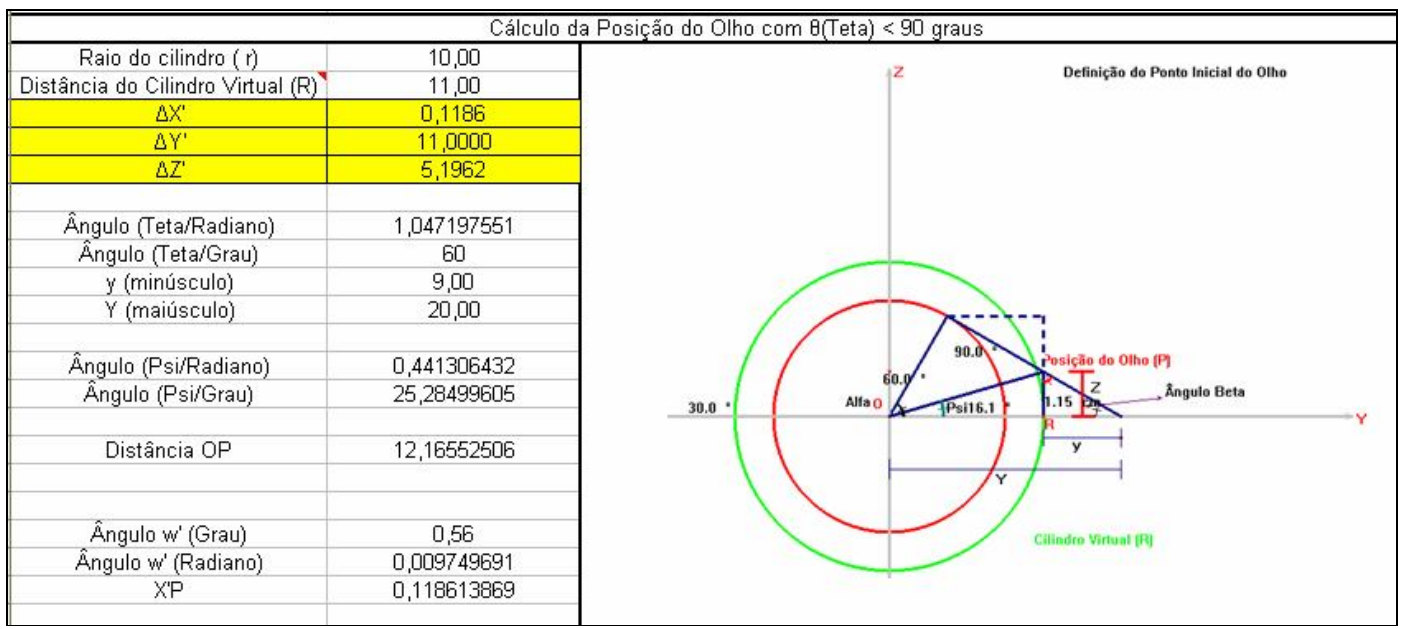

Figura 3.26 - Cálculo da posição do Olho com ângulo $\theta<90^{\circ}$ (Fonte: GOMES, 2009).

Após determinar os cálculos auxiliares nos três estados, vamos apresentar os cálculos dos quadrantes e radiano do olho. Para determinar o Ângulo $\psi$ inicial, com base nos cálculos auxiliares é necessário uma seqüência de testes lógicos como:

$$
\psi=\left\{\begin{array}{l}
\text { se } \theta=90^{\circ} \Rightarrow \psi_{1} \\
\operatorname{se} \theta>90^{\circ} \Rightarrow \psi_{2} \\
\text { se } \theta<90^{\circ} \Rightarrow \psi_{3}
\end{array}\right.
$$

Sendo $\psi_{1}$ é o ângulo $\psi$ correspondente aos cálculo do ângulo $\theta$ igual a $90^{\circ}$, $\psi_{2}$ é o ângulo $\psi$ correspondente aos cálculo do ângulo $\theta$ maior que $90^{\circ}$ e $\psi_{3}$ é o ângulo $\psi$ correspondente aos cálculo do ângulo $\theta$ menor que $90^{\circ}$. Determinado este ângulo para a primeira iteração, a obtenção de $\psi$ para as demais iterações é adicionando a cada iteração o decremento de $\theta$. Para transformar $\psi$ em radianos $\left(\psi_{\mathrm{r}}\right)$ basta fazer:

$$
\psi_{r}=\frac{\pi \cdot \psi_{i}}{180}
$$


O próximo passo é descrever o ângulo $\psi$ entre $0^{\circ}$ e $359^{\circ}$. Inicialmente iremos desenvolver o número de Voltas do Olho $\left(N V_{o}\right)$, dá seguinte maneira:

$$
\begin{aligned}
& N V_{O}=I N T\left(\frac{\theta}{360}\right) \\
& \psi_{e}=\psi-360 . N V
\end{aligned}
$$

Após o cálculo acima é inserido uma seqüência lógica para determinar o Quadrante do Olho $\left(\mathrm{Q}_{\mathrm{o}}\right.$ da seguinte forma:

$$
Q_{o}=\left\{\begin{array}{c}
\operatorname{se} \psi_{e}=0 ; 1^{\circ} \\
\operatorname{se} \psi_{e}<=90 ; 1^{\circ} \\
\operatorname{se} \psi_{e}<=180 ; 2^{\circ} \\
\operatorname{se} \psi_{e}<=270 ; 3^{\circ} \\
\operatorname{se} \psi_{e}<=359 ; 4^{\circ}
\end{array}\right.
$$

Resumindo:

As coordenadas (X, Y e Z) que formam os pontos da trajetória do olho (pay-out) utilizados para visualização 3D e enviados para máquina de Filament Winding são:

$$
\begin{aligned}
& \Delta \mathrm{X}^{\prime}=X^{\prime} P \\
& \Delta \mathrm{Y}^{\prime}=R_{v} \\
& \Delta \mathrm{Z}^{\prime}=R .
\end{aligned}
$$

\subsubsection{Estratégia de Preenchimento das Camadas no Revestimento Circular}

O número de camadas para o preenchimento do cilindro é informado pelo usuário do sistema. Esse número é armazenado em uma variável $N$. Existem somente dois estagios de preenchimento: "ida" e "volta". Se $N=3$, têm-se 2 idas e 1 volta; se N = 4 Têm-se, 2 idas e 2 
voltas e assim por diante. A cada camada preenchida, ou seja, a cada término da ida e da volta o diâmetro do cilindro é adicionado 2 vezes pela espessura do filamento escolhido pelo usuário. A figura 3.27 mostra um esquema da estratégia do revestimento circular.

Para ida segue:

$$
\begin{aligned}
& X=0 \\
& X=X+\left(I_{r c}\right) ; \\
& D=D+2(\text { ef }) ;
\end{aligned}
$$

Para volta temo:

$$
\begin{aligned}
& X=0 \\
& X=X-\left(I_{r c}\right) ; \\
& D=D+2(\text { ef }) ;
\end{aligned}
$$

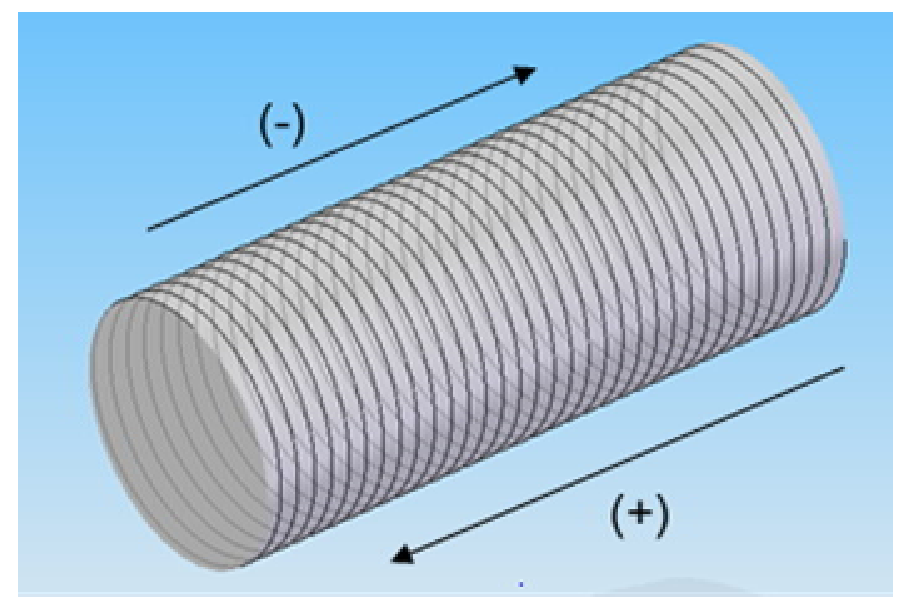

Figura 3.27 - Estratégia de preenchimento circular.

\subsubsection{Revestimento Helicoidal}


Segundo Gomes (2008), o conceito básico do revestimento helicoidal tem sido estendido aos formatos não simétricos. Algoritmos especiais determinam a seqüência adequada para o preenchimento das superfícies mais complexas.

Para determinar o cálculo da trajetória o usuário deve informar o tipo de material que deseja trabalhar. Feito isso o sistema calcula o número de interações até $360^{\circ}$ e o incremento do revestimento, pois os mesmos não são relevantes para esse tipo de revestimento. De acordo com Scholliers (1992), diferentemente do revestimento circular o revestimento helicoidal, não depende do decremento de $\theta$ para determinar o melhor posicionamento das fibras, pois o mesmo é calculado a partir da variável X e do Ângulo $\omega$ (winding angle), da seguinte forma:

$$
\theta=\theta_{0}+\frac{c_{c}\left(x-x_{0}\right)}{r \sqrt{r^{2}-c_{c}^{2}}}=\theta_{0}+\left(x-x_{0}\right) \tan \omega
$$

Os dados de entrada fornecidos pelo usuário são: Diâmetro do Cilindro $(D)$, Ângulo $\theta$, Ângulo $\omega$ (winding angle), Comprimento do Revestimento $\left(C_{r}\right)$, Distância do Olho em Relação ao Cilindro e Incremento de X.

Para que a condição do revestimento helicoidal seja satisfeita, o Ângulo Omega deve respeitar a seguinte condição:

$$
\omega_{i}<\omega<\omega_{f}
$$

Sendo:

$$
\omega_{i}=\arctan \left(\frac{D}{C_{r}}\right)
$$


Onde: $D$ é o diâmetro do cilindro e $C_{r}$ o comprimento.

$$
\omega_{f}=\arctan \left(\frac{\Delta y}{\Delta x}\right)
$$

A figura 3.28 mostra os limites de ângulo para o revestimento helicoidal.

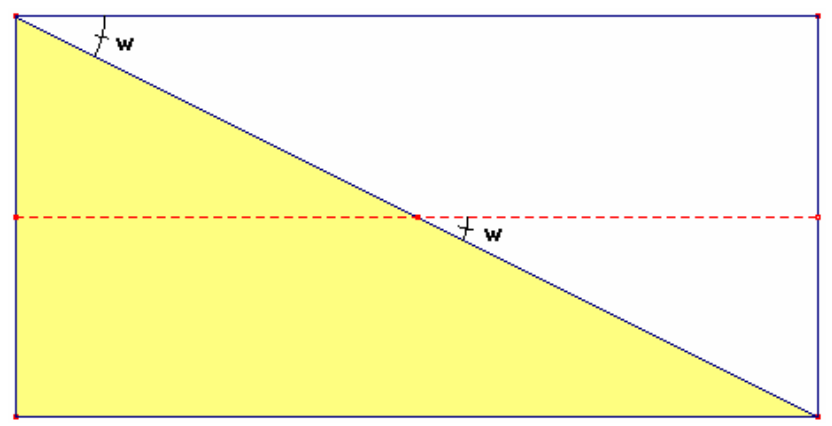

Figura 3.28 - Limite do Ângulo $\omega$ (Fonte: GOMES, 2009).

Com a entrada dos dados, as coordenadas $\mathrm{X}, \mathrm{Y}$ e $\mathrm{Z}$ podem ser calculadas pelo sistema da mesma forma que no revestimento circular.

Assim como no cálculo da trajetória, o cálculo do olho (pay-out) segue o mesmo conceito não dependendo do decremento de $\theta$ para determinar o melhor posicionamento das fibras, pois o mesmo é calculado a partir da variável X e do Ângulo $\omega$ (winding angle), da seguinte forma:

$$
\psi=\psi_{0}+\frac{c_{c}\left(x-x_{0}\right)}{r \sqrt{r^{2}-c_{c}^{2}}}=\psi_{0}+\left(x-x_{0}\right) \tan \omega
$$

Os procedimentos para determinar as coordenadas $\Delta \mathrm{X}^{\prime}, \Delta \mathrm{Y}^{\prime}$ e $\Delta \mathrm{Z}^{\prime}$ são as mesmas do revestimento circular. 


\subsubsection{Revestimento Polar}

Os cálculos do revestimento polar são semelhantes aos cálculos do revestimento helicoidal. A única diferença entre eles é a condição do limite do Ângulo Omega.

Para que a condição do revestimento seja satisfeita, o Ângulo Omega deve respeitar a seguinte condição:

$0<\omega<\omega_{f}$

Sendo:

$$
\omega_{f}=\arctan \left(\frac{D}{C_{r}}\right)
$$

Onde: $D$ é o diâmetro do cilindro e $C_{r}$ o comprimento.

A figura 3.29 mostra os limites de ângulo para o revestimento Polar.

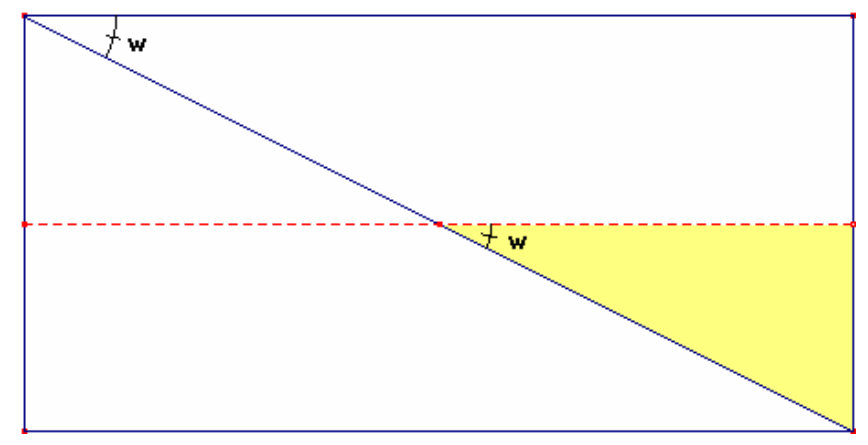

Figura 3.29 - Limite do Ângulo $\omega$ para o Revestimento Polar (Fonte GOMES, 2009).

\subsubsection{Estratégia de Preenchimento das Camadas no Revestimento Helicoidal e Polar}

Nesse trabalho será sugerida uma estratégia de revestimento chamado de "22/45" como mostra a figura 3.30. A cada novo ciclo, o mandril irá gira uma fração de 22/45 ou $172^{\circ}$ 
para iniciar um novo ciclo da trajetória, resultando na seqüência: $1,23,45,22,44,21$, etc. Essa estratégia visa que a cada novo ciclo o próprio filamento se fixe nas extremidades do cilindro, não permitindo que mesmo deslize sobre as extremidades perdendo a geometria desejada. Essa estratégia se repetirá até que a superfície seja revestida completamente.

Para isso criou-se o seguinte algoritmo:

$$
\text { Step }=\operatorname{int}(P I X \text { Raio }) * 2
$$

Sendo: Step a quantidade de idas e voltas necessárias para revestir toda a superfície do cilindro. Para ida o valor da coodenada(x) foi incrementado ao valor determinado pelo usuário. Quando a trajetória da fibra chega à extremidade do cilindro, o ângulo teta sofre um acréscimo de 180 graus.

$$
\begin{aligned}
& \text { Coordenada }(X)=\text { Coordenada }(X) \text { - Incremento } \\
& \text { angulo_teta }=\text { angulo_teta }+180
\end{aligned}
$$

Para volta, o valor da coodenada(x) foi decrementado ao valor determinado pelo usuário. Quando a trajetória da fibra chega à outra extremidade do cilindro, o ângulo teta sofre um acréscimo de 180 graus mais a espessura do filamento, fazendo com que a fibra siga novamente o mesmo caminho ao lado da outra fibra. Como mostra a figura 3.31

$$
\begin{aligned}
& \text { Coordenada }(X)=\text { Coordenada }(X) \text { - Incremento } \\
& \text { angulo_teta }=\text { angulo_teta }+180+\text { fibra }
\end{aligned}
$$




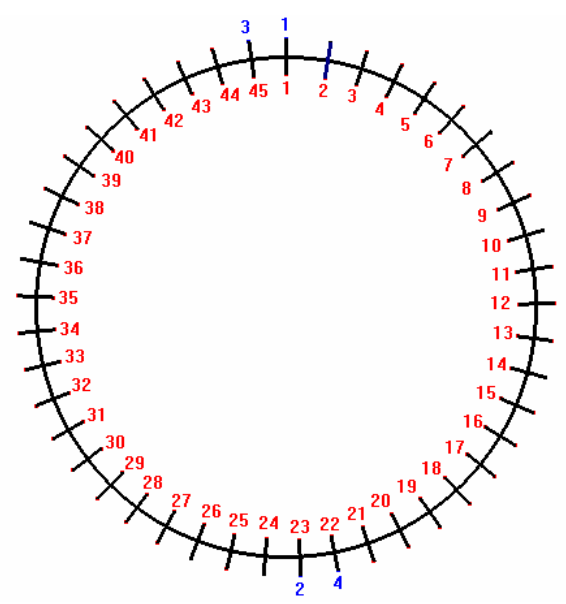

Figura 3.30 - Estratégia de divisão dos Steps. (Fonte: GOMES, 2009)

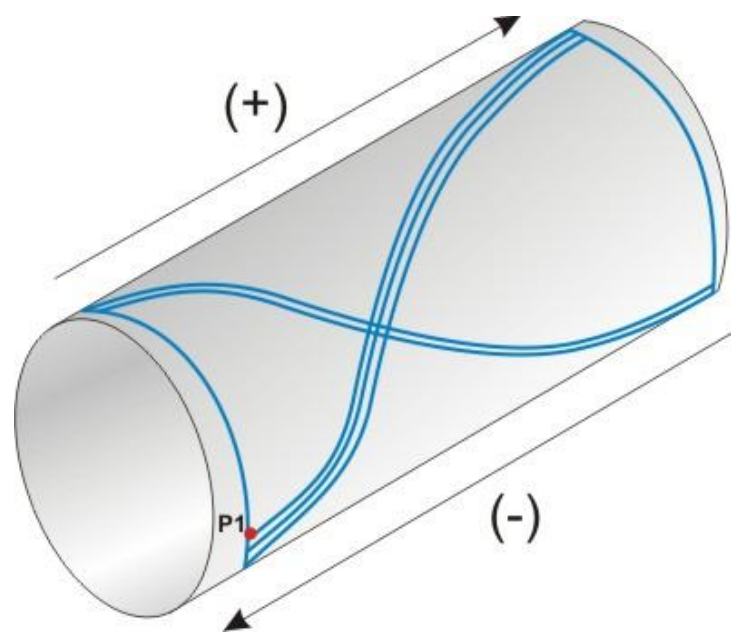

Figura 3.31 - Estratégia de Revestimento Helicoidal e Polar. 


\section{CAPÍTULO 4}

\section{ESTUDO DE CASO}

No capítulo 3 foi apresentado a implementação do sistema computacional para cálculo das trajetórias SISCAWIND, detalhando o funcionamento individual do módulo de revestimento circular, helicoidal e polar. Neste capítulo são descritos os resultados obtidos na realização dos cálculos em cada módulo, apresentando uma análise dos resultados.

\subsection{INTRODUÇÃO}

O sistema computacional SISCAWIND tem por objetivo calcular as coordenadas X, $\mathrm{Y}$ e $\mathrm{Z}$ que formam a trajetória da fibra no processo de Filament Winding. Essa trajetória é orientada, através do olho pay-out da máquina de Filament Winding, caracterizada pelo comprimento e o diâmetro do mandril.

Para realizar o cálculo de uma trajetória no software, o usuário deve informar ao sistema a espessura do material que irá utilizar, o número de fios que formará a malha de revestimento, o diâmetro do cilindro, o ângulo teta, o comprimento do cilindro, à distância do olho, a precisão dos pontos, o ângulo winding em caso de revestimentos helicoidal ou polar e o número de camadas utilizadas para compor o revestimento.

Os valores calculados pelo software são salvos em um banco de dados Access, podendo ser exportado para o formato de arquivo compatível com o Microsoft Excel 
(extensão xls), padrão utilizado para visualização de uma matriz de pontos no software CAD Solid Edge. Esse software permite a visualização dos pontos formados pelas coordenadas X, $\mathrm{Y}$ e $\mathrm{Z}$ em formato 3D.

\subsection{Testes de validação}

A metodologia utilizada para realização dos testes de validação consiste em simular o cálculo da superfície dos cilindros através do software SISCAWIND, comparando os valores obtidos com os valores esperados, gerados pela planilha eletrônica desenvolvida por Gomes (2009). Os valores obtidos através dos cálculos do programa, são interpretados pelo software CAD Solid Edge, dessa forma, pode-se comparar graficamente a simulação do resultado real das medidas da superfície do sólido como, por exemplo: diâmetro e comprimento.

\subsubsection{Aplicação do Teste no Revestimento Circular}

Primeiramente foi definido um padrão de teste contendo as seguintes características:

- Material utilizado: Fibra de 3000 filamentos contendo o diâmetro de 0,390 oferecido pelo fabricante HECXEL®;

- Diâmetro do cilindro: 20 milímetros;

- Comprimento do cilindro: 100 milímetros;

- O ponto inicial do cálculo: ângulo de 90 graus;

- Distância do olho pay-out: 50 milímetros;

- Decremento de teta (precisão entre os pontos): 5;

- Número de camadas: 3 . 
Após o término do cálculo o software apresenta os valores do resultado da trajetória do cilindro e do olho (pay-out):

1. Número da Interação;

2. Coordenada X;

3. Coordenada Y;

4. Coordenada Z;

5. Ângulo Teta;

6. Posição do Quadrante;

7. Total de Interações;

8. Valor do Incremento;

9. Valor do Raio Inicial e Final;

10. Ângulo Winding;

11. Valor do Passo;

12. Delta $X$;

13. Delta Y;

14. Delta X;

A figura 4.1 mostra o formulário de cálculo do revestimento circular com os valores de entrada descritos acima. O total de interações, representa o número de pontos formados pelas coordenadas $\mathrm{X}, \mathrm{Y}$ e Z. No caso do exemplo, foram necessários 55386 pontos para formar a trajetória. O Ângulo Winding com valor 89,44 comprovando os resultados dos cálculos, sendo que, para o revestimento circular o Ângulo Winding deve ser próximo aos $90^{\circ}$. O mesmo acontece com o valor do passo. Esse valor deve ser igual ao valor da espessura do filamento no caso $0,390 \mathrm{~mm}$. O raio final do cilindro tem valor 10,78 devido as duas camadas 
$(0,390 \mathrm{~mm})$ revestidas sob a primeira. $\Delta \mathrm{X}$ é calculado pela equação (3.27) demonstrada no capítulo anterior, $\Delta \mathrm{Y}$ é igual ao raio virtual e $\Delta \mathrm{Z}$ igual ao raio.

Esses valores são informados nos três tipos de revestimento, por isso nos próximos cálculos não serão citados.

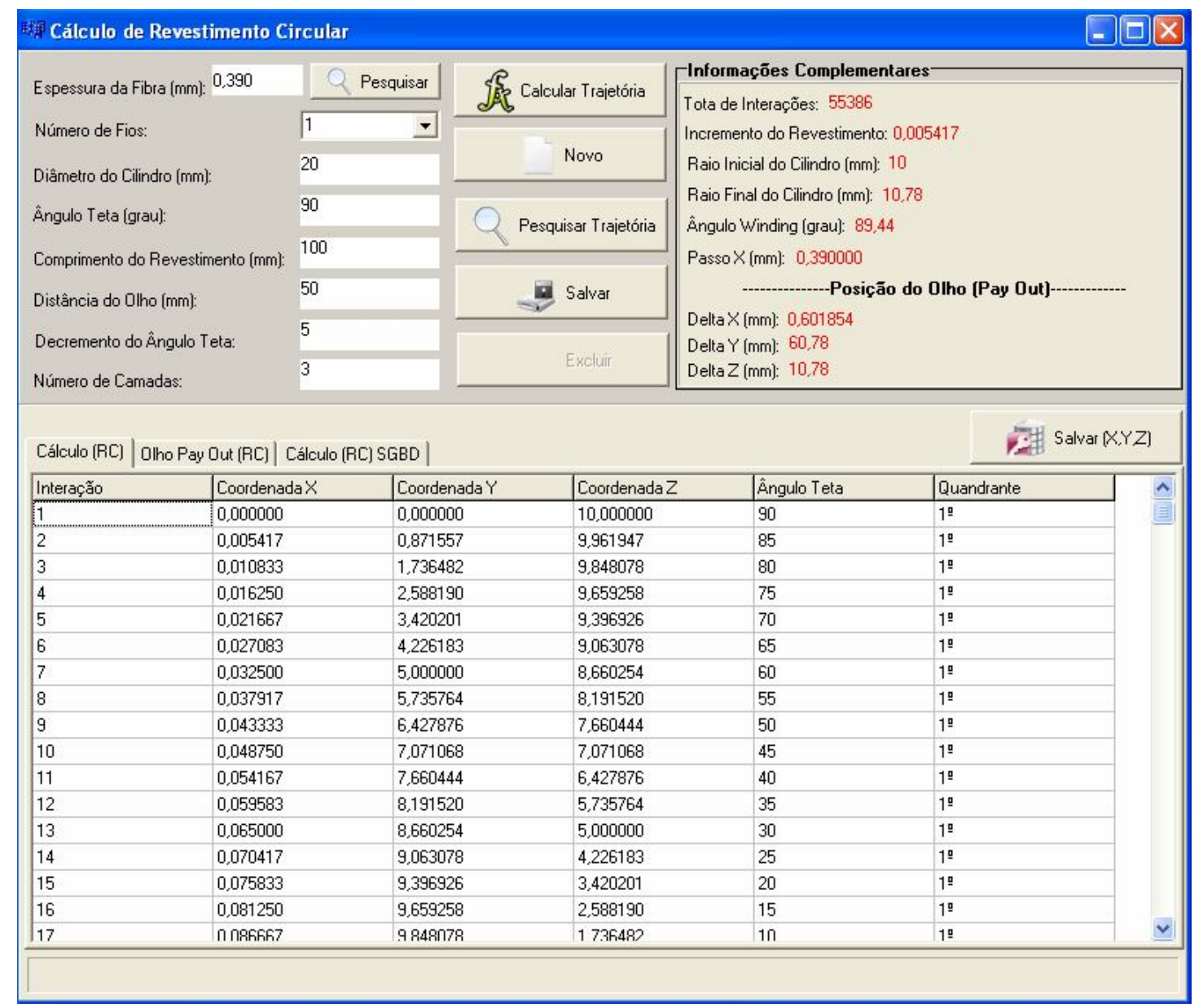

Figura 4.1 - Caso de teste do revestimento circular.

A planilha de cálculos desenvolvida por Gomes (2009), e utilizada como parâmetro de comparação, contem os resultado obtidos através dos mesmos dados de entrada utilizados no SISCAWIND. O resultado da planilha pode ser visto na figura 4.2. 


\begin{tabular}{|c|c|c|c|c|c|}
\hline \multirow{3}{*}{$\begin{array}{l}\text { Números } \\
\text { de } \\
\text { Iteraçốes }\end{array}$} & \multicolumn{5}{|c|}{ Resultados dos Cálculos: } \\
\hline & Raio $r(x)$ & 10,00 & \multirow[b]{2}{*}{ Coordenada Z } & \multirow[b]{2}{*}{ Ângulo (Teta) } & \multirow[b]{2}{*}{ Quadrante } \\
\hline & Coordenada $X$ & Coordenada $Y$ & & & \\
\hline 1 & 0,000000 & 0,000000 & 10,000000 & 90 & $1^{\circ}$ \\
\hline 2 & 0,005417 & 0,871557 & 9,961947 & 85 & $1^{\circ}$ \\
\hline 3 & 0,010833 & 1,736482 & 9,848078 & 80 & $1^{\circ}$ \\
\hline 4 & 0,016250 & 2,588190 & 9,659258 & 75 & $1^{\circ}$ \\
\hline 5 & 0,021667 & 3,420201 & 9,396926 & 70 & $1^{\circ}$ \\
\hline 6 & 0,027083 & 4,226183 & 9,063078 & 65 & $1^{\circ}$ \\
\hline 7 & 0,032500 & 5,000000 & 8,660254 & 60 & $1^{\circ}$ \\
\hline 8 & 0,037917 & 5,735764 & 8,191520 & 55 & $1^{\circ}$ \\
\hline 9 & 0,043333 & 6,427876 & 7,660444 & 50 & $1^{\circ}$ \\
\hline 10 & 0,048750 & 7,071068 & 7,071068 & 45 & $1^{\circ}$ \\
\hline 11 & 0,054167 & 7,660444 & 6,427876 & 40 & $1^{\circ}$ \\
\hline 12 & 0,059583 & 8,191520 & 5,735764 & 35 & $1^{\circ}$ \\
\hline 13 & 0,065000 & 8,660254 & 5,000000 & 30 & $1^{\circ}$ \\
\hline 14 & 0,070417 & 9,063078 & 4,226183 & 25 & $1^{\circ}$ \\
\hline 15 & 0,075833 & 9,396926 & 3,420201 & 20 & $1^{\circ}$ \\
\hline 16 & 0,081250 & 9,659258 & 2,588190 & 15 & $1^{\circ}$ \\
\hline 17 & 0,086667 & 9,848078 & 1,736482 & 10 & $1^{\circ}$ \\
\hline 18 & 0,092083 & 9,961947 & 0,871557 & 5 & $1^{\circ}$ \\
\hline 19 & 0,097500 & 10,000000 & 0,000000 & 0 & $1^{\circ}$ \\
\hline 20 & 0,102917 & 9,961947 & $-0,871557$ & -5 & $4^{\circ}$ \\
\hline 21 & 0,108333 & 9,848078 & $-1,736482$ & -10 & $4^{\circ}$ \\
\hline 22 & 0,113750 & 9,659258 & $-2,588190$ & -15 & $4^{\circ}$ \\
\hline 23 & 0,119167 & 9,396926 & $-3,420201$ & -20 & $4^{\circ}$ \\
\hline 24 & 0,124583 & 9,063078 & $-4,226183$ & -25 & $4^{\circ}$ \\
\hline 25 & 0,130000 & 8,660254 & $-5,000000$ & -30 & $4^{\circ}$ \\
\hline 26 & 0,135417 & 8,191520 & $-5,735764$ & -35 & $4^{\circ}$ \\
\hline 27 & 0,140833 & 7,660444 & $-6,427876$ & -40 & $4^{\circ}$ \\
\hline 28 & 0,146250 & 7,071068 & $-7,071068$ & -45 & $4^{\circ}$ \\
\hline
\end{tabular}

Figura 4.2 - Planilha de cálculo do revestimento circular (Fonte: GOMES, 2009).

Os valores obtidos pelo sistema SISCAWIND do cálculo do olho (pay-out) são mostrados na figura 4.3 .

\begin{tabular}{|c|c|c|c|c|c|c|}
\hline \multirow{2}{*}{$\begin{array}{l}\text { Cálculo (RC) } \\
\text { Interação }\end{array}$} & \multicolumn{4}{|c|}{ Olho Pay Out (RC) | Cálculo (RC) SGBD | } & \multicolumn{2}{|c|}{ Fifle Salvar $(X Y Z)$} \\
\hline & Coordenada X & Coordenada $Y$ & Coordenada Z & Ângulo Psi & Quandrante & $\hat{\Lambda}$ \\
\hline 1 & 0,593069 & 60,000000 & 10,000000 & 9,462322 & $1^{9}$ & \\
\hline 2 & 0,598486 & 60,643239 & 4,732602 & 4,462322 & $1^{\underline{9}}$ & \\
\hline 3 & 0,603903 & 60,824947 & $-0,570813$ & $-0,537678$ & $1^{\underline{9}}$ & \\
\hline 4 & 0,609319 & 60,543740 & $-5,869884$ & 354,462322 & $4^{9}$ & \\
\hline 5 & 0,614736 & 59,801759 & $-11,124282$ & 349,462322 & $4^{a}$ & \\
\hline 6 & 0,620153 & 58,604650 & $-16,294018$ & 344,462322 & $4^{a}$ & \\
\hline 7 & 0,625569 & 56,961524 & $-21,339746$ & 339,462322 & $4^{a}$ & \\
\hline 8 & 0,630986 & 54,884887 & $-26,223066$ & 334,462322 & $4=$ & \\
\hline 9 & 0,636403 & 52,390543 & $-30,906812$ & 329,462322 & 49 & \\
\hline 10 & 0,641819 & 49,497475 & $-35,355339$ & 324,462322 & $4^{9}$ & \\
\hline 11 & 0,647236 & 46,227701 & $-39,534790$ & 319,462322 & $4=$ & \\
\hline 12 & 0,652653 & 42,606107 & $-43,413358$ & 314,462322 & $4=$ & \\
\hline 13 & 0,658069 & 38,660254 & $-46,961524$ & 309,462322 & $4^{a}$ & \\
\hline 14 & 0,663486 & 34,420174 & $-50,152285$ & 304,462322 & $4^{9}$ & \\
\hline 15 & 0,668903 & 29,918135 & $-52,961356$ & 299,462322 & $4^{9}$ & \\
\hline 16 & 0,674319 & 25,188401 & $-55,367359$ & 294,462322 & $4^{a}$ & \\
\hline 17 & ก 67.9736 & 2ก 2fF.9FR & .57 .351 .98 .3 & 2894462.372 & 49 & $\underline{v}$ \\
\hline
\end{tabular}

Figura 4.3 - Valores do olho (pay-out) no revestimento circular. 
Os valores do cálculo do olho (pay-out) obtidos através da planilha de Gomes (2009) são apresentados na figura 4.4 .

\begin{tabular}{|c|c|c|c|c|c|}
\hline \multirow{6}{*}{$\begin{array}{l}\text { Números } \\
\text { de } \\
\text { lteraçốes }\end{array}$} & \multicolumn{5}{|c|}{ Cálculos da Posição do Olho (Pay-out): } \\
\hline & Diâmetro $d(x)$ & \multicolumn{2}{|l|}{20,00} & & Tipos de Revestimento \\
\hline & \multirow{3}{*}{ Ponto Inicial } & & & & \\
\hline & & $x^{\prime}$ & $Y^{\prime}$ & $Z^{\prime}$ & Distância do Cilindro \\
\hline & & 0,5931 & 60,0000 & 10,0000 & 50 \\
\hline & Coordenada $X^{\prime}$ & Coordenada $Y^{\prime}$ & Coordenada Z' & Quadrante & Ángulo $\psi$ \\
\hline 1 & 0,593069 & 60,000000 & 10,000000 & $\mid 1^{\circ}$ & 9,4623 \\
\hline 2 & 0,598486 & 60,643239 & 4,732602 & $1^{\circ}$ & 4,4623 \\
\hline 3 & 0,603903 & 60,824947 & $-0,570813$ & $4^{\circ}$ & 359,4623 \\
\hline 4 & 0,609319 & 60,543740 & $-5,869884$ & $4^{\circ}$ & 354,4623 \\
\hline 5 & 0,614736 & 59,801759 & $-11,124282$ & $4^{\circ}$ & 349,4623 \\
\hline 6 & 0,620153 & 58,604650 & $-16,294018$ & $4^{\circ}$ & 344,4623 \\
\hline 7 & 0,625569 & 56,961524 & $-21,339746$ & $4^{\circ}$ & 339,4623 \\
\hline 8 & 0,630986 & 54,884887 & $-26,223066$ & $4^{\circ}$ & 334,4623 \\
\hline 9 & 0,636403 & 52,390543 & $-30,906812$ & $4^{\circ}$ & 329,4623 \\
\hline 10 & 0,641819 & 49,497475 & $-35,355339$ & $4^{\circ}$ & 324,4623 \\
\hline 11 & 0,647236 & 46,227701 & $-39,534790$ & $4^{\circ}$ & 319,4623 \\
\hline 12 & 0,652653 & 42,606107 & $-43,413358$ & $4^{\circ}$ & 314,4623 \\
\hline 13 & 0,658069 & 38,660254 & $-46,961524$ & $4^{\circ}$ & 309,4623 \\
\hline 14 & 0,663486 & 34,420174 & $-50,152285$ & $4^{\circ}$ & 304,4623 \\
\hline 15 & 0,668903 & 29,918135 & $-52,961356$ & $4^{\circ}$ & 299,4623 \\
\hline 16 & 0,674319 & 25,188401 & $-55,367359$ & $4^{\circ}$ & 294,4623 \\
\hline 17 & 0,679736 & 20,266968 & $-57,351983$ & $4^{\circ}$ & 289,4623 \\
\hline 18 & 0,685153 & 15,191292 & $-58,900124$ & $4^{\circ}$ & 284,4623 \\
\hline 19 & 0,690569 & 10,000000 & $-60,000000$ & $4^{\circ}$ & 279,4623 \\
\hline 20 & 0,695986 & 4,732602 & $-60,643239$ & $4^{\circ}$ & 274,4623 \\
\hline 21 & 0,701403 & $-0,570813$ & $-60,824947$ & $3^{\circ}$ & 269,4623 \\
\hline 22 & 0,706819 & $-5,869884$ & $-60,543740$ & $3^{\circ}$ & 264,4623 \\
\hline 23 & 0,712236 & $-11,124282$ & $-59,801759$ & $3^{\circ}$ & 259,4623 \\
\hline 24 & 0,717653 & $-16,294018$ & $-58,604650$ & $3^{\circ}$ & 254,4623 \\
\hline 25 & 0,723069 & $-21,339746$ & $-56,961524$ & $3^{\circ}$ & 249,4623 \\
\hline 26 & 0,728486 & $-26,223066$ & $-54,884887$ & $3^{\circ}$ & 244,4623 \\
\hline 27 & 0.733903 & $-30,906812$ & $-52,390543$ & $3^{\circ}$ & 239.4623 \\
\hline
\end{tabular}

Figura 4.4 - Valores do olho (pay-out) no revestimento circular (Fonte: GOMES, 2009).

A figura 4.5 (a) e (b) mostra o resultado gerado pelo software CAD Solid Edge na interpretação dos valores $\mathrm{X}, \mathrm{Y}$ e Z apresentados pelo SISCAWIND. 


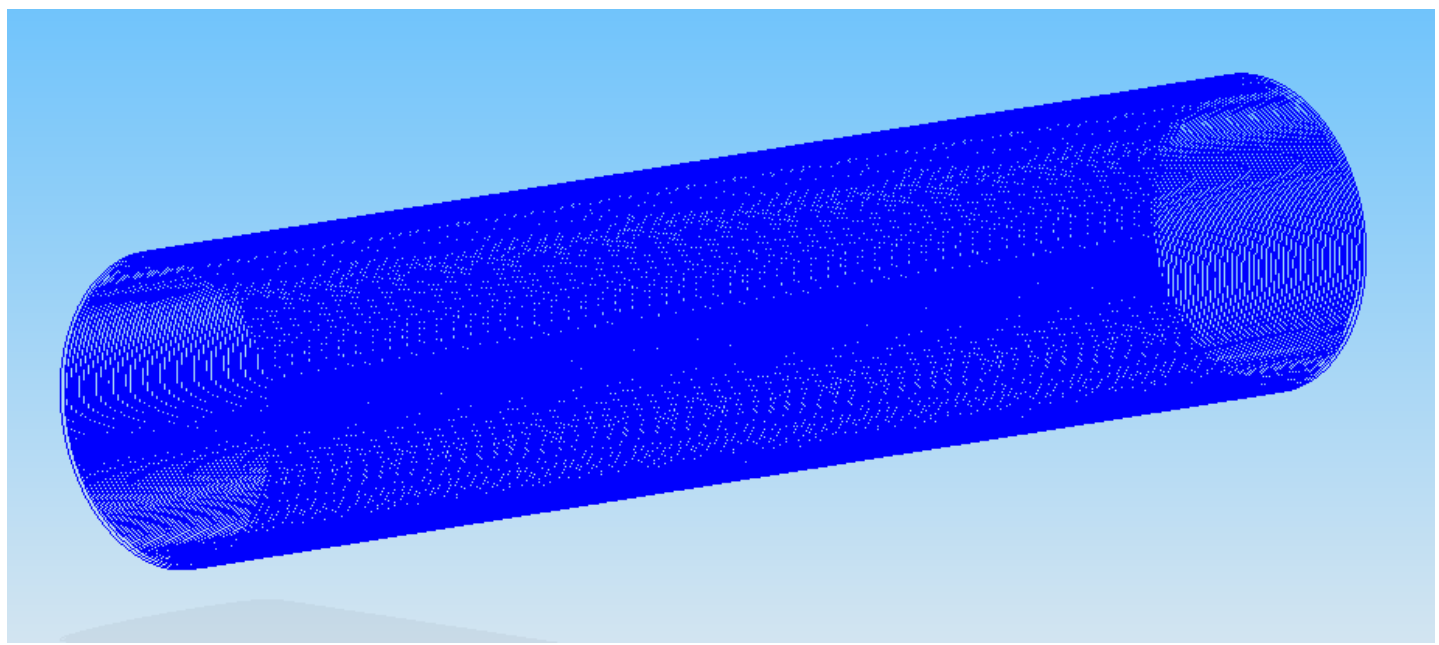

Figura 4.5(a) - Revestimento Circular.

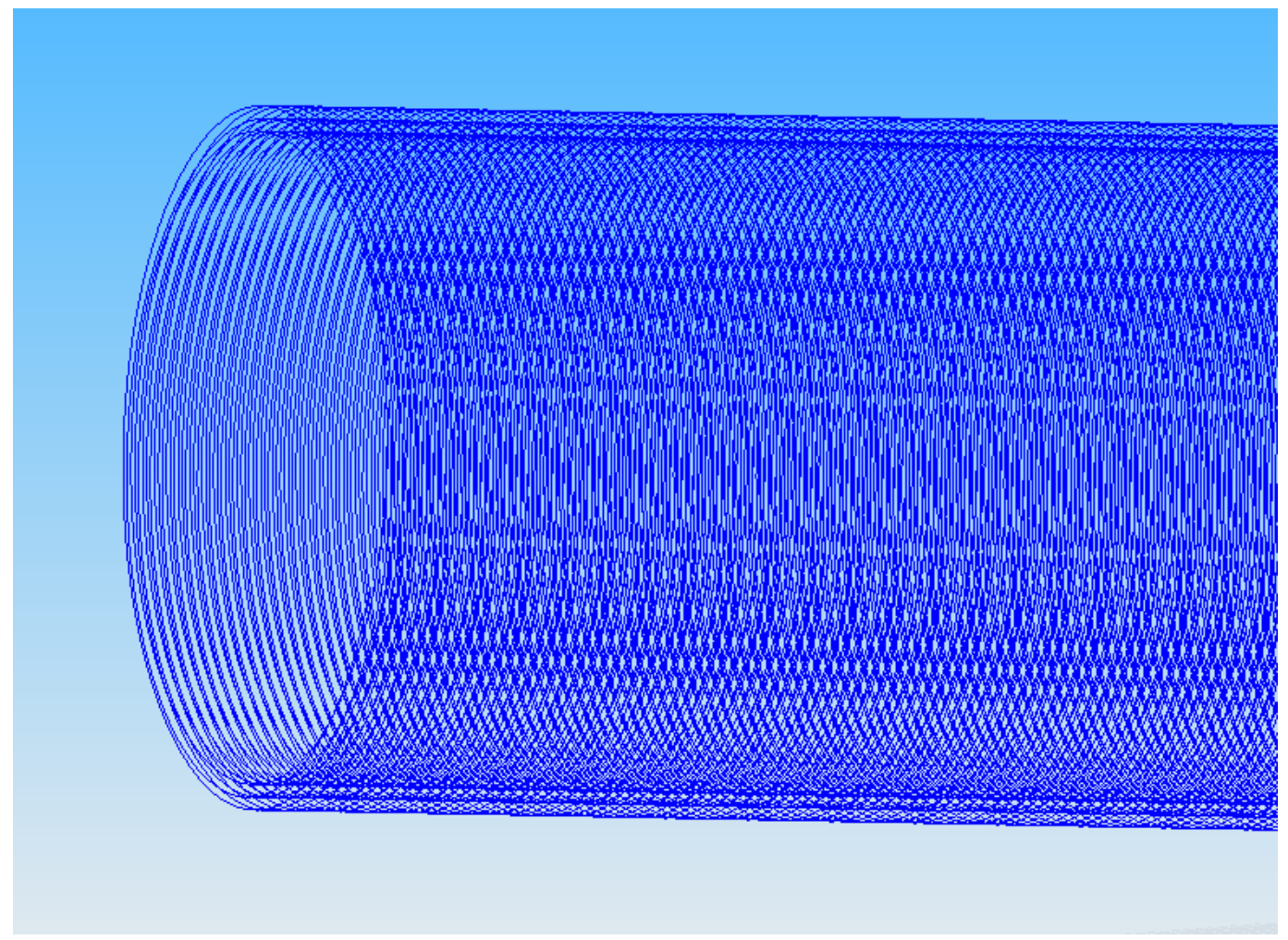

Figura 4.5(b) - Revestimento Circular Ampliada.

Como pode-se perceber, os valores obtidos pelas coordenadas $\mathrm{X}, \mathrm{Y}$ e $\mathrm{Z}$, representando a superfície do cilindro e a trajetória do olho (pay-out), apresentam os mesmos 
resultados tanto no software SISCAWIND quanto na planilha de Gomes (2009), o que valida os procedimentos de cálculos implementados no SISCAWIND.

A exatidão dos pontos gerados pelo software foi comprovada com a qualidade visual do desenho 3D. A figura 4.5(b) mostra claramente a forma circular da trajetória e suas respectivas camadas, o que comprova visualmente a eficaz dos cálculos.

\subsubsection{Aplicação do Teste no Revestimento Helicoidal}

A definição dos dados de entrada para o cálculo do cilindro foi:

- Material utilizado: Fibra AS4 de 3000 filamentos contendo o diâmetro de 0,390

- Diâmetro do cilindro: 20 milímetros;

- Comprimento do cilindro: 150 milímetros;

- O ponto inicial do cálculo: ângulo de 60 graus;

- Distância do olho pay-out: 50 milímetros;

- Incremento para coordenada $(\mathrm{X})$ : 1 ;

- Número de camadas: 1.

Após o término dos cálculos, os resultados obtidos são indicados na figura 4.6: 


\begin{tabular}{|c|c|c|c|c|c|c|}
\hline \multicolumn{5}{|c|}{ Cálculo (RC) | Otho Pay Out (RC)| } & \multicolumn{2}{|c|}{ Nalle Salvar $(X, Y Z)$} \\
\hline Interação & CoordenadaX & Coordenada Y & Coordenada Z & Ângulo Teta & Quandrante & $\wedge$ \\
\hline 1 & 0,000000 & 5,000000 & 8,660254 & 60 & $1^{0}$ & 目 \\
\hline 2 & 1,000000 & 5,831341 & 8.123759 & 54,3287181803823 & $1^{\underline{9}}$ & \\
\hline 3 & 2,000000 & 6,605596 & 7,507736 & 48,6574363607646 & $1^{\underline{9}}$ & \\
\hline 4 & 3,000000 & 7,315185 & 6,818216 & 42,9861545411469 & $1^{\underline{9}}$ & \\
\hline 5 & 4,000000 & 7,953162 & 6,061949 & 37,3148727215292 & $1^{\underline{9}}$ & \\
\hline 6 & 5,000000 & 8,513280 & 5,246338 & 31,6435909019115 & $1^{\underline{9}}$ & \\
\hline 7 & 6,000000 & 8,990058 & 4,379367 & 25,9723090822938 & 19 & \\
\hline 8 & 7,000000 & 9,378827 & 3,469525 & 20,3010272626761 & 19 & \\
\hline 9 & 8,000000 & 9,675782 & 2,525717 & 14,6297454430584 & 19 & \\
\hline 10 & 9.000000 & 9,878015 & 1,557184 & 8,95846362344065 & 19 & \\
\hline 11 & 10,000000 & 9,983547 & 0,573407 & 3,28718180382294 & 19 & \\
\hline 12 & 11,000000 & 9,991344 & $-0,415984$ & $-2,38410001579477$ & $4^{9}$ & \\
\hline 13 & 12,000000 & 9,901331 & $-1,401302$ & $-8,05538183541247$ & $4^{9}$ & \\
\hline 14 & 13,000000 & 9,714388 & $.2,372902$ & $-13,7266636550302$ & 49 & \\
\hline 15 & 14,000000 & 9,432346 & $-3,321273$ & $-19,3979454746479$ & 49 & \\
\hline 16 & 15,000000 & 9,057965 & $-4,237130$ & $-25,0692272942656$ & 49 & $v$ \\
\hline
\end{tabular}

Figura 4.6- Valores das coordenadas X, Y e Z resultado do revestimento helicoidal.

Na figura 4.7 são indicados os valores do cálculo da trajetória do cilindro obtidos através da planilha de Gomes (2009).

\begin{tabular}{|c|c|c|c|c|c|}
\hline \multirow{3}{*}{$\begin{array}{c}\text { Números } \\
\text { de } \\
\text { theraçổes }\end{array}$} & \multicolumn{5}{|c|}{ Resultados dos Cálculos: } \\
\hline & Raio $r(x)$ & \multicolumn{2}{|l|}{10,00} & \multirow[b]{2}{*}{ Ângulo (Teta) } & \multirow[b]{2}{*}{ Quadrante } \\
\hline & Coordenada $X$ & Coordenada $Y$ & Coordenada Z & & \\
\hline 1 & 0,000000 & 5,000000 & 8,660254 & | 60 & $1^{\circ}$ \\
\hline 2 & 1,000000 & 5,831341 & 8,123759 & 54 & $1^{\circ}$ \\
\hline 3 & 2,000000 & 6,605596 & 7,507736 & 49 & $1^{\circ}$ \\
\hline 4 & 3,000000 & 7,315185 & 6,818216 & 43 & $1^{\circ}$ \\
\hline 5 & 4,000000 & 7,953162 & 6,061949 & 37 & $1^{\circ}$ \\
\hline 6 & 5,000000 & 8,513280 & 5,246338 & 32 & $1^{\circ}$ \\
\hline 7 & 6,000000 & 8.990058 & 4,379367 & 26 & $1^{\circ}$ \\
\hline 8 & 7,000000 & 9,378827 & 3,469525 & 20 & $1^{\circ}$ \\
\hline 9 & 8,000000 & 9.675782 & 2,525717 & 15 & $1^{\circ}$ \\
\hline 10 & 9,000000 & 9,878015 & 1,557184 & 9 & $1^{\circ}$ \\
\hline 11 & 10,000000 & 9,983547 & 0,573407 & 3 & $1^{\circ}$ \\
\hline 12 & 11,000000 & 9,991344 & $-0,415984$ & -2 & $4^{\circ}$ \\
\hline 13 & 12,000000 & 9,901331 & $-1,401302$ & -8 & $4^{\circ}$ \\
\hline 14 & 13,000000 & 9,714388 & $-2,372902$ & -14 & $4^{\circ}$ \\
\hline 15 & 14,000000 & 9,432346 & $-3,321273$ & -19 & $4^{\circ}$ \\
\hline 16 & 15,000000 & 9,057965 & $-4,237130$ & -25 & $4^{\circ}$ \\
\hline 17 & 16,000000 & 8,594911 & $-5,111507$ & -31 & $4^{\circ}$ \\
\hline 18 & 17,000000 & 8,047717 & $-5,935845$ & -36 & $4^{\circ}$ \\
\hline 19 & 18,000000 & 7,421739 & $-6,702074$ & -42 & $4^{\circ}$ \\
\hline 20 & 19,000000 & 6,723105 & $-7,402692$ & -48 & $4^{\circ}$ \\
\hline 21 & 20,000000 & 5,958656 & $-8,030842$ & -53 & $4^{\circ}$ \\
\hline 22 & 21,000000 & 5,135874 & $-8,580373$ & -59 & $4^{\circ}$ \\
\hline 23 & 22,000000 & 4,262814 & $-9,045906$ & -65 & $4^{\circ}$ \\
\hline 24 & 23,000000 & 3,348023 & $-9,422884$ & -70 & $4^{\circ}$ \\
\hline & & & & & \\
\hline
\end{tabular}

Figura 4.7 - Valores das coordenadas X, Y e Z resultado do revestimento helicoidal. (Fonte GOMES, 2009).

Da mesma forma que no revestimento circular, o revestimento helicoidal apresentou resultados satisfatórios com relação aos valores obtidos. Tanto o software quanto a planilha demonstraram os mesmos resultados para as coordenadas X, Y e Z. 


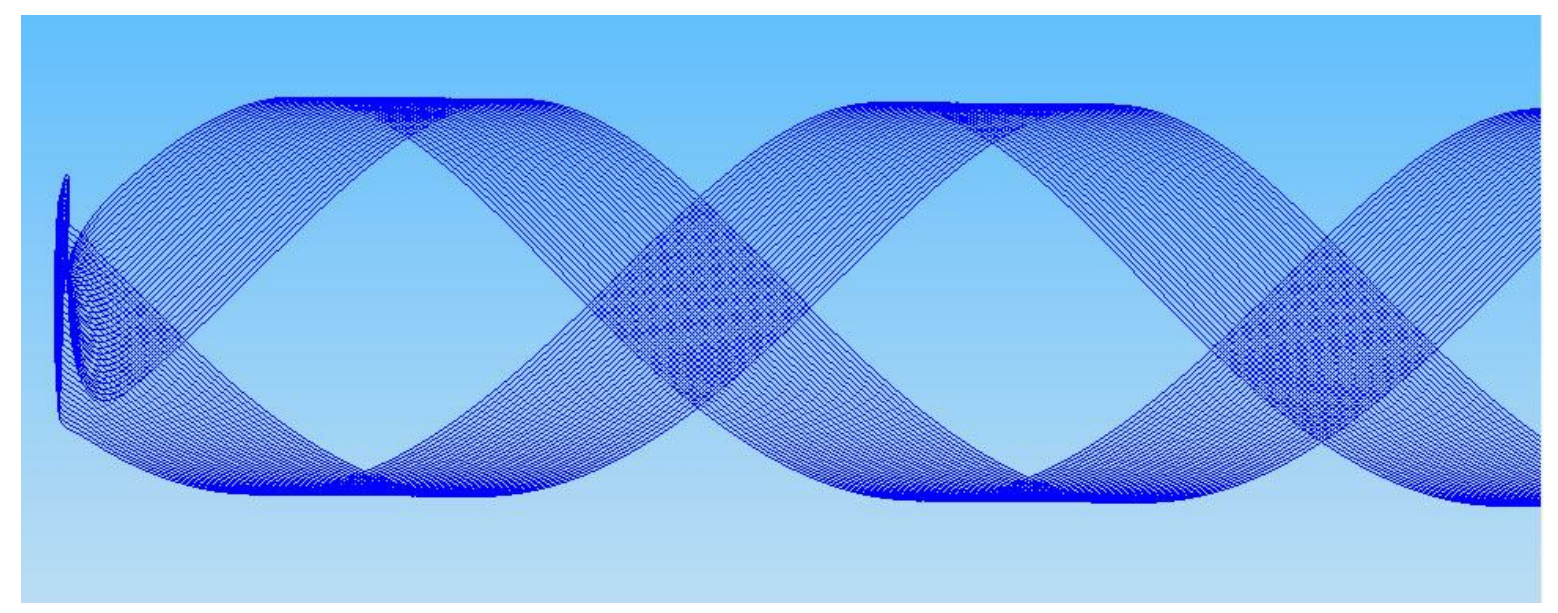

Figura 4.8(a) - Revestimento Helicoidal em Andamento

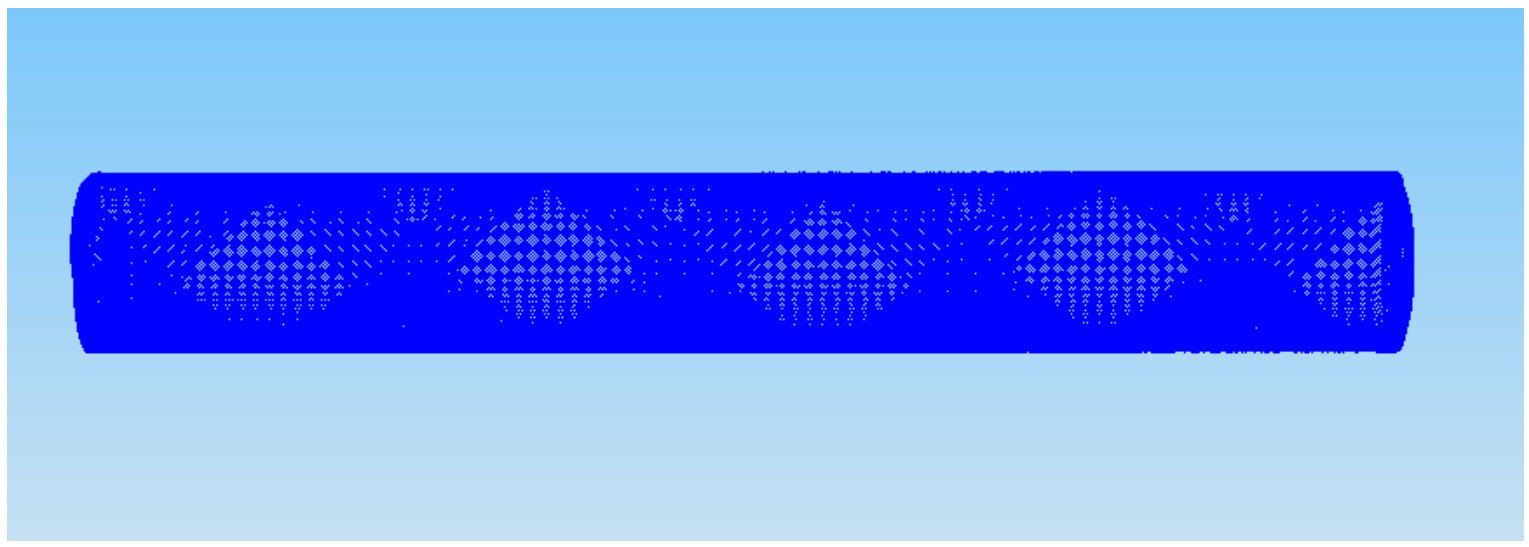

Figura 4.8(b) - Revestimento Helicoidal Finalizado. 


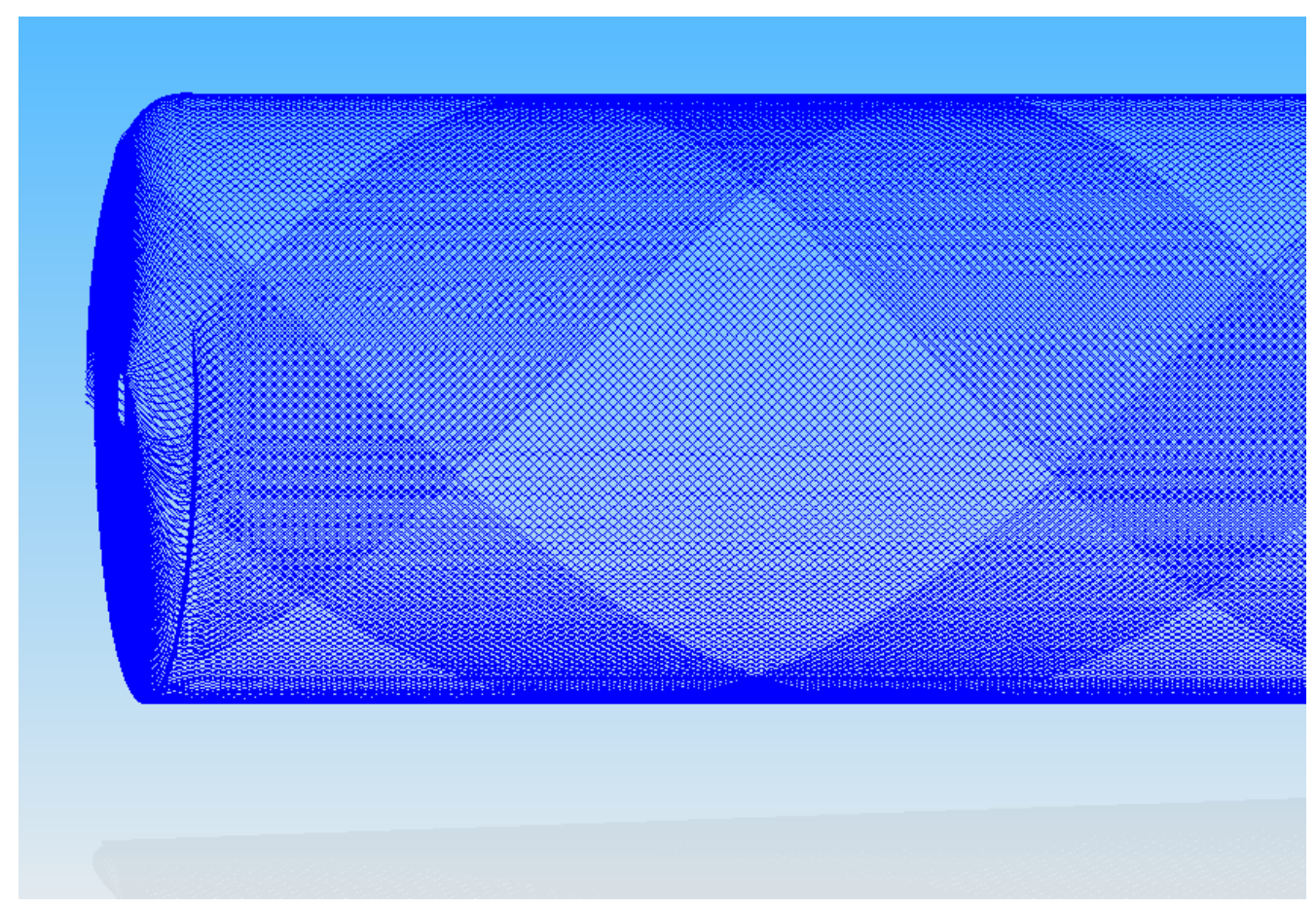

Figura 4.8(c) - Revestimento Helicoidal Ampliado.

As figuras 4.8 (a), 4.8 (b) e 4.8 (c) mostram claramente a compatibilidade dos resultados obtidos com relação à obtenção dos pontos no revestimento helicoidal. Como podemos observar, o desenho da trajetória apresentou uma geodésica sem acúmulo de pontos, o que demonstra a precisão da confecção da malha.

\subsubsection{Aplicação do Teste no Revestimento Polar}

A definição dos dados de entrada do cilindro para o revestimento polar foi:

- Material utilizado: Fibra AS4 de 3000 filamentos contendo o diâmetro de 0,390 ;

- Diâmetro do cilindro: 20 milímetros;

- Comprimento do cilindro: 100 milímetros;

- $\quad$ O ponto inicial do cálculo: ângulo de 3 graus; 
- Distância do olho pay-out: 50 milímetros;

- $\quad$ Incremento para coordenada (X): 1;

- $\quad$ Número de camadas: 1.

Com o término do cálculo, foi apresentado o seguinte resultado para o revestimento polar:

\begin{tabular}{|c|c|c|c|c|c|c|}
\hline \multicolumn{3}{|c|}{ Cálculo (RC) | Olho Pay Out (RC) | } & \multirow[b]{2}{*}{ CoordenadaZ } & \multirow[b]{2}{*}{ Ângulo Teta } & \multicolumn{2}{|c|}{ Vilf Salvar $(X, Y Z)$} \\
\hline Interação & Coordenada $X$ & Coordenada Y & & & Quandrante & $\hat{\wedge}$ \\
\hline 1 & 0,000000 & 5,000000 & 8,660254 & 60 & 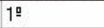 & 非 \\
\hline 2 & 1,000000 & 5,007919 & 8.655677 & 59,947592220717 & $1^{0}$ & \\
\hline 3 & 2,000000 & 5,015834 & 8,651093 & 59,8951844414339 & $1^{0}$ & \\
\hline 4 & 3,000000 & 5,023745 & 8,646501 & 59,8427766621509 & $1^{\underline{9}}$ & \\
\hline 5 & 4,000000 & 5,031652 & 8,641902 & 59,7903688828678 & $1^{0}$ & \\
\hline 6 & 5,000000 & 5,039555 & 8,637296 & 59,7379611035848 & $1^{\underline{a}}$ & \\
\hline 7 & 6,000000 & 5,047453 & 8.632683 & 59,6855533243017 & $1^{9}$ & \\
\hline 8 & 7,000000 & 5,055347 & 8,628063 & 59,6331455450187 & $1^{9}$ & \\
\hline 9 & 8,000000 & 5,063237 & 8,623435 & 59,5807377657357 & 19 & \\
\hline 10 & 9,000000 & 5,071123 & 8,618800 & 59,5283299864526 & $1^{n}$ & \\
\hline 11 & 10,000000 & 5,079004 & 8,614158 & 59,4759222071696 & $1^{9}$ & \\
\hline 12 & 11,000000 & 5,086881 & 8,609509 & 59,4235144278865 & $1^{9}$ & \\
\hline 13 & 12,000000 & 5,094754 & 8,604852 & 59,3711066486035 & $1^{n}$ & \\
\hline 14 & 13,000000 & 5.102623 & 8.600188 & 59,3186988693204 & 19 & \\
\hline 15 & 14,000000 & 5,110487 & 8.595518 & 59,2662910900374 & $1^{9}$ & \\
\hline 16 & 15,000000 & 5,118347 & 8,590839 & 59,2138833107543 & $1^{n}$ & v \\
\hline
\end{tabular}

Figura 4.9 - Valores das coordenadas X, Y e Z resultado do revestimento Polar.

Os valores obtidos pela planilha de Gomes (2009) são:

\begin{tabular}{|c|c|c|c|c|c|}
\hline \multirow{3}{*}{$\begin{array}{l}\text { Números } \\
\text { de } \\
\text { Heraçốes }\end{array}$} & \multicolumn{5}{|c|}{ Resultados dos Cálculos: } \\
\hline & Raio $r(x)$ & \multicolumn{2}{|l|}{10,00} & \multirow[b]{2}{*}{ Ângulo (Teta) } & \multirow[b]{2}{*}{ Quadrante } \\
\hline & \begin{tabular}{|l} 
Coordenada $X$ \\
\end{tabular} & Coordenada $Y$ & Coordenada 2 & & \\
\hline 1 & 0,000000 & 5,000000 & 8,660254 & 60 & $1^{\circ}$ \\
\hline 2 & 1,000000 & 5,007919 & 8,655677 & 60 & $1^{\circ}$ \\
\hline 3 & 2,000000 & 5,015834 & 8,651093 & 60 & $1^{\circ}$ \\
\hline 4 & 3,000000 & 5,023745 & 8,646501 & 60 & $1^{\circ}$ \\
\hline 5 & 4,000000 & 5,031652 & 8,641902 & 60 & $1^{\circ}$ \\
\hline 6 & 5,000000 & 5,039555 & 8.637296 & 60 & $1^{\circ}$ \\
\hline 7 & 6,000000 & 5,047453 & 8,632683 & 60 & $1^{\circ}$ \\
\hline 8 & 7,000000 & 5,055347 & 8,628063 & 60 & $1^{\circ}$ \\
\hline 9 & 8,000000 & 5,063237 & 8,623435 & 60 & $1^{\circ}$ \\
\hline 10 & 9,000000 & 5,071123 & 8,618800 & 60 & $1^{\circ}$ \\
\hline 11 & 10,000000 & 5,079004 & 8,614158 & 59 & $1^{\circ}$ \\
\hline 12 & 11,000000 & 5,086881 & 8,609509 & 59 & $1^{\circ}$ \\
\hline 13 & 12,000000 & 5,094754 & 8,604852 & 59 & $1^{\circ}$ \\
\hline 14 & 13,000000 & 5,102623 & 8,600188 & 59 & $1^{\circ}$ \\
\hline 15 & 14,000000 & 5,110487 & 8,595518 & 59 & $1^{\circ}$ \\
\hline 16 & 15,000000 & 5,118347 & 8,590839 & 59 & $1^{\circ}$ \\
\hline 17 & 16,000000 & 5,126203 & 8,586154 & 59 & $1^{\circ}$ \\
\hline 18 & 17,000000 & 5,134054 & 8,581462 & 59 & $1^{\circ}$ \\
\hline 19 & 18,000000 & 5,141902 & 8,576762 & 59 & $1^{\circ}$ \\
\hline 20 & 19,000000 & 5,149745 & 8,572055 & 59 & $1^{\circ}$ \\
\hline 21 & 20,000000 & 5,157583 & 8,567341 & 59 & $1^{\circ}$ \\
\hline 22 & 21,000000 & 5,165417 & 8,562620 & 59 & $1^{\circ}$ \\
\hline 23 & 22,000000 & 5,173247 & 8,557892 & 59 & $1^{\circ}$ \\
\hline 24 & 23,000000 & 5,181073 & 8,553156 & 59 & $1^{\circ}$ \\
\hline 7 & & {$[10000 \mathrm{~A}$} & $O 510414$ & & 10 \\
\hline
\end{tabular}

Figura 4.10 - Valores das coordenadas X, Y e Z resultado do revestimento polar. (Fonte GOMES, 
Como nos resultados anteriores, o revestimento polar também apresentou um resultado satisfatório, tanto na comparação dos valores das coordenadas $\mathrm{X}, \mathrm{Y}$ e $\mathrm{Z}$ quanto na comprovação do desenho da trajetória.

A figura 4.11 (a) e 4.11 (b) mostram claramente o formato de um vaso de pressão com o termino da trajetória.

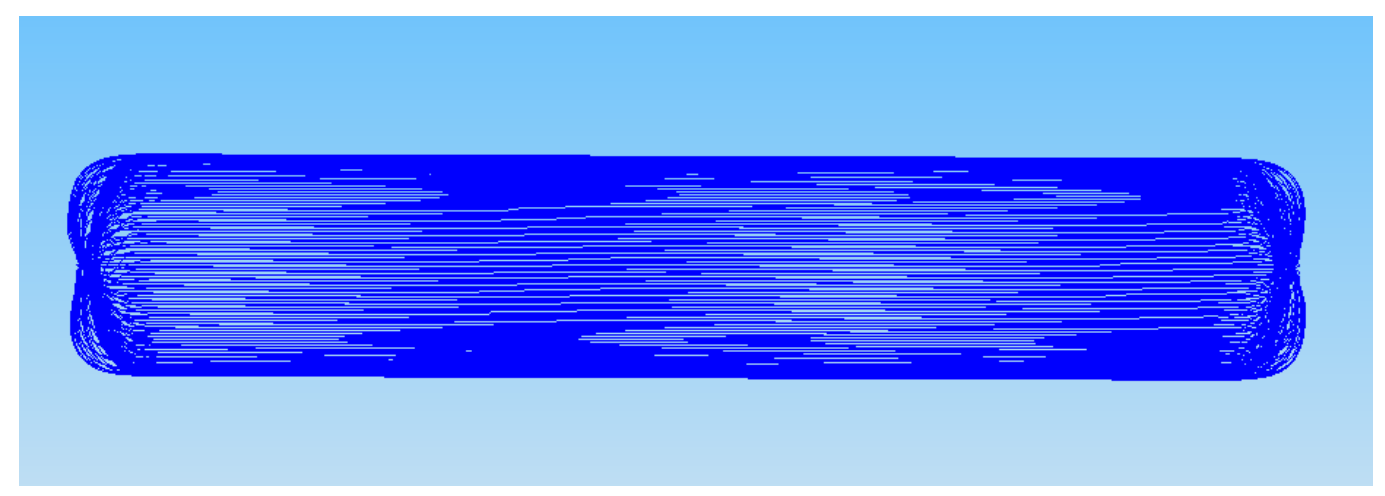

Figura 4.11(a) - Revestimento Polar.

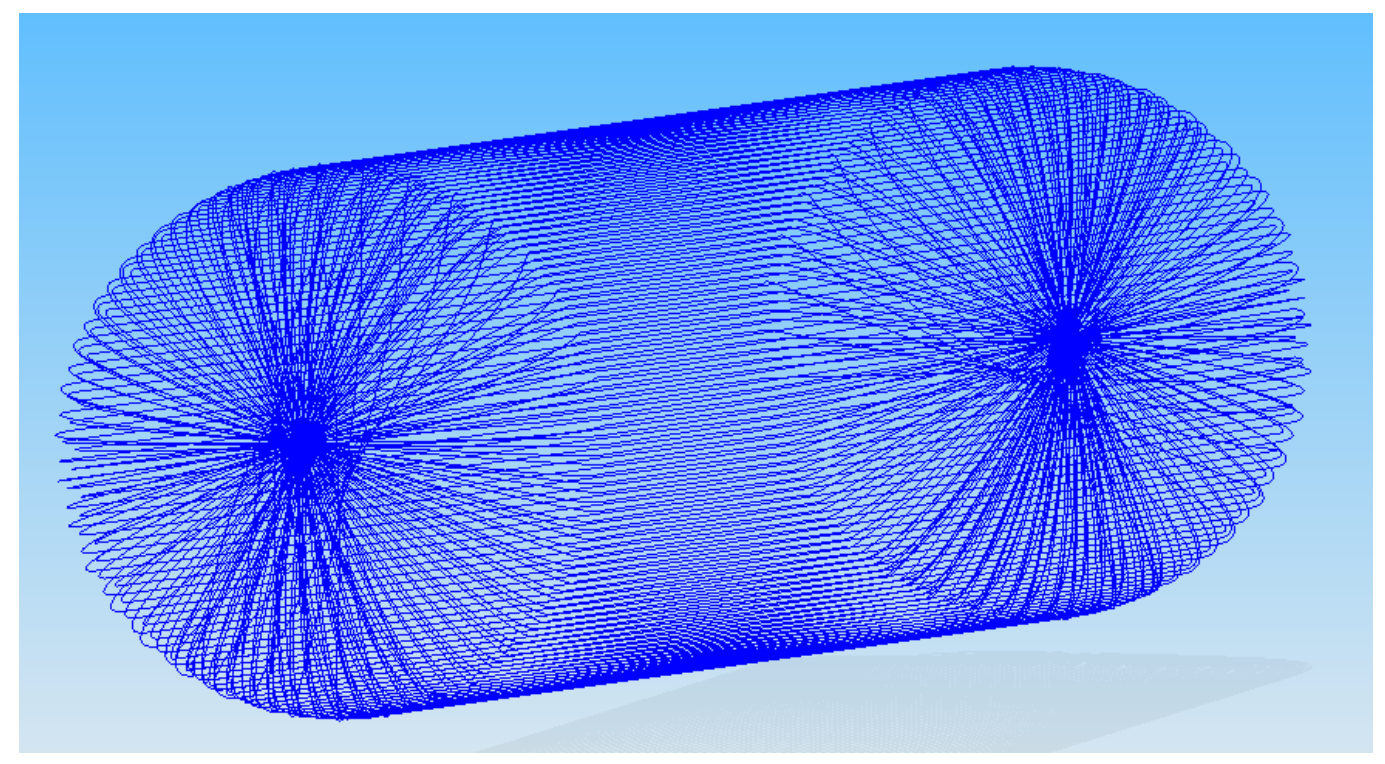

Figura 4.11(b) - Revestimento Polar ampliado. 
De acordo com Carvalho (1996), os melhores resultados quando se está desenvolvendo um projeto que envolve materiais compósitos é saber como obter o máximo benefício das propriedades inerentes do material. Em geral, projetos e técnicas de otimização tem tido bons resultados atualmente. Entretanto, no caso de "Filament Winding", aspectos restritivos na manufatura, como a precisão das máquinas e equipamentos para desenvolver a trajetória calculada, mostram resultados melhores obtendo-se a melhor trajetória calculada para a fibra dentro dos limites da capacidade da manufatura. 


\section{CAPÍtULO 5}

\section{CONCLUSÕES E SUGESTÕES}

\subsection{CONCLUSÕES}

Durante os últimos anos os materiais compósitos vem sendo amplamente utilizados em aplicações estruturais. Esses materiais apresentam vantagens em relação aos materiais convencionais tais como: alta resistência e rigidez, ótimos resultados estruturais, isolantes térmicos, resistência à corrosão e oxidação, baixo peso dentre outros. $\mathrm{O}$ avanço tecnológico proporcionou o desenvolvimento de diversas novas tecnologias para a fabricação de materiais compósitos, entre eles o processo de Filament Winding.

Atualmente, no mercado internacional existem alguns softwares dedicados ao cálculo de trajetórias, seqüências e controle deste tipo de processo, porém todos eles apresentam arquitetura fechada, o que impossibilita a implementação de novas técnicas e aperfeiçoamentos muitas vezes desejado para aplicações inovadoras.

Como já citado anteriormente, este trabalho abordou apenas trajetórias geodésicas em estruturas axissimétricas, mais especificamente cilindros, sendo que valores como: espessura do material de trabalho, diâmetro do cilindro, comprimento do cilindro, ângulo de início da trajetória, ângulo winding, precisão dos pontos e número de camadas são fornecidos pelo usuário do sistema.

Foram testadas situações anormais ao funcionamento do sistema como limites de ângulos inválidos, valores negativos, valores em branco dentre outros. Em todos essas 
situações, o sistema apresentou uma mensagem de erro informando a operação incorreta no software.

Os valores obtidos através do software SISCAWIND apresentaram resultados satisfatórios comparados aos valores obtidos pela planilha de cálculo manual desenvolvida por Gomes (2009). Seguindo os mesmos dados de entrada na confecção do cilindro, tanto o software quanto a planilha, apresentaram os mesmos valores na trajetória circular, helicoidal e polar.

Com os valores dos pontos formados pela coordenada $\mathrm{X}, \mathrm{Y}$ e $\mathrm{Z}$, foi possível visualizar a simulação da trajetória através do software CAD 3D. De acordo com os desenhos apresentados, foi verificada a precisão dos cálculos com a formação da malha da trajetória nos três tipos de revestimento.

Todas as características acima citadas vieram a validar os cálculos implementados no sistema SISCAWIND para otimização dos cálculos de cilindro na trajetória circular, helicoidal e circular.

A partir, do desenvolvimento deste trabalho podem-se tirar as seguintes conclusões:

a) A ferramenta Borland C++ Builder, adotada para a implementação dos módulos do sistema SISCAWIND, apresentou bons resultados em termos de interface gráfica com o usuário e comunicação com a base de dados;

b) $\mathrm{O}$ banco de dados utilizado no sistema promoveu a centralização e integração dos dados obtidos nos cálculos. A escolha do banco de dados Access facilitou a exportação dos dados do sistema para o formato xls, formato aceito pela grande maiorias dos sistemas $\mathrm{CAD}$;

c) O software SISCAWIND apresentou resultados satisfatórios nos testes de validação realizados; 
d) A visualização gráfica dos cálculos gerados pelo sistema proporcionou ao usuário uma simulação real da forma da trajetória da fibra antes da execução final do processo.

e) Embora o sistema implementado tenha considerado somente cálculos em superfícies cilíndricas, foi dado uma grande contribuição no sentido de disponibilizar uma plataforma onde novas implementações possam ser facilmente desenvolvidas.

f) Com o revestimento em superfícies de revolução nos padrões circular, helicoidal e polar, conseguimos contemplar aproximadamente $80 \%$ dos casos utilizados no processo de revestimento em materiais compósitos utilizados na técnica de filament winding.

\subsection{SUGESTÕES PARA TRABALHOS FUTUROS}

As sugestões propostas para a continuação deste trabalho são:

a) Desenvolver algorítmos para cálculos de trajetórias em superfícies mais complexas;

b) Desenvolver um módulo que calcule a trajetória do sólido através de protocolos fornecidos por sistemas CAD como o formato STL, facilitando a entrada de dados ao sistema e permitindo o uso de trajetórias não geodésicas;

c) Desenvolver algoritmos que permitam a mudança de ângulo durante o preenchimento das diferentes camadas do revestimento da peça, isto é ao longo do processo de filament winding; 
d) Desenvolver um módulo que integre o cálculo da trajetória com a geração de dados de materiais para análise pelo método dos elementos finitos;

e) Implementar na mesma plataforma os sistemas de controle dos servos e motores de uma máquina de Filament Winding;

f) Desenvolver um algoritmo para cálculo de dados do processo, como por exemplo, o tempo de manufatura da peça. 


\section{REFERÊNCIAS BIBLIOGRAFICAS}

ARAKAKI, R. et al. (1989). Fundamentos de Programação C. 2ed. São Paulo, Livros Técnicos e Científicos

BANNISTER, M. (2001). Challenges for composites into the next millennium - a reinforcement perspective. Composites Part A: Applied Science and Manufacturing. v.32, p.901-910.

BEAUMONT, P.W.R. (1989). The failure of fibre composites: an overview. Journal of Strain Analysis. V.24, n.4, p.189-205.

CALLISTER W. D. (1994). Materials Science and Engineering: An introduction, third edition. P.521-531. New York, John Wiley \& Sons, Inc.

CARVALHO, J. (1996). Computer Integrated Desing Optimisation and Manufacturing of Filament Wound Parts. Tese (Doutorado) - Faculty of Applied Sciences, Division PMA, K.U. Leuven.

CHAWLA, K.K. (1998). Composites materials: science and engineering. 2nd ed. New York: Springer-Verlag.

Diretrizes para elaboração de dissertação e teses na EESC-USP (2004). São Carlo. Biblioteca Central 
FILHO, GERALDO DANTAS S. (2001). Comportamento Mecânico do Poliuretano Derivado de Óleo de Mamona Reforçado por Fibra de Carbono: Contribuição para o Projeto de Hastes de Implante de Quadril. 156f. Dissertação (Mestrado) - Escola de Engenharia de São Carlos, Universidade de São Paulo, São Carlos, 2001.

FILHO, GERALDO DANTAS S. (2006). Projeto e Análise Estrutural de Haste Femoral de Implante de Quadril em Material Compósito Polimérico. 192f. Tese (Doutorado) Escola de Engenharia de São Carlos, Universidade de São Paulo, São Carlos, 2006.

GOMES, E. S. (2009). Implementação de rotinas computacionais para o cálculo de trajetórias geodésicas no processo de Filament Winding. 155p. Dissertação (Mestrado) Escola de Engenharia de São Carlos, Universidade de São Paulo, São Carlos, 2008.

HULL, D. (1981). An introduction to composites materials. London, Cambridge University Press.

HULL, D.; CLYNE T.W. (1996). An introduction to composite materials. 2nd ed. London: Cambridge University Press.

KAW, A. K. (1997). Mechanics of composite materials. Boca Raton: CRC Press LLC.

MAGAGNIN FILHO, N. (1996). Placas laminadas em materiais compósitos de fibras longas: propriedades termoelásticas dos materiais constituintes; critérios de ruptura 
análise pelo método dos elementos finitos. São Carlos, p.146-148. Dissertação (Mestrado) Escola de Engenharia de São Carlos, Universidade de São Paulo, São Carlos, 1996.

MANZANO, J.A.N.G. (1998). C++ - ANSI (ISO/IEC 14882:1998) - Programação de Computadores. São Paulo. Érica.

MATTHEWS, F.L.; RAWLINGS, R.D. (1994). Composite material: engineering and science. London, Chapman \& Hall.

MATTHYS, S., 2000, Structural Behavior and Design of Concrete Members Strengthened with externally bonded FRP Reinforcement. D.Sc. Thesis, Ghent University, Belgium.

MIZRAHI, V.V. (1990). Treinamento em linguagem C. v1 2nd.ed.. São Paulo, McGrawHill

NOTON, B.R. (1987). Engineered materials handbook, v.1, Composites. p.35-37. Ohio, ASM International.

PRESSMAN, R. (2002). Engenharia de Software. 5ed. São Paulo, McGrawHill.

REINHART, T.J.; CLEMENTS, L.L. (1987). Engineered materials handbook. V1, composites. P.27-34. 
SILVA, M. M. (2004) Protótipo de uma plataforma para software de cálculos para otimização da trajetória de fibras em revestimento de materiais compósitos. Dissertação (Mestrado) - Escola de Engenharia de São Carlos, Universidade de São Paulo, São Carlos, 2005 .

SHACKELFORD, J.F. (1996). Introduction to materials science for engineers, 4nd.ed.. New Jersey, Prentice-Hall, Inc.

SCHOLLIERS, JOHAN (1992). Filament Winding: a Manufacturing Technique for Composites. v. 1 p. 5-59/64 - 80. Tese (Doutorado) - Faculty of Applied Sciences, Division PMA, K.U. Leuven

SMITH , W.F. (1993). Materials science and engineering, 2.ed. p.330. Singapore, McGrawHill, Inc.

TAERWE, L. et al, Behavior of RC Beams Strengthened in Shear by External CFRP Sheets. In: Proceedings of the Third International Symposium of Non-metallic (FRP) Reinforcement for Concrete Structures, v. 2, pp. 559-566, Japan, october,1997.

TITA, V. (1999). Análise dinâmica teórica e experimental de vigas fabricadas a partir de materiais compósitos poliméricos reforçados. 125f. Dissertação (Mestrado) - Escola de Engenharia de São Carlos, Universidade de São Paulo, São Carlos, 1999. 